University of Tennessee Health Science Center

UTHSC Digital Commons

\title{
Design, Validation, and Clinical Testing of a Novel Fastening Device for a Scoliosis Brace
}

Cody Keith Bateman

University of Tennessee Health Science Center

Follow this and additional works at: https://dc.uthsc.edu/dissertations

Part of the Equipment and Supplies Commons, and the Therapeutics Commons

\section{Recommended Citation}

Bateman, Cody Keith (http://orcid.org/0000-0001-8654-9464), "Design, Validation, and Clinical Testing of a Novel Fastening Device for a Scoliosis Brace" (2017). Theses and Dissertations (ETD). Paper 443. http://dx.doi.org/10.21007/etd.cghs.2017.0431.

This Thesis is brought to you for free and open access by the College of Graduate Health Sciences at UTHSC Digital Commons. It has been accepted for inclusion in Theses and Dissertations (ETD) by an authorized administrator of UTHSC Digital Commons. For more information, please contact jwelch30@uthsc.edu. 


\title{
Design, Validation, and Clinical Testing of a Novel Fastening Device for a Scoliosis Brace
}

\author{
Abstract \\ Each year, thirty thousand children in the US were put into a scoliosis brace. The primary function of \\ scoliosis braces was to reduce and prevent progression of the spinal deformity as the patient grew by \\ application of corrective forces to the spine. Straps, often made of Velcro, were attached to the back of \\ the brace that applied forces to the spine when the straps were tightened. Braces were prescribed to be \\ worn up to 23 hours a day. Studies have concluded that discomfort increased with increasing strap \\ tension and pad pressure. They have also shown an increase in strap tension occurred during deep \\ breathing and some daily activities which led to discomfort. Consequently, discomfort often led to poor \\ user compliance and reduced brace wear hence decreasing treatment efficacy. Treatment efficacy also \\ decreased due to a loss of strap tension activities of lying down. The overall goals were to develop a \\ novel fastening device, or controlled tension unit (CTU), for a scoliosis brace that allowed the user to set \\ the strap tension to the prescribed value as determined by the orthotist at the time of brace fitting and to \\ maintain the prescribed strap tension during a variety of typical daily living activities. This device should \\ ensure the corrective force capacity of the scoliosis brace was present and the occurrence of strap \\ loosening and tension loss was minimized. In the end, three studies were carried out to design and \\ validate the CTU devices. For Study One, the objective was to determine the force-displacement \\ properties of the controlled tension devices alone. The materials used were: Controlled Tension Units \\ (CTU), Robotic Testing Platform. The methods were as follows: The controlled tension units were \\ mounted in a robotic testing platform that was programmed to displace the CTU device at a set speed (or \\ rate of spring displacement) and measure the force response of the device. Three different speeds and \\ spring tensions were tested. The results were as follows: The CTU were designed with desired load \\ settings of $20 \mathrm{~N}, 30 \mathrm{~N}$, and $40 \mathrm{~N}$ which were confirmed. The units applied a relatively constant tension over \\ a working range of $12.7 \mathrm{~mm}$ and maintained a load tolerance within $\pm 10 \%$. The force output response and \\ load tolerances were independent of the rate of spring displacement. In conclusion, CTU devices could be \\ fabricated with selectable load settings that held a relatively constant tension throughout a desired range \\ of displacement. For Study Two, the first objective was to validate that the CTU force output was \\ maintained over a finite amount of brace gap opening and closing (as it related to the brace gap \\ separation). The second objective was to evaluate the corrective force capacity and structural stiffness \\ properties of a standard 3-strap brace using either Velcro straps or CTU devices as the fastening system. \\ The materials used were: Controlled Tension Units, Standard (Velcro Strap) Brace, Standard (CTU) Brace, \\ Robotic Testing Platform, Scoliosis Analog Model (SAM), Lab Tensiometers. The methods were as \\ follows: Three brace configurations were tested: Native Standard Brace, Standard (CTU) Brace, and \\ Standard (Velcro Strap) Brace. A low tension CTU $(\approx 20 \mathrm{~N})$ was used for all tests. Throughout the \\ movement, the reaction forces and strap tensions in the craniocaudal and mediolateral axes were \\ continuously recorded. The results were as follows: The CTU devices provided a greater range of brace \\ gap displacement compared to the Velcro straps. For the CTU devices, the strap tension was constant \\ over the range of displacement and remained close to the tension value of the CTU device (approximately \\ $20 \mathrm{~N}$ ). However, the tensiometer readings were significantly greater with the Velcro straps being greatest \\ at the top strap and lowest at the bottom. In conclusion, CTU devices could be used to develop a more \\ flexible dynamic brace that allowed for directional movement without compromising the corrective force \\ capacity of the brace. Contrary to the Velcro straps, the CTU strap tension setting would remain present \\ independent of the brace gap allowing for opportunities of deep breathing, increased range of movement, \\ and/or improved brace force correction. For Study Three, the objective was to determine if CTU reduced \\ discomfort while maintaining a constant strap tension. The materials used were: Standard (Velcro Strap) \\ Brace, Standard (CTU) Brace, Portable Tensiometers. The methods were as follows: The discomfort, strap \\ tension, and gap distance were evaluated during typical daily activities as well as the range of motion
}


where applicable using the Standard (Velcro Strap) Brace and the Standard (CTU) Brace. Afterwards, a CTU Increase Test was performed in which the tension in each CTU fastener was incrementally increased until the patient experienced a greater level of discomfort than with the Velcro strap condition at the prescribed tension. In conclusion, CTU improved bracing in scoliosis by maintaining strap tension, improving brace flexibility, decreasing discomfort at similar strap tensions, or by achieving higher strap tensions without increasing discomfort. In conclusion, the CTU devices allowed the user to set the strap tension to the prescribed value as determined by the orthotist at the time of brace fitting and maintained the prescribed strap tension during a variety of typical daily living activities to ensure the corrective force capacity of the scoliosis brace was present and the occurrence of strap loosening and tension loss was minimized.

\section{Document Type}

Thesis

Degree Name

Master of Science (MS)

Program

Biomedical Engineering

Research Advisor

Denis J. DiAngelo, Ph.D.

Keywords

Brace, Clinical Testing, Controlled Tension Unit (CTU), Fastening Device, Scoliosis, Strap Tension

Subject Categories

Analytical, Diagnostic and Therapeutic Techniques and Equipment | Equipment and Supplies | Medicine and Health Sciences | Therapeutics

Comments

One year embargo expires July 2018. 


\title{
Design, Validation, and Clinical Testing of a Novel Fastening Device for a Scoliosis
} Brace

\author{
A Thesis \\ Presented for \\ The Graduate Studies Council \\ The University of Tennessee \\ Health Science Center
}

\author{
In Partial Fulfillment \\ Of the Requirements for the Degree \\ Master of Science \\ In the Joint Graduate Program in Biomedical Engineering \\ From The University of Tennessee \\ And \\ The University of Memphis
}

By

Cody Keith Bateman

May 2017 
Copyright (C) 2017 by Cody Bateman. All rights reserved. 


\section{DEDICATION}

To my God, my family, and my friends, this was for you. 


\section{ACKNOWLEDGEMENTS}

I would like to thank Dr. Denis DiAngelo, Chloe Chung, Clay Hillyard, and Michael Parker for their support, guidance, and contribution of helpful ideas to this work.

I would like to thank Dr. Kelly, Dr. Sawyer, and Dr. Spence for contributing a clinical perspective and helping transition this work to the clinic.

I would like to thank Jack Steele and Terry Tate for offering their insight of scoliosis bracing and outlining design parameters.

I would like to thank my committee members for their skillful guidance throughout my research.

I would like to thank my family for always being there for me. 


\begin{abstract}
Each year, thirty thousand children in the US were put into a scoliosis brace. The primary function of scoliosis braces was to reduce and prevent progression of the spinal deformity as the patient grew by application of corrective forces to the spine. Straps, often made of Velcro, were attached to the back of the brace that applied forces to the spine when the straps were tightened. Braces were prescribed to be worn up to 23 hours a day. Studies have concluded that discomfort increased with increasing strap tension and pad pressure. They have also shown an increase in strap tension occurred during deep breathing and some daily activities which led to discomfort. Consequently, discomfort often led to poor user compliance and reduced brace wear hence decreasing treatment efficacy. Treatment efficacy also decreased due to a loss of strap tension activities of lying down.
\end{abstract}

The overall goals were to develop a novel fastening device, or controlled tension unit (CTU), for a scoliosis brace that allowed the user to set the strap tension to the prescribed value as determined by the orthotist at the time of brace fitting and to maintain the prescribed strap tension during a variety of typical daily living activities. This device should ensure the corrective force capacity of the scoliosis brace was present and the occurrence of strap loosening and tension loss was minimized.

In the end, three studies were carried out to design and validate the CTU devices.

For Study One, the objective was to determine the force-displacement properties of the controlled tension devices alone. The materials used were: Controlled Tension Units (CTU), Robotic Testing Platform. The methods were as follows: The controlled tension units were mounted in a robotic testing platform that was programmed to displace the CTU device at a set speed (or rate of spring displacement) and measure the force response of the device. Three different speeds and spring tensions were tested. The results were as follows: The CTU were designed with desired load settings of $20 \mathrm{~N}, 30 \mathrm{~N}$, and $40 \mathrm{~N}$ which were confirmed. The units applied a relatively constant tension over a working range of $12.7 \mathrm{~mm}$ and maintained a load tolerance within $\pm 10 \%$. The force output response and load tolerances were independent of the rate of spring displacement. In conclusion, CTU devices could be fabricated with selectable load settings that held a relatively constant tension throughout a desired range of displacement.

For Study Two, the first objective was to validate that the CTU force output was maintained over a finite amount of brace gap opening and closing (as it related to the brace gap separation). The second objective was to evaluate the corrective force capacity and structural stiffness properties of a standard 3-strap brace using either Velcro straps or CTU devices as the fastening system. The materials used were: Controlled Tension Units, Standard (Velcro Strap) Brace, Standard (CTU) Brace, Robotic Testing Platform, Scoliosis Analog Model (SAM), Lab Tensiometers. The methods were as follows: Three brace configurations were tested: Native Standard Brace, Standard (CTU) Brace, and Standard (Velcro Strap) Brace. A low tension CTU $(\approx 20 \mathrm{~N})$ was used for all tests. 
Throughout the movement, the reaction forces and strap tensions in the craniocaudal and mediolateral axes were continuously recorded. The results were as follows: The CTU devices provided a greater range of brace gap displacement compared to the Velcro straps. For the CTU devices, the strap tension was constant over the range of displacement and remained close to the tension value of the CTU device (approximately $20 \mathrm{~N})$. However, the tensiometer readings were significantly greater with the Velcro straps being greatest at the top strap and lowest at the bottom. In conclusion, CTU devices could be used to develop a more flexible dynamic brace that allowed for directional movement without compromising the corrective force capacity of the brace. Contrary to the Velcro straps, the CTU strap tension setting would remain present independent of the brace gap allowing for opportunities of deep breathing, increased range of movement, and/or improved brace force correction.

For Study Three, the objective was to determine if CTU reduced discomfort while maintaining a constant strap tension. The materials used were: Standard (Velcro Strap) Brace, Standard (CTU) Brace, Portable Tensiometers. The methods were as follows: The discomfort, strap tension, and gap distance were evaluated during typical daily activities as well as the range of motion where applicable using the Standard (Velcro Strap) Brace and the Standard (CTU) Brace. Afterwards, a CTU Increase Test was performed in which the tension in each CTU fastener was incrementally increased until the patient experienced a greater level of discomfort than with the Velcro strap condition at the prescribed tension. In conclusion, CTU improved bracing in scoliosis by maintaining strap tension, improving brace flexibility, decreasing discomfort at similar strap tensions, or by achieving higher strap tensions without increasing discomfort.

In conclusion, the CTU devices allowed the user to set the strap tension to the prescribed value as determined by the orthotist at the time of brace fitting and maintained the prescribed strap tension during a variety of typical daily living activities to ensure the corrective force capacity of the scoliosis brace was present and the occurrence of strap loosening and tension loss was minimized. 


\section{TABLE OF CONTENTS}

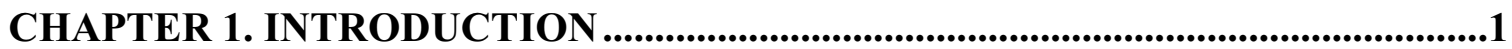

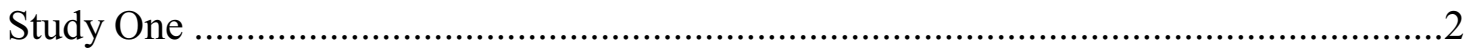

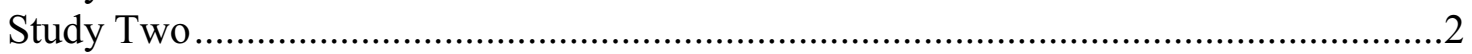

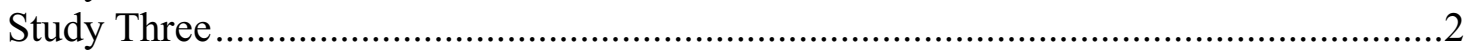

CHAPTER 2. LITERATURE REVIEW .........................................................................

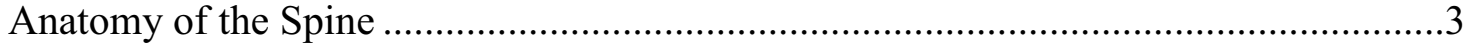

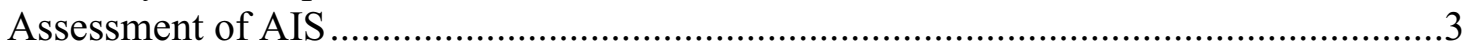

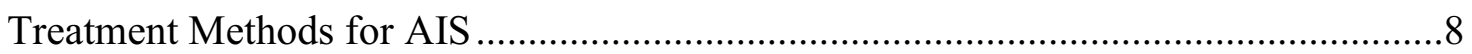

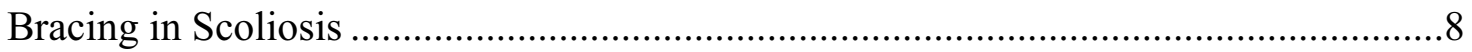

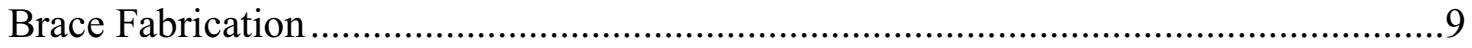

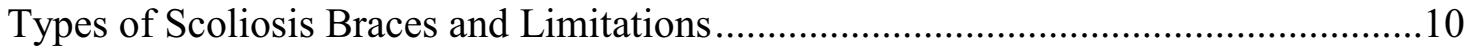

Strap Tension Effects on Curve Correction and Discomfort .......................................11

Computer Models for Improving Bracing in AIS ....................................................... 12

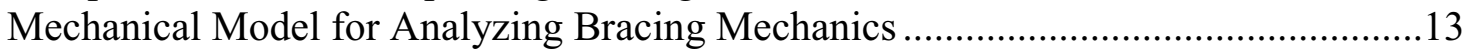

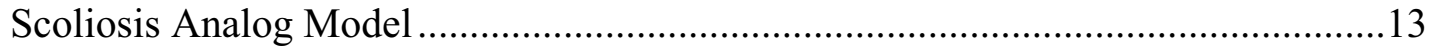

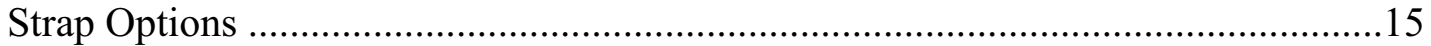

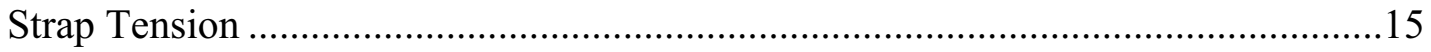

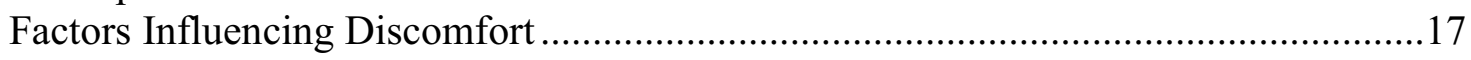

\section{CHAPTER 3. STUDY ONE: DESIGN AND VALIDATION TESTING OF} CONTROLLED TENSION FASTENING DEVICES ............................................18

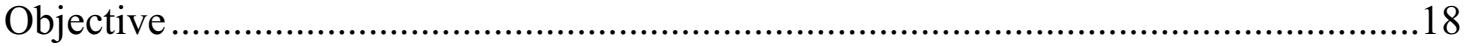

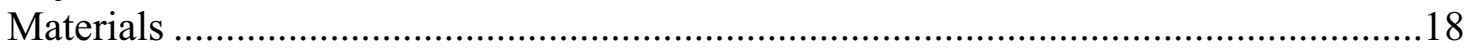

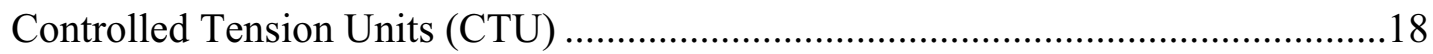

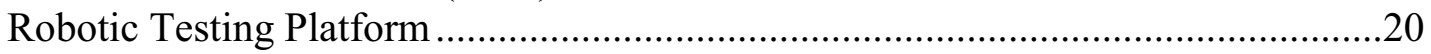

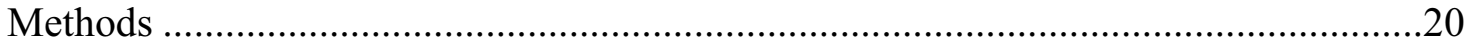

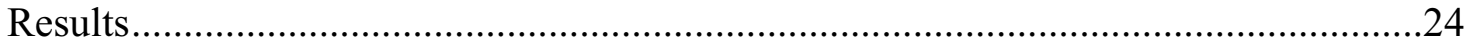

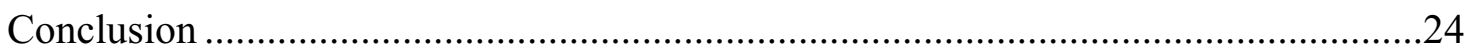

\section{CHAPTER 4. STUDY TWO: COMPARATIVE LABORATORY TESTING OF} TRADITIONAL VELCRO STRAPS VERSUS VELCRO STRAPS WITH CTU

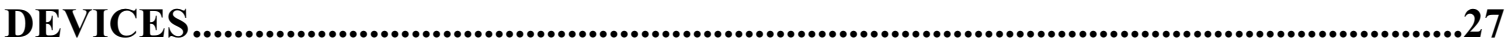

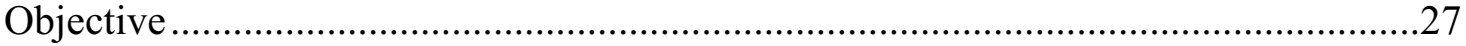

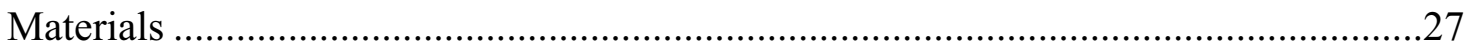

Controlled Tension Units ...............................................................................2 27

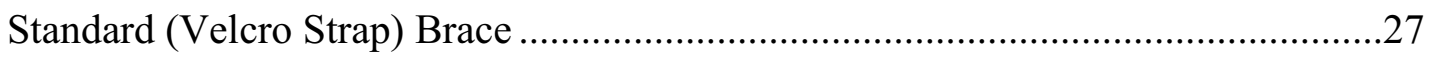

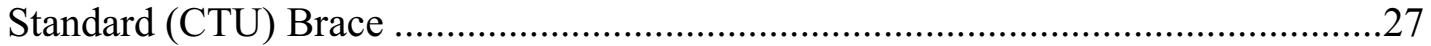

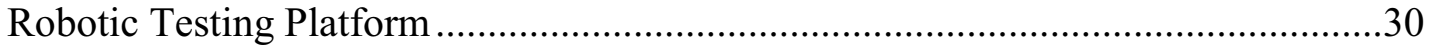

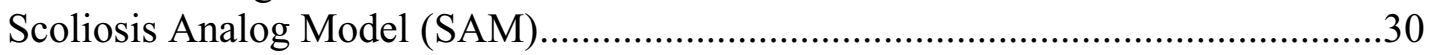

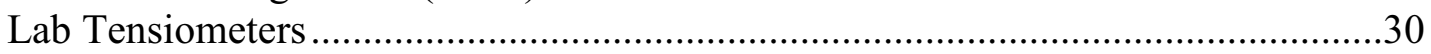

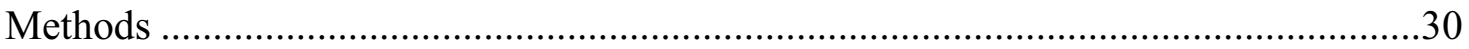




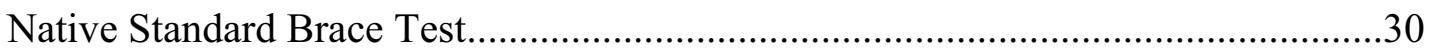

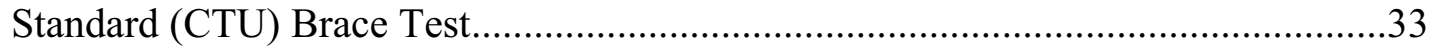

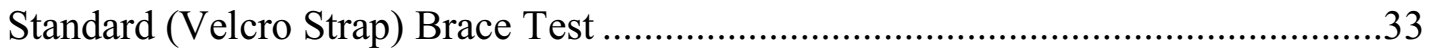

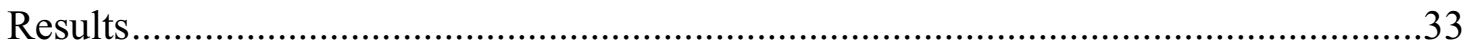

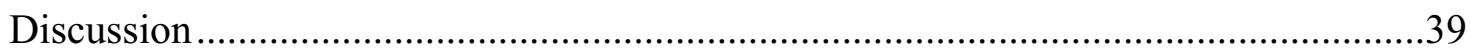

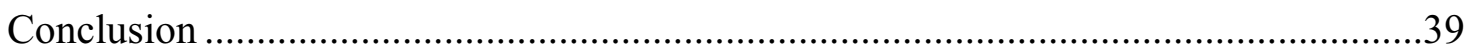

\section{CHAPTER 5. STUDY THREE: COMPARATIVE CLINICAL TESTING OF TRADITIONAL VELCRO STRAPS VERSUS VELCRO STRAPS WITH CTU

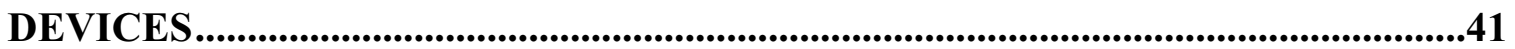

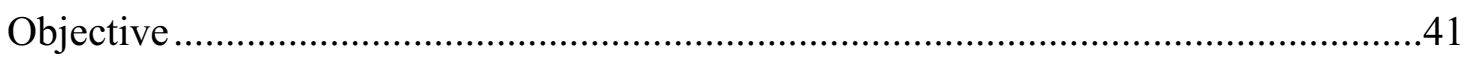

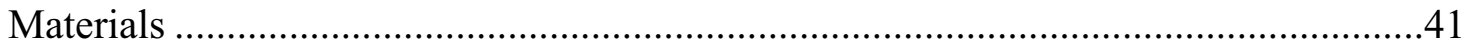

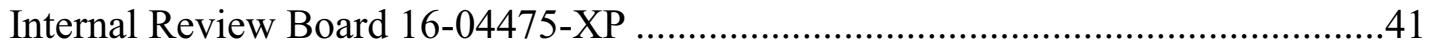

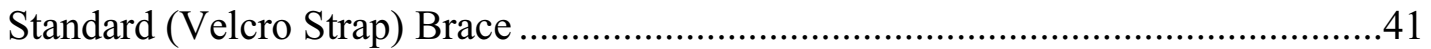

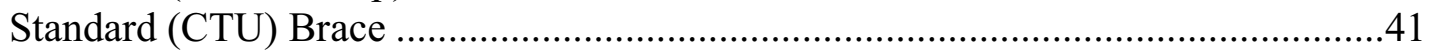

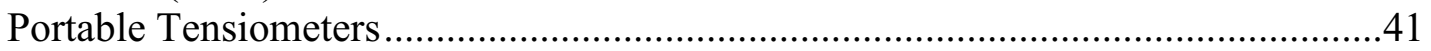

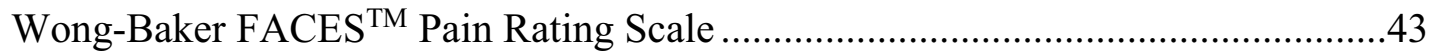

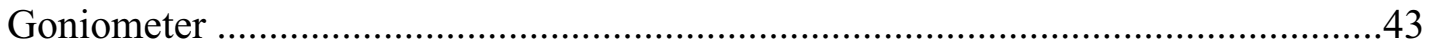

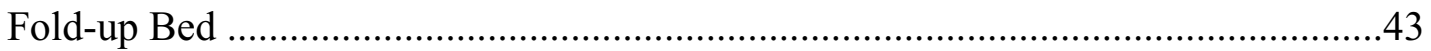

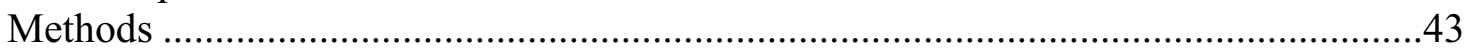

Standard (Velcro Strap) Brace Test ......................................................................43

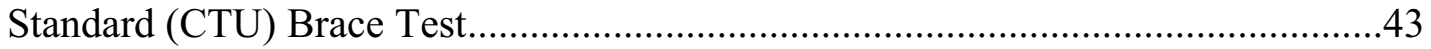

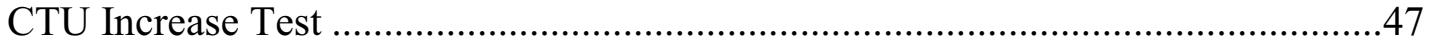

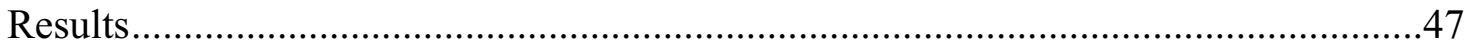

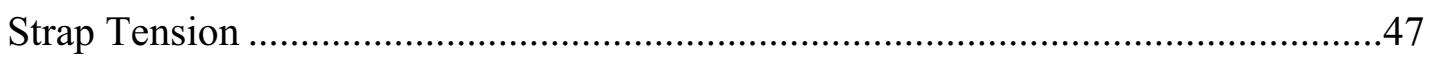

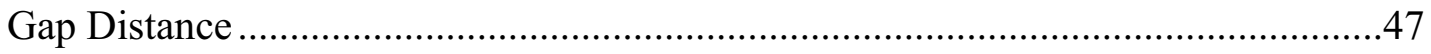

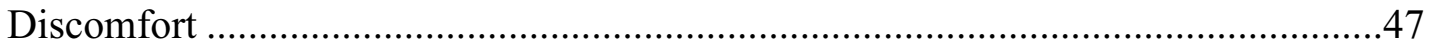

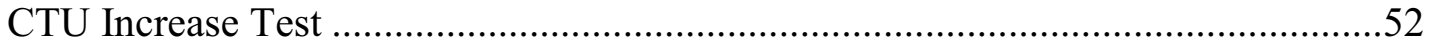

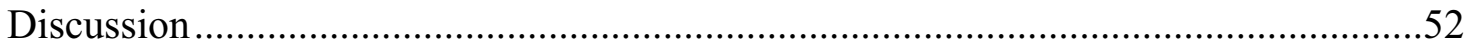

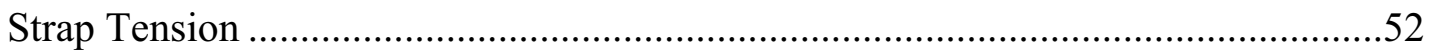

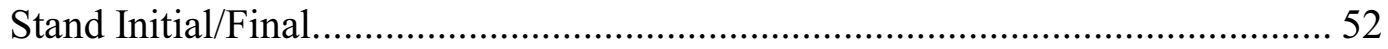

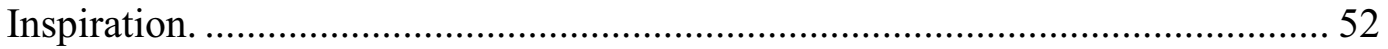

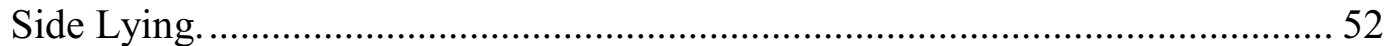

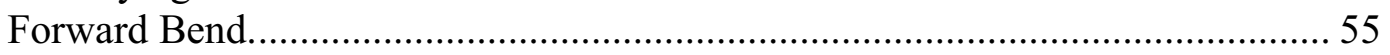

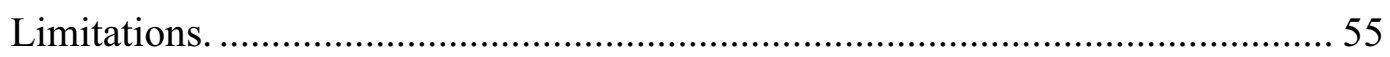

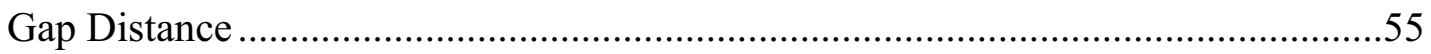

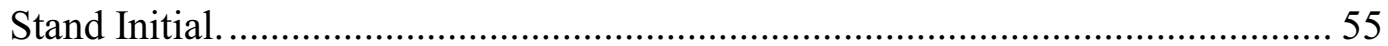

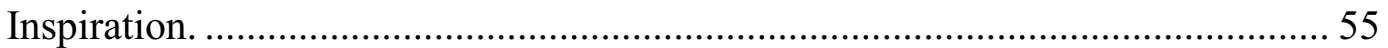

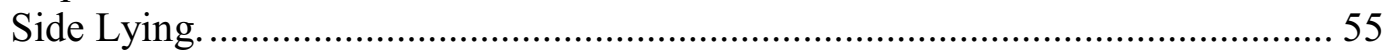

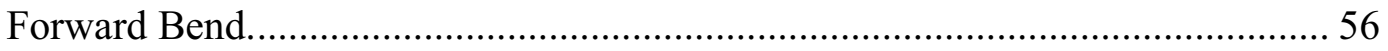

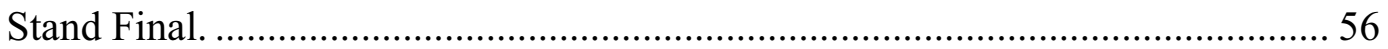

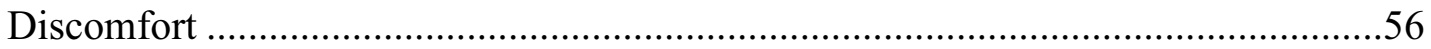

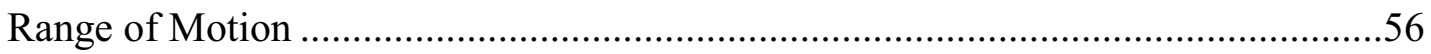

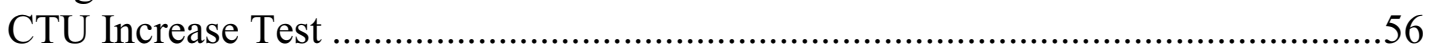

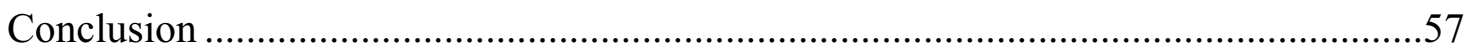


LIST OF REFERENCES ................................................................................................59

APPENDIX. ROBOTIC TESTING PLATFORM LOAD CELL VALIDATION...65

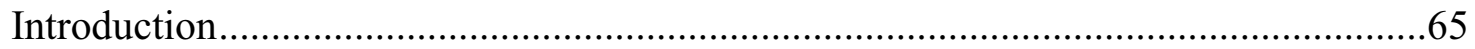

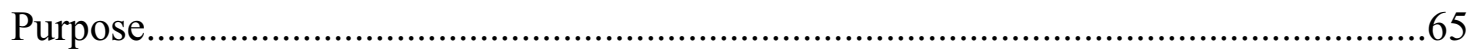

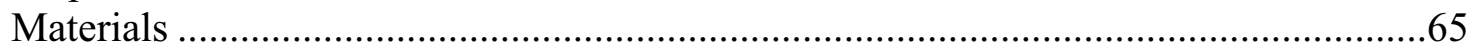

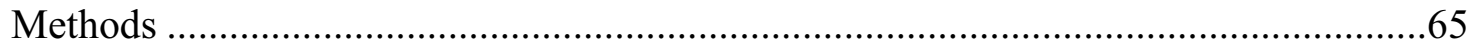

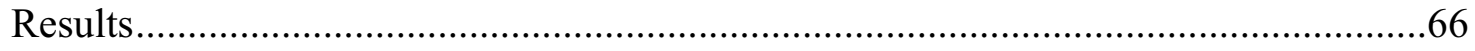

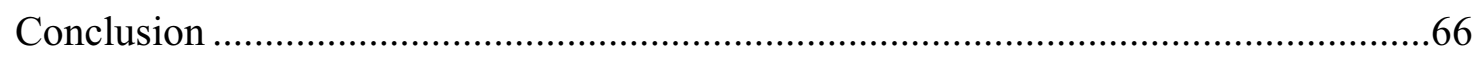

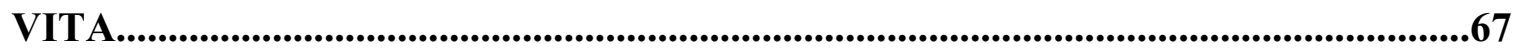




\section{LIST OF TABLES}

Table 2-1. Mean Radial and Axial Stiffness Values of Brace Configurations (N/º)....16

Table 3-1. Tension Setting and Speed Combinations. ............................................23

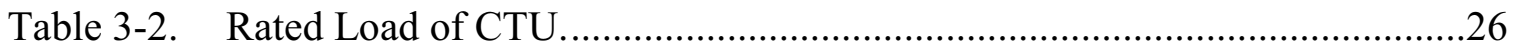

Table 4-1. Standard (CTU) Brace: Mean Tensiometer Readout Values........................36

Table 4-2. Standard (Velcro Strap) Brace: Mean Tensiometer Readout Values for Displacement in All Straps $<1 \mathrm{~mm}$........................................................36

Table 5-1. Velcro Tension Loss at Top, Middle, and Bottom Levels..........................48

Table 5-2. Velcro Versus CTU Mean Tension at Top, Middle, and Bottom Levels. ....49

Table 5-3. Velcro Versus CTU Mean Upper and Lower Gap Distance Change Relative to Stand Initial. ......................................................................50

Table 5-4. Velcro Versus CTU Mean Discomfort. ..................................................51

Table 5-5. CTU Increase Test Mean Values. .............................................................53 


\section{LIST OF FIGURES}

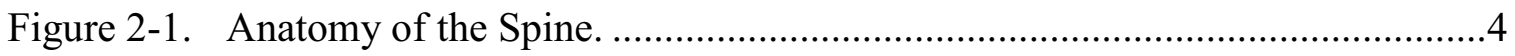

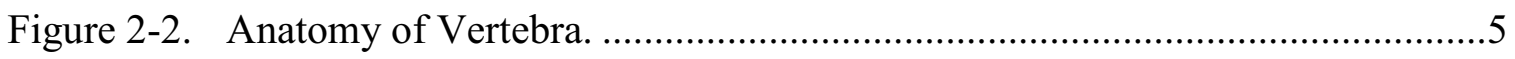

Figure 2-3. Cobb Angle Measurement. ...................................................................

Figure 2-4. SterEOS 3D Model Reconstruction of Thoracic Curve..................................7

Figure 2-5. SAM Customization and Testing Setup.....................................................14

Figure 2-6. Interpretation of Force Mechanics............................................................16

Figure 3-1. Exploded Line Drawing of a CTU Device. ....................................................19

Figure 3-2. Behavior of a Constant-Force Spring. ......................................................21

Figure 3-3. Laminating the Springs for Increased Force Output....................................21

Figure 3-4. Robotic Testing Platform.....................................................................22

Figure 3-5. Test Set-up of a CTU on the Testing Platform. ..........................................23

Figure 3-6. Tension-Displacement Relationship of a CTU Device..................................25

Figure 3-7. Low Tension at Varying Speeds...........................................................25

Figure 3-8. Medium Tension at Varying Speeds.......................................................25

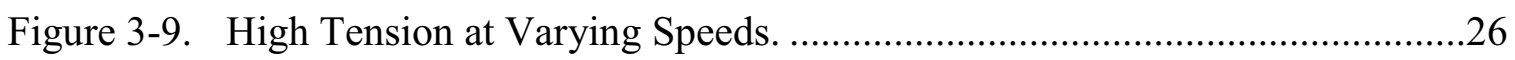

Figure 4-1. In This Study, the Boston Brace Was Called the Standard (Velcro Strap)

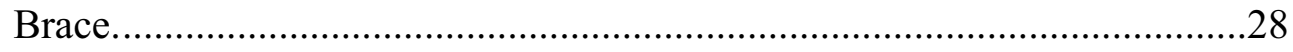

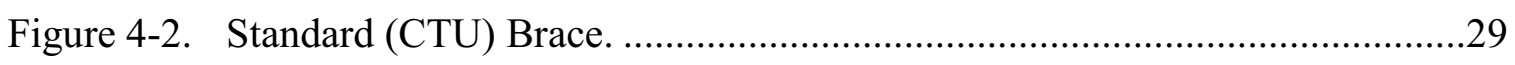

Figure 4-3. SAM Customization and Testing Setup.......................................................31

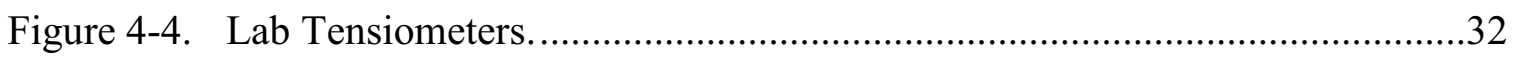

Figure 4-5. Native Standard Brace Test. ...................................................................32

Figure 4-6. Standard (CTU) Brace Test. ......................................................................

Figure 4-7. Standard (Velcro Strap) Brace Test. ..............................................................35 
Figure 4-8. Force-Displacement Response along the Craniocaudal Axis of the Standard (CTU) Brace.

Figure 4-9. Force-Displacement Response along the Craniocaudal Axis of the Standard (Velcro Strap) Brace.

Figure 4-10. Mean CTU Tension Throughout Mediolateral Displacement. ......................38

Figure 4-11. Mean Velcro Strap Tension Throughout Mediolateral Displacement..........38

Figure 4-12. Mean Tensiometer Readouts at End Limit of Travel for CTU Devices, $\mathrm{N}=3$

Figure 4-13. Mean Tensiometer Readouts at End Limit of Travel for Velcro Straps, $\mathrm{N}=3$

Figure 5-1. Portable Tensiometers on a Brace.

Figure 5-2. Wong-Baker FACES ${ }^{\mathrm{TM}}$ Pain Rating Scale.

Figure 5-3. Concave and Convex Side Lying. .44

Figure 5-4. Body Mechanics During Bracing While Standing Versus Side Lying .45

Figure 5-5. Strap Tension and Gap Distance Measurement. .46

Figure 5-6. Velcro Tension Loss at Top, Middle, and Bottom Levels....... .48

Figure 5-7. Velcro Versus CTU Mean Tension at Top, Middle, and Bottom Levels. ....49

Figure 5-8. Velcro Versus CTU Mean Upper and Lower Gap Distance Change Relative to Stand Initial. .50

Figure 5-9. Velcro Versus CTU Mean Discomfort. .51

Figure 5-10. CTU Increase Test Mean Strap Tension with 8 Subjects. 53

Figure 5-11. CTU Increase Test Mean Gap Distance with 8 Subjects.... .54

Figure A-1. Displacement Versus Force Plot Showing Max Load Cell Error. .66 


\section{LIST OF ABBREVIATIONS}

$\begin{array}{ll}\text { AIS } & \text { Adolescent Idiopathic Scoliosis } \\ \text { AR } & \text { Axial Rotation } \\ \text { AVT } & \text { Apical Vertebral Translation } \\ \text { B } & \text { Bottom Strap } \\ \text { BLC } & \text { Bottom Load Cell } \\ \text { CA } & \text { Cobb Angle } \\ \text { CAD } & \text { Computer Aided Design } \\ \text { CAM } & \text { Computer Aided Manufacturing } \\ \text { CTU } & \text { Controlled Tension Units } \\ \text { F } & \text { Fast Speed } \\ \text { FD } & \text { Distractive Force } \\ \text { H } & \text { High Tension } \\ \text { I } & \text { Intermediate Speed } \\ \text { IRB } & \text { Institutional Review Board } \\ \text { L } & \text { Low Tension } \\ \text { M } & \text { Medium Tension } \\ \text { M } & \text { Middle Strap } \\ \text { O1 } & \text { Orthotist 1 } \\ \text { O2 } & \text { Orthotist 2 } \\ \text { S } & \text { Slow Speed } \\ \text { SAM } & \text { Scoliosis Analog Model } \\ \text { T } & \text { Top Strap } \\ \text { TB } & \text { Bottom Strap Tension } \\ \text { TM } & \text { Middle Strap Tension } \\ \text { TO } & \text { Overall Tension } \\ \text { TT } & \text { Top Strap Tension } \\ \text { ULC } & \text { Upper Load Cell } \\ & \end{array}$




\section{CHAPTER 1. INTRODUCTION}

Scoliosis is a three dimensional skeletal deformity of the spine consisting of a combination of axial rotation and lateral curvature [3]. It affects an estimated 6 million people in the United States alone. Adolescent idiopathic scoliosis (AIS) has an unknown cause and represents approximately $2-3 \%$ of the pediatric population [5]. It was estimated that out of the 600,000 annual patient visits, 30,000 were considered moderate (with spinal curves less than $45^{\circ}$ ) and treated with a brace and 38,000 were considered severe or rapidly progressive (when the curve exceeds $50^{\circ}$ ) and treated with spinal fusion surgery [5]. These surgical treatments were very costly and usually increase health risks. Recent clinical findings $[13,42]$ had shown bracing treatment to be $72 \%$ effective in preventing curve progression past $50^{\circ}$ and more clinicians were considering it as a treatment option.

Scoliosis braces are classified as Soft/Flexible Braces, Semi-Rigid Braces, or Hard/Rigid Braces. Soft and Semi-Rigid Braces provided limited torso stabilization with poor force corrective capacity and were proven to be less effective than Hard/Rigid Braces [27]. Hard/Rigid Braces, such as the Boston Brace, Milwaukee Brace, Charleston Brace, Providence Brace, etc., were the most frequently used braces [5] in the United States. These braces consisted of a rigid shell that fits over the patient's upper torso and pelvic anatomy. An orthotist carried out a series of design alterations to custom fit the brace to the patient. The alterations included number and tension of fastening devices; size and shape of fitting pads, location and size of cut-out sections, etc.

Fastening devices, like Velcro straps, are used to engage and secure the brace around the upper body and were responsible for the majority of the corrective forces applied to the spine [56]. However, Velcro strapping systems had been associated with strap loosening and tension loss following two or more weeks of daily brace wear [43], after various daily living activities [19,38], or when lying down [19,38,39,42,43]. Loss of strap tension decreased the brace stiffness properties and reduced the corrective spinal force applied by the brace, both contributing to a loss of spinal correction that negated the benefit of wearing the brace. In addition, besides reduced corrective forces and spinal correctional losses, braces had also been reported as being uncomfortable to wear, resulting in reduced brace wear time or complete abandonment [27,33]. Although monitoring systems could have been employed to determine if the user wore the brace the prescribed time $[42,43]$ active adjustment to correct the strap tension loss was not yet available. They relied on the caregiver to manually readjust the strap tension settings, which may have frequently been set below the original prescribed value. The ongoing loosening of Velcro straps perpetuated the need for the strap monitoring/adjustment cycle [18]. To that end, there remained a need for a scoliosis brace fastening system that maintained the prescribed tension level set by the practitioner over the daily usage of the brace.

The overall goals were to develop an alternative fastening device, referred to as a controlled tension unit (CTU), for a scoliosis brace that allowed the user to: 
1) Set the strap tension to the prescribed value as determined by the orthotist at the time of brace fitting.

2) Maintain the prescribed strap tension during a variety of typical daily living activities to ensure the corrective force capacity of the scoliosis brace was present and the occurrence of strap loosening and tension loss was minimized.

In the end, three studies were carried out to design the CTU devices.

\section{Study One}

The objective was to determine the force-displacement properties of controlled tension devices alone.

\section{Study Two}

The first objective was to validate that the CTU force output was maintained over a finite amount of brace gap opening and closing (as it related to the brace gap separation). The second objective was to evaluate the corrective force capacity and structural stiffness properties of a standard 3-strap brace using either Velcro straps or CTU devices as the fastening system.

\section{Study Three}

This ongoing study is an approved IRB study (16-04475-XP) with two local orthotists. Pilot data from eight patients have been analyzed. The objective of this study was to determine if CTU reduced discomfort while maintaining a constant strap tension. 


\section{CHAPTER 2. LITERATURE REVIEW}

\section{Anatomy of the Spine}

Twenty-six separate bony structures make up the vertebral column or "spine", which spans from the base of the skull to the coccyx (Figure 2-1). Starting from the base of the skull, the spine begins with seven cervical vertebrae, twelve thoracic vertebrae, five lumbar vertebrae, the sacrum, and ends with the coccyx or "tailbone". Between each structure is a fibrocartilaginous intervertebral disc which serves to reduce stress due to support of body weight and movement. The structures are connected by ligaments and bony interlocking processes.

Vertebrae have cylindrical shaped geometries on the anterior, superior, and inferior sides (Figure 2-2). However, on the posterior side, each vertebral body consists of four types of bony structures known as the spinous process, transverse process, superior articular processes, and inferior articular processes. These processes serve mechanical purposes, for instance, the spinous and transverse processes provide vital muscle attachment points while the superior and inferior processes make up the facet joint. The facet joint allows for movement of the spine in certain directions, such as axial rotation in the cervical region, while limiting movement in directions that could be detrimental to body. It also provides structural support. The orientation of the superior and inferior processes gradually transitions to become more medial and lateral in the lumbar region than the cervical region. This orientation allows for optimal axial rotation in the cervical region and forward bending in the lumbar region. The spinous process and transverse process are connected by bony tissue known as the lamina, and the transverse process is connected to the vertebral body by bony tissue known as the pedicle. Ribs are connected to the twelve thoracic vertebrae by attaching to the bodies and the transverse processes.

In the sagittal plane, a mature spine consists of lordosis and kyphosis. Lordosis is a curvature that is present in the cervical and lumbar regions. Kyphosis is a convex curvature that is present in the thoracic and pelvic region. In the coronal plane, the spine is straight unless it is laterally deformed by a skeletal condition known as scoliosis. In the transverse plane, the vertebral bodies have no axial rotation unless scoliosis is present $[1,2]$.

\section{Assessment of AIS}

Adolescent Idiopathic Scoliosis (AIS) is defined as a deformity of the spine that is characterized by both lateral curvature in the coronal plane and axial rotation in the transverse plane that occurs in patients between the ages of eight and eighteen. This deformity has no known cause making it idiopathic, however hypothesized causes include mechanical, metabolic, hormonal, neuromuscular, growth, and genetic abnormalities $[2,3]$. This aesthetically displeasing condition can result in mild to intense 


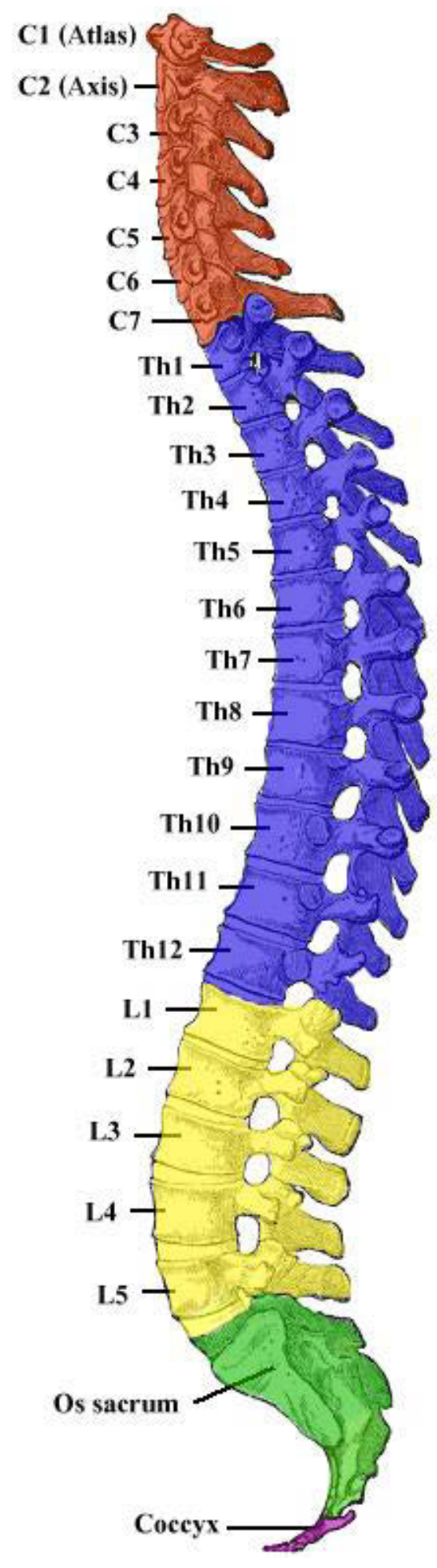

Figure 2-1. Anatomy of the Spine.

Source: Reprinted with permission. Carter HV. Anatomy of the Spine. Public domain, via Wikimedia Commons https://en.wikipedia.org/wiki/Vertebral_column [65] 


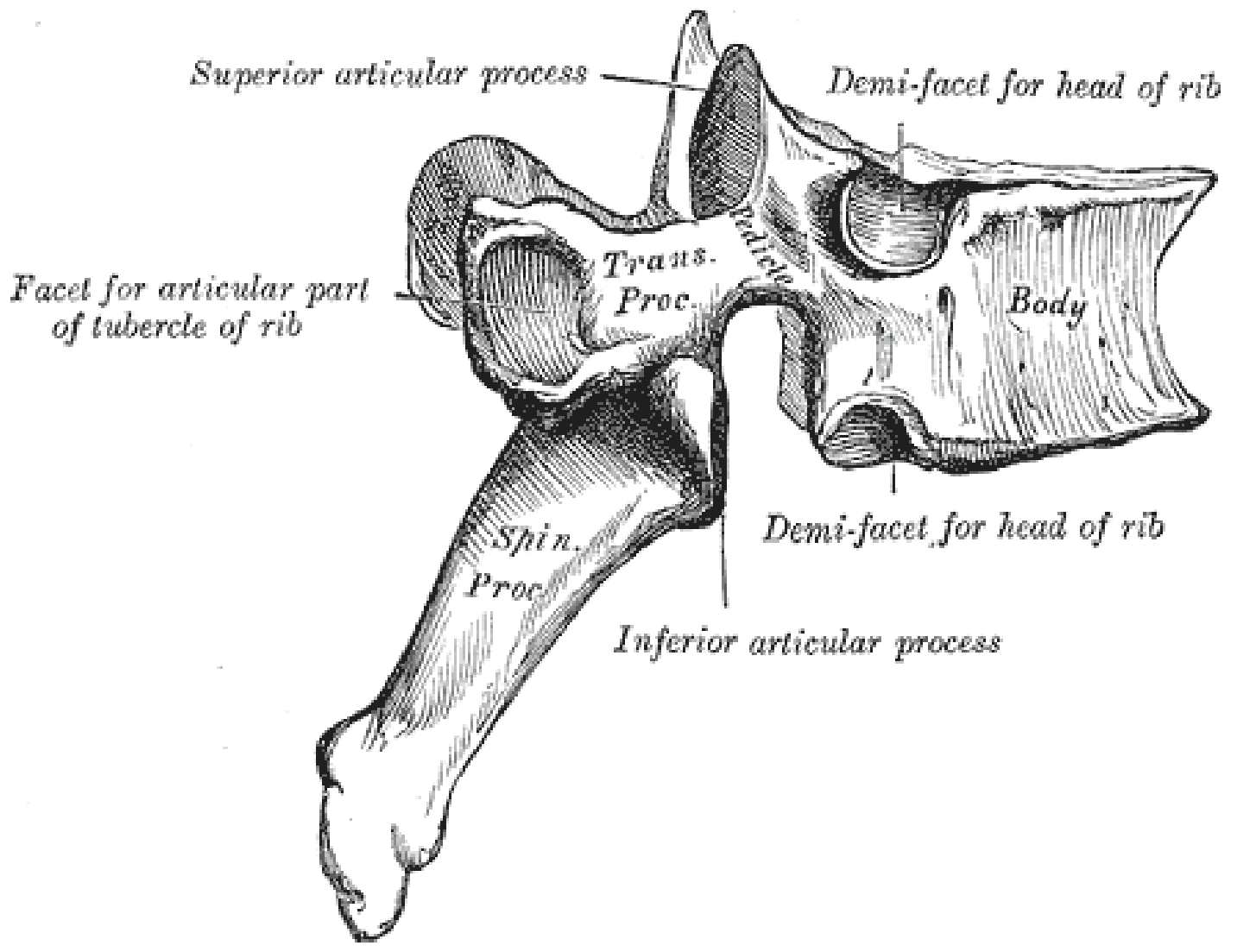

Figure 2-2. Anatomy of Vertebra.

Source: Reprinted with permission. Carter HV. Anatomy of the Spine. Public domain, vie Wikimedia Commons https://en.wikipedia.org/wiki/Vertebral_column [65] 
back pain and even diminished lung function in severe cases [4]. According to the National Scoliosis Foundation, scoliosis affects an estimated 6 million people in the U.S. alone, approximately $2-3 \%$ of the population. AIS represents $85 \%$ of cases or $0.5-3.0 \%$ of the pediatric population [5]. It is estimated that out of the 600,000 patient visits, only 30,000 are treated with an orthosis and 38,000 are treated with spinal fusion surgery annually [5]. During the assessment of scoliosis, four factors are examined in order to determine the treatment method: general characteristics, Cobb angle, risk of curve progression, and spinal flexibility.

General characteristics include age, weight, height, BMI, sex, patient history, posture, gait, body symmetry, and the presence of abnormal lumbar lordosis or thoracic kyphosis. When analyzing the patient history, an emphasis is placed on the growth and development of the child. Abnormalities in posture, gait, or body asymmetry such as shoulders or iliac crest asymmetry may be an indicator of scoliosis. A physician may use the Adam's Forward Bend test as a diagnostic tool. In this test, the patient bends forward causing body asymmetry to be more obvious [3]. If the general characteristics indicate the presence of a scoliotic deformity, then the patient is imaged using radiographic techniques.

The Cobb angle is determined from posteroanterior radiographs of the trunk. To calculate this angle, parallel lines are drawn from the endplates of the most tilted vertebral bodies, two perpendicular lines are then drawn extending from the parallel lines. The angle formed between the intersecting perpendicular lines is known as the Cobb angle (Figure 2-3) [6]. Conventionally, the Cobb angle has been measured using two dimensional posteroanterior radiographs. Recently, a new technology has been created that can create a three dimensional torso model called the EOS Imaging System and SterEOS software (Figure 2-4). The EOS Imaging System simultaneously captures a posteroanterior and a lateral radiograph on a 1:1 scale using slot scanning technology. Moreover, this process exposes the patient to one tenth the radiation than conventional imaging techniques. These images are sent to SterEOS software to construct a three dimensional model and provide information of the Cobb angle, critical vertebrae, vertebral rotation, and three dimensional anatomic measurements $[7,8]$.

Evaluation of the risk of curve progression is accomplished through observation and examination of skeletal maturity. Skeletal maturity is defined by a Risser Grade, which is a measure of the amount of ossification of the iliac crests. This measure is done by taking an AP radiograph of the pelvis and measuring the ossification of the crest on a scale of one to five where zero, one, or two is considered skeletally immature [9]. During observation, if an increase in Cobb angle of five degrees or more, when measured by the same clinician, occurs over a short period of time in a skeletally immature patient, then the curve is considered to be at high risk for further progression or "progressive"[10].

Spinal flexibility is measured by the extent to which a spine can be displaced due to an applied load. In this case, the amount of displacement is measured by Cobb angle reduction. The current practice for evaluating spinal flexibility includes side-bending, 


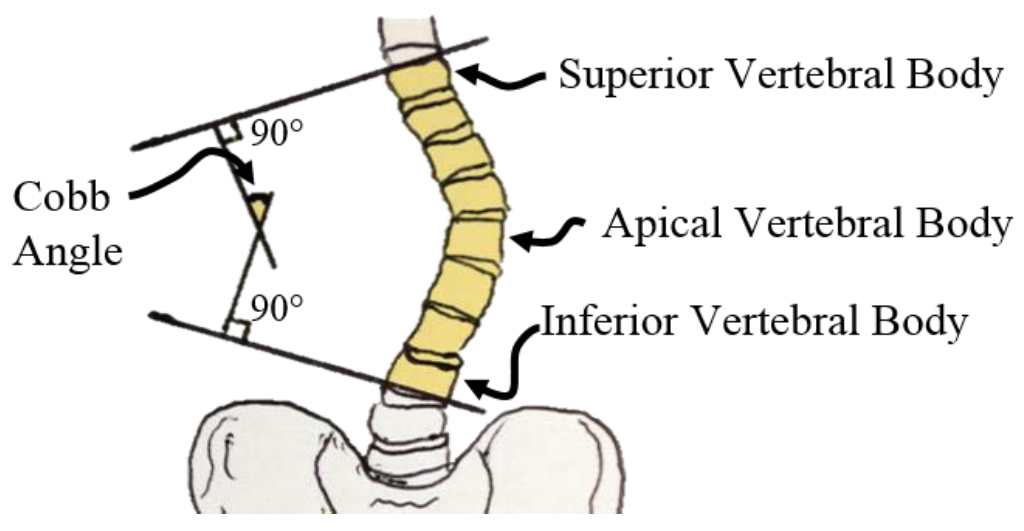

Figure 2-3. Cobb Angle Measurement.

Source: Reprinted with permission. Chung CL. Scoliosis Analog Model for the Evaluation of Bracing Technology [Master's]. (2015). Orthopaedic Surgery and

Biomedical Engineering, The University of Tennessee Health Science Center, 8. [65]

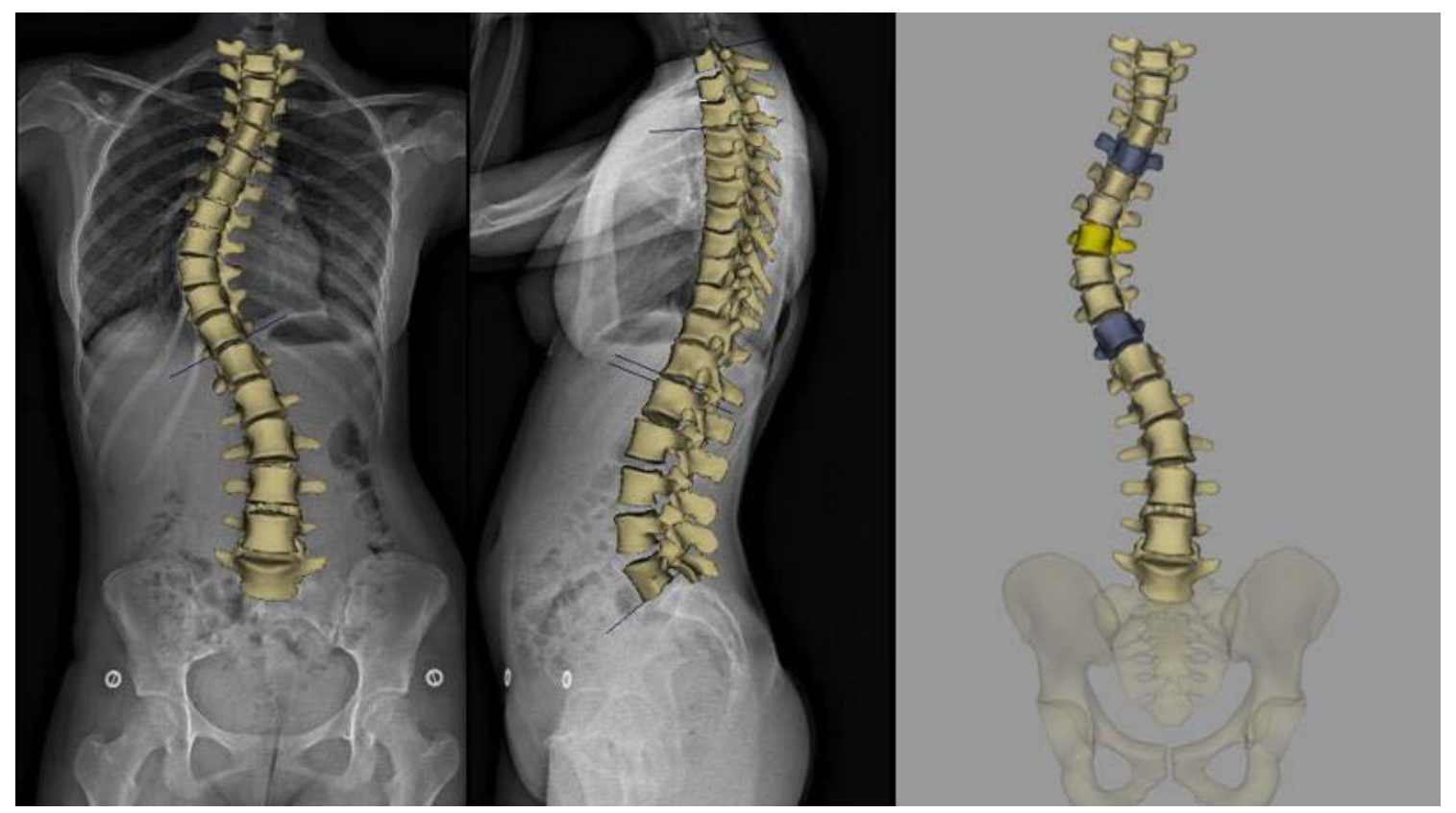

Figure 2-4. SterEOS 3D Model Reconstruction of Thoracic Curve.

Source: Reprinted with permission. Chung CL. Scoliosis Analog Model for the Evaluation of Bracing Technology [Master's]. (2015). Orthopaedic Surgery and Biomedical Engineering, The University of Tennessee Health Science Center, 11. [65] 
traction, and/or push-prone radiographs. In push-prone radiographs, the physician applies manual pressure to the apices of the curve during the radiograph. Using some or all of these techniques, the spine can be evaluated as having "sufficient flexibility" for bracing $[11,12]$.

\section{Treatment Methods for AIS}

The described assessment factors are instrumental in prescribing the proper treatment method for scoliosis. It is important to note that the procedure for prescribing proper treatment methods varies among physicians thus is a general description. Once the physician has confirmed the presence of scoliosis, the patient is imaged and the Cobb angle is found. If the Cobb angle is less than approximately fifteen degrees, the patient is skeletally mature (Risser Grade $>4$ ) and there is little to no risk of curve progression, and then no treatment or follow-up visit is necessary. However, if this patient is skeletally immature (Risser Grade $<2$ ) with a risk of curve progression, then further observation is necessary. Some physicians prescribe physical therapy in order to prevent further progression until the patient reaches skeletal maturity or the curve progresses past approximately twenty degrees. If the curve progresses past approximately twenty degrees or is "progressive", the patient is skeletally immature, and the spine has sufficient flexibility, then bracing is prescribed until the patient reaches skeletal maturity or the curve progresses past approximately forty-five degrees. If the curve progresses past approximately forty-five degrees, then the patient must undergo surgery $[4,6,13]$. The number and location of curves can be used to classify the severity of deformity and become part of the decision process between conservative or surgical treatment (e.g., Lenke Classification System of AIS) [14].

\section{Bracing in Scoliosis}

Each year, thirty thousand children in the US are put into a scoliosis brace [4]. Weinstein et al. defined brace treatment success as preventing curve progression past fifty degrees and reported that treatment is successful seventy-two percent of the time. The primary function of scoliosis braces is to reduce and prevent progression of the curve as the patient grows by application of corrective forces to the spine $[13,15,16]$. A secondary function of scoliosis braces is to reduce the deformity when worn, however treatment may still be successful without in-brace Cobb angle reduction. Straps, often made of Velcro, are attached to the back of the brace and corrective forces are applied to the spine by tightening the straps. Many braces use a three point pressure principle to correct the deformity in the coronal plane. These braces attempt to couple forces above and below the apex with an opposing force at the apex. Some braces, such as the Boston Brace, seek to apply forces that correct the deformity in the transverse plane, often referred to as axial derotation. To achieve derotation in a Boston Brace, for example, foam pads are placed in the lumbar section to create an anteriorly directed force and coupled with pads placed in the abdomen section that create a posteriorly directed force. Braces can be prescribed to be worn up to 23 hours a day. Treatment efficacy decreases 
as a result of poor patient compliance $[2,13,17]$ and/or loss of strap tension throughout the day $[18,19]$.

\section{Brace Fabrication}

There are three methods that can be used to create a scoliosis brace: the Manual Method which primarily uses artisan techniques, the Combined Method which uses a combination of artisan and CAD/CAM techniques, and the 3D Printing Method which primarily uses CAD/CAM techniques. In order to fabricate a Wilmington Brace using the manual method, for example, a scoliotic patient first needs to be manipulated into a less scoliotic position. This curve correction is often accomplished using a Risser table. The patient lies down on the table in the supine position and the clinician employs a system of straps and harnesses to pull the patient into the desired position. This system often requires the spine to undergo traction. Since this desired position eventually becomes the position that the brace enforces, the clinician attempts to find the optimal balance between correction and comfort. This position is maintained while the clinician wraps the patient in a sticky, cloth like material that quickly hardens. This method is known as casting. After the cast dries, it is cut off of the patient. The cut is then repaired to create a negative mold of the torso. This negative mold is then filled with plaster which hardens overnight to produce a positive mold. The positive mold is rectified by a highly skilled artisan by adding/removing plaster to improve brace comfort and effectiveness according to his/her professional opinion. Afterwards, a thin sheet of thermoplastic is heated and molded around the rectified plaster to produce the brace. The brace is then modified with trim lines to fit the patient and straps are added. Finally, a clinician places the brace on the patient and makes further modifications to the straps and trim lines in order to fit the patient as efficiently as possible. The patient is often instructed to wear the brace 23 hours a day [20]. However, the fabrication method varies depending on the type of brace. For example, when fabricating a Boston Brace, the cast is taken of a patient in the uncorrected or "native" posture. A brace is fabricated and outfitted with pads that are responsible for the corrective capacity of the brace. A radiograph and specific body measurements are used to determine the size, position, and orientation of the pads. The Boston Brace is modified with trim lines, straps, and fitted to the patient [21]. Over time, new technologies have arisen that can expedite fabrication, reduce costs, and even improve the effectiveness of bracing.

The Combined Method for fabricating scoliosis braces takes advantage of technologies such as 3D scanning, Computer Aided Design (CAD), and Computer Aided Manufacturing (CAM). There are several types of 3D scanners such as contact 3D scanners, non-contact laser scanners, white light scanners, etc. These scanners can determine spatial location of a point on an object and exports to a computer. If the scanner is then used to find the spatial location of hundreds of thousands of points on the object, then a cloud of points is generated on the computer. This cloud of points, or pointcloud, is now a digital representation of the object. This point-cloud can then be imported into reconstruction software, where a 3D model can be produced and exported to CAD software [22]. CAD software is used widely by engineers to design products. Most CAD 
software implements a user-defined approach in which dimensions of an object are specified by the user and the computer calculates the vector in 2D or 3D space. Most 3D CAD software have tools such as sketch, extrude, cut, etc. Other CAD programs have been developed specifically for scoliosis brace design and use an object-defined approach in which the dimensions are defined by the 3D scanned object and manipulated by the user. In Rodin 4D, for example, a 3D scan of a scoliotic torso can be imported into this software and digitally rectified using tools such as shift, add/subtract material, bend, etc. Once a satisfactory digital model has been designed, it is imported into a CNC machine [23]. The CNC machine implements subtractive manufacturing in which a carver methodically subtracts material from a block according to the specified shape, which in this case is a rectified torso mold [24]. Afterwards, a thin sheet of thermoplastic is heated and molded around the rectified torso mold to produce the brace [25].

The 3D Printing Method also makes use of a 3D scan and CAD software as seen in the Combined Method. However, the Combined Method uses CAD software to produce a torso mold whereas the 3D printing method produces a fully finished brace. This type of fabrication is possible because in 3D printing the object is built from consecutive layering of the material, also known as additive manufacturing [24]. Using this advanced technique, braces can be made slimmer, more aesthetically pleasing, and more comfortable. Innovative features can also be implemented into braces such as ventilation holes to improve thermal comfort. The orientation and size of these holes can also be used to define flexibility, optimize comfort, and improve corrective capacity. Strategic placement of these holes results in asymmetric flexibility to allow for greater movement in particular directions without sacrificing corrective capacity [26].

\section{Types of Scoliosis Braces and Limitations}

Scoliosis braces can be classified as Hard/Rigid Braces, Semi-Rigid Braces, or Soft/Flexible Braces. Hard/Rigid Braces, such as the Boston Brace, Wilmington Brace, Milwaukee Brace, Charleston Brace, Providence Brace, etc., are the most frequently used braces [13] in the US. These braces consist of a rigid shell that has been custom fitted to the torso. Rigid braces have been reported to be $72 \%$ effective in preventing curve progression past fifty degrees [13], however the most important limitation of this brace is user compliance $[13,27]$. Due to the rigid nature of these braces, the user feels constricted and uncomfortable [27]. This discomfort often leads to poor compliance to the prescribed duration of brace wear $[13,28]$. Thus, more flexible braces were created to address this issue [27].

Many Semi-Rigid Braces have been designed in order to improve comfort while maintaining effectiveness for preventing curve progression. Semi-Rigid braces are generally a combination of hard plastic pads and movement-enabling elements such as springs, joints, or elastic material. These braces include the Body Brace [29], Derotational Brace [30], Dynamic Scoliosis Orthosis [31], and more. The most popular and widely accepted of these braces is the TriaC Brace developed by Veldhuizen et al. The TriaC Brace makes use of a flexible coupling, spring elements, and hard plastic pads 
to allow for body fluctuations such as breathing, eating, bending, etc. [32]. This brace improves comfort by enabling greater flexibility. However, it achieves limited stabilization on the torso, especially on obese patients, causing it to become misaligned thus reducing effectiveness. Also, due to the flimsy design of the TriaC, it has a limited ability to apply large corrective forces to the spine which reduces its capacity to correct the deformity. Due to these critical limitations, the TriaC brace along with other SemiRigid Braces are not recommended for treating scoliosis [33].

Soft/Flexible braces such as the SpineCor Dynamic Corrective Brace consist of a system of elastic bands and straps that encompass the torso. These braces allow for a large range of movement and superior comfort even during exercises. However, similar to Semi-Rigid Braces, Soft/Flexible Braces have limited stabilization on the torso and poor corrective capacity [33]. Moreover, Wong et al. reported the SpineCor Brace to be significantly less effective than Hard/Rigid Braces [27].

\section{Strap Tension Effects on Curve Correction and Discomfort}

In a study by Mac-Thiong et al. [34], mini load cells were attached to a brace in order to measure strap tension. A force-sensing pressure pad outfitted with 192 force sensing transducers was placed between the torso and the brace. The straps were then tightened to 20,40 , and $60 \mathrm{~N}$ and the applied pressures were read on 8 regions of the body. The authors concluded that the applied pressure increased with increasing strap tension [34]. In a similar study by Wong et al., it was found that as strap tension increased, applied pressure increased, and the initial in-brace Cobb angle correction increased [35]. Noonan et al. reported a correlation between initial in-brace correction and treatment success [36]. Both Wong and Mac-Thiong concluded that physicians should prescribe high strap tensions to enhance brace treatment efficacy. Jiang et al. also reported that low strap tensions resulted in a higher risk of curve progression [37].

In the same study described above, Mac-Thiong also concluded that discomfort increased with increasing strap tension and pad pressure [34]. In the study by Wong et al., it was also found that strap tension increased during deep breathing [35]. Other studies have also shown an increase in strap tension during deep breathing $[19,38,39]$ and have found this led to discomfort [40]. Kennedy et al. reported a significant reduction in total lung volume, vital capacity, and residual capacity during bracing. They also reported a significant decrease in lower ribcage and abdominal movement during bracing in sitting and supine. Kennedy reported an increase in gastric pressure and concluded this led to an increase in inspiratory effort [41]. According to Nicholson et al., user compliance to the treatment is often poor due to discomfort [28]. Moreover, studies have shown that user compliance had a direct effect on treatment efficacy $[13,42]$. A past study by Katz et al. [42] found that wearing a brace for more than $12 \mathrm{hrs} /$ day controlled curve progression in patients with idiopathic scoliosis. In fact, Katz et al. found that the number of hours of brace wear was a much more influential factor than initial in-brace correction [42]. 
According to the Academy of Orthotists and Prosthetists, "Loss of strap tension could be a direct link to a loss of initial in-brace correction and should be monitored." Aubin et al. performed an experiment in which a patient wearing a scoliosis brace outfitted with strap tension load cells attempted different body positions. A great deal of strap tension variability was found between positions regardless of the initial strap tension. Most importantly, a loss of strap tension was reported in lying positions which has been reported by other authors as well $[38,39,40,43]$. Katz et al. reported that patients who wore their brace during the day were more strongly associated with successful outcomes than those who wore the standard daytime brace at night [42], it is possible that this was due to a loss of strap tension when lying down. Moreover, Aubin et al. concluded that loss of strap tension during nighttime wear may have important consequences concerning brace efficacy [19]. Some studies have concluded that the sidelying position using a nighttime brace achieved the greatest in-brace correction of the sleeping postures $[39,40]$, which evidenced potential for greater in-brace correction during nighttime wear. Yokoyama et al. reported significant trunk muscle relaxation in lying postures compared with standing postures [44], which could have explained strap tension loss or indicate an opportunity for greater in-brace correction during nighttime wear. It has also been found that strap tension loss occurs shortly after initial brace fitting possibly due to material relaxation, torso repositioning within the brace, soft tissue adjustment, or patient growth $[19,39,43]$. Additionally, strap tension loss occurs throughout the day due to Velcro loosening during daily body movements and fluctuations $[19,38,39,43]$. Aubin et al. as well as other authors stated that maintaining strap tension throughout the day, during nighttime wear, and throughout the weeks between follow-up visits would improve brace efficacy $[19,39,43]$.

\section{Computer Models for Improving Bracing in AIS}

A study by Desbiens-Blais et al. was conducted where biplanar radiographs of a patient were acquired. Using these images, a 3D model of the bony skeleton was created, which included the spine, ribcage, and pelvis. Then, a 3D surface scan was obtained of the patient. Using multiple radiopaque markers that were visible on the radiographs and the 3D surface scans, the 3D surface model was accurately overlaid on the 3D skeleton model to create a full torso model. Based on the geometry acquired from the full torso model, a Finite Element Model (FEM) was created by representing the vertebrae, intervertebral discs, sternum, ribs, abdominal cavity, and costal cartilage as 3D elastic beam elements. The mechanical properties of each element were assigned based on experimental and published data. Using this model, an initial brace shape was designed and converted to an FEM. It was then placed on the torso FEM for simulation and testing. Forces in the model were created based on the forces in the brace straps. Through iterative simulations and design changes, an optimized brace shape was found that achieved the most theoretical Cobb angle correction. A positive mold for this brace shape was milled and a brace was created by thermoforming plastic around this mold, this was called the New Brace. For each patient, a New Brace and a conventionally fabricated Standard Brace were created. This study then compared the apical vertebral translation (AVT) and the Cobb angle between the New Brace simulation, the New Brace, and the 
Standard Brace. There was no significant difference found for Cobb angle and AVT between any of the three comparisons. However, the New Brace had significantly reduced the kyphosis and lordosis angles compared to the standard brace. The results proved that the new brace was sufficient for fabricating an effective scoliosis brace. The main advantages for the New Brace included lower fabrication time, a more consistent protocol for brace design, and recorded initial brace shape to assist with patient follow-up [45].

A study was conducted by Nie et al. where a complete thoracolumbosacral scoliosis finite element model was created to simulate the forces and geometry change of a specific patient when wearing a brace. The simulated results were then compared to the clinical data. The patient was subjected to a CT scan which allowed for the acquisition of the skeleton from head to pelvis. The geometry of the thoracolumbosacral-pelvis was imported into a finite element software known as ANSYS 7.0. The model was then modified to contain intervertebral discs, a number of joints, ligaments, and cartilage. These components were assigned mechanical properties based on generic cadaveric data found from published studies. A finite element model of a brace was created and fitted to the finite element torso model. A simulation was conducted assigning strap tensions of $20 \mathrm{~N}, 40 \mathrm{~N}$, and $60 \mathrm{~N}$ incrementally. Forces generated on many regions of the brace were calculated for each strap tension and recorded. During the clinical assessment, the same patient was used as in the simulation. This patient's brace was outfitted with a digital pressure sensing mat that was overlaid throughout the entire brace interior. By measuring the contact area in certain regions between the patient's torso and the pressure mat, the amount of force applied by the brace in that region was calculated. This force was called the equivalent force. The straps were then tensioned to $20 \mathrm{~N}, 40 \mathrm{~N}$, and $60 \mathrm{~N}$ incrementally and the forces generated on particular regions of the brace were calculated. By using the same patient, strap tension, and regions evaluated; the simulation and clinical experiments were able to be easily compared. The authors concluded that the results from the finite element model were consistent with the clinical results [46].

In both FE models produced by Nie and Desbian-Blais, the ligaments, cartilage, and other structures were modeled by elastic beam elements. The properties of these elements were assigned based on average published data found from cadaveric specimens. This method means that the mechanical properties of these FE models did not replicate a specific patient, but was only an approximation and could be a source of error in their models.

\section{Mechanical Model for Analyzing Bracing Mechanics}

\section{Scoliosis Analog Model}

A mechanically equivalent analog model of the AIS condition was developed (Figure 2-5A) for the purposes of evaluating scoliosis bracing technology [47]. The Scoliosis Analog Model (SAM) used a linkage-based system to simulate 3D spinal 


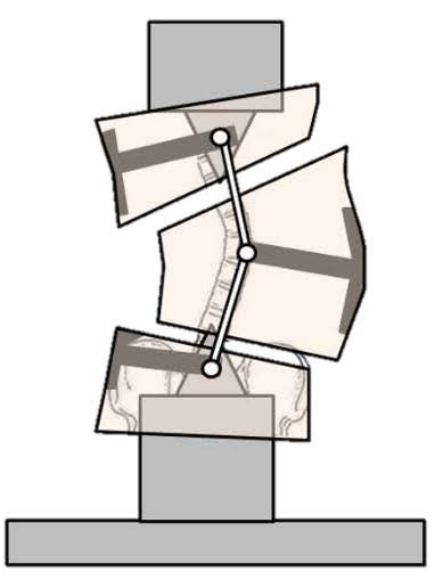

(a)

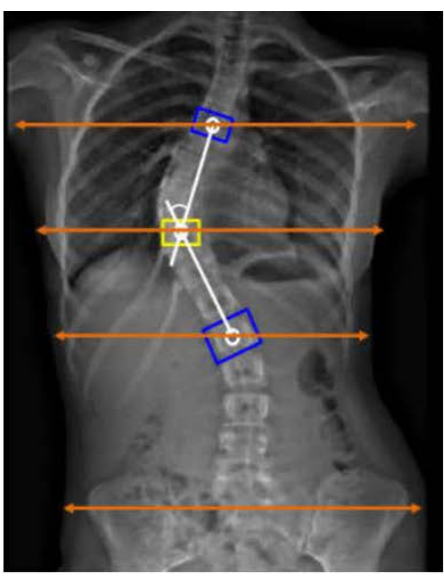

(b)

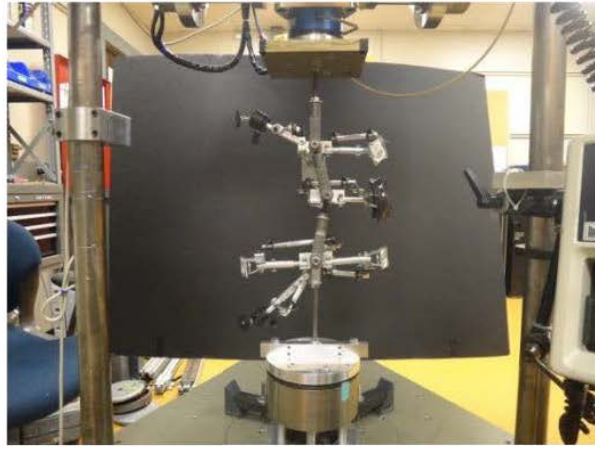

(c)

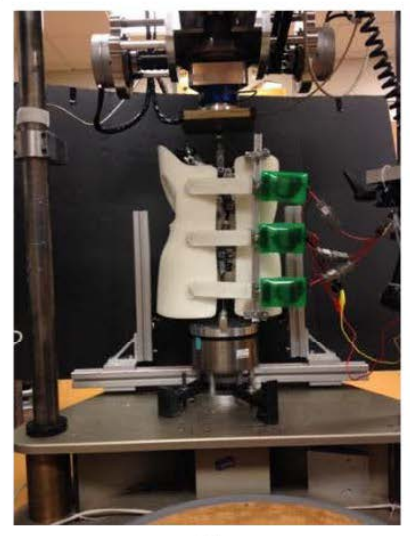

(d)

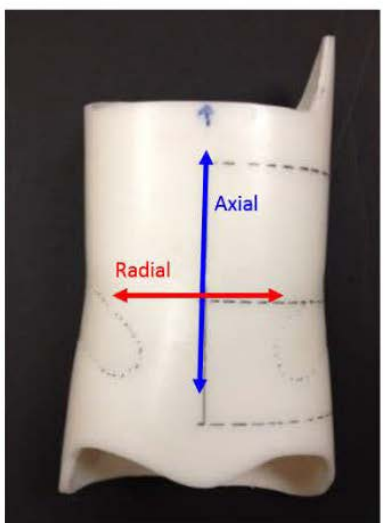

(e)

Figure 2-5. SAM Customization and Testing Setup.

A) SAM Concept, B) X-ray Measures, C) SAM Assembly, D) SAM and Brace, E) Brace Directions. Source: Modified with permission. Chung CL. Scoliosis Analog Model for the Evaluation of Bracing Technology [Master's]. (2015). Orthopaedic Surgery and Biomedical Engineering, The University of Tennessee Health Science Center, 54-59. [65] 
correction of Cobb Angle (CA) and axial rotation (AR) deformity of a single-curve scoliotic spine. The SAM removes the effects of gravity and muscle activity, and provides insight into the pure brace loading mechanics. The model was adjustable to accommodate unique scoliotic deformities and associated braces. The SAM was designed to engage with the interior surface of a scoliosis brace at each of the three levels, superior, inferior, and at the apex. Characteristics and dimensions from patient records and EOS images (EOS Imaging, France) [6-8,48] (IRB 14-03110-XP) (Figure 2-5B) were used to customize the SAM (Figure 2-5C) for use with a Boston brace, including sex (male), age (13), height $(1.7 \mathrm{~m})$, and weight $(570 \mathrm{~N})$, pre-brace measures CA $\left(33^{\circ}\right)$ and AR $\left(5^{\circ}\right)$, and in-brace measures of CA $\left(26^{\circ}\right)$ and AR $\left(0^{\circ}\right)$. This work has been presented at engineering conferences [49-51] and accepted for presentation at clinically-related meetings [52-55].

\section{Strap Options}

The SAM was used to investigate the effects of altering the number of Velcro brace straps $(0,1,2,3$, or 4$)$ on the brace structural properties and spinal loading mechanics [56]. The SAM was mounted on a programmable testing platform [57], which was programmed to displace the linkage system. With a scoliosis brace mounted on the SAM (Figure 2-5D), downward displacement caused the linkage components and shells to move outward and engage with the inner walls of the brace. During the simulation, forces and angular displacement of the linkages were measured and used to calculate the brace structural stiffness properties along the axial (caudal/cranial axis or long axis) and radial (medial/lateral axis) directions of the brace (Figure 2-5E) (Table 2-1).

Compared to the unconstrained (no strap) brace, a significant increase in both stiffness values was observed with the addition of straps. An average 9-fold increase was observed between the axial and radial stiffness values. An optimal brace radial stiffness was achieved with three Velcro straps, i.e., there was no significant stiffness gained by adding a fourth strap, which supports the use of a 3-Velcro strap brace in the proposed study. Measured differences in brace force response and structural properties due to brace design alterations agreed with clinical observations made by Lebel et al. [58]. Radial and axial force responses were measured (Figure 2-6). The difference in measured and theoretical axial force components (i.e., $510 \mathrm{~N}$ versus $320 \mathrm{~N}$ ) suggests that the brace applies both inward and upward corrective forces, similar to a distractive brace. Force ranges measured with the SAM were comparable to the applied forces measured by Van den Hout et al. [59].

\section{Strap Tension}

Two orthotists tightened a 3-strap brace onto the Scoliosis Analog Model (SAM) in set strap orders of top (T), middle (M), and bottom (B). The orthotists preferred to tighten all three straps and then retighten the initial strap, specifically in the orders of 
Table 2-1. Mean Radial and Axial Stiffness Values of Brace Configurations $\left(\mathrm{N} /{ }^{\circ}\right)$.

\begin{tabular}{ccccc}
\hline $\begin{array}{c}\text { Brace } \\
\text { Configuration }\end{array}$ & Radial & \pm SD & Axial & \pm SD \\
\hline No Straps & 0.0 & 0.2 & 1.0 & 0.5 \\
One Velcro Strap & 1.3 & 0.1 & 17.6 & 2.3 \\
Two Velcro Straps & 2.4 & 0.2 & 23.3 & 4.4 \\
Three Velcro Straps & 3.5 & 0.3 & 27.2 & 3.4 \\
Four Velcro Straps & 3.6 & 0.2 & 29.3 & 0.8 \\
\hline
\end{tabular}
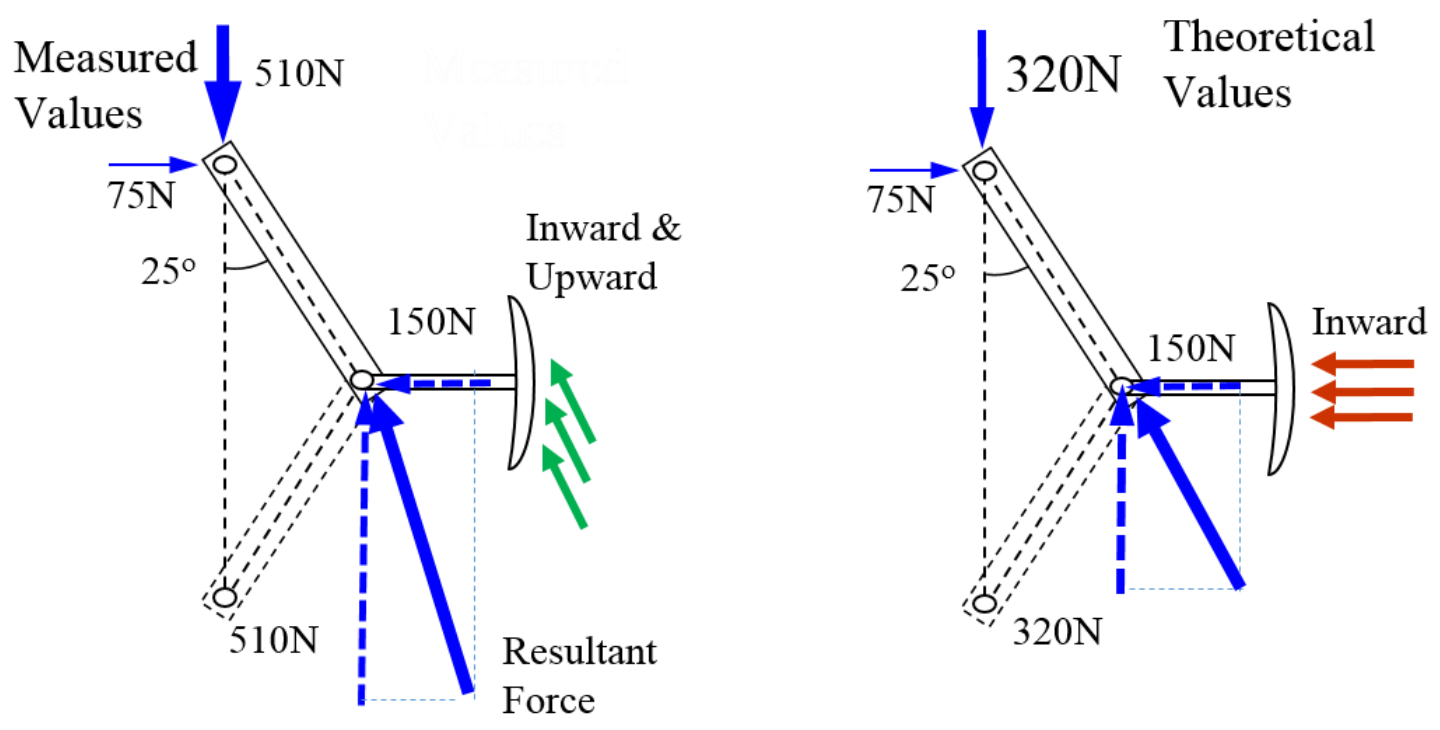

Figure 2-6. Interpretation of Force Mechanics.

Source: Reprinted with permission. Chung CL. Scoliosis Analog Model for the Evaluation of Bracing Technology [Master's]. (2015). Orthopaedic Surgery and

Biomedical Engineering, The University of Tennessee Health Science Center, 46. [65] 
M-T-B-M and M-B-T-M. The distractive force (FD) generated by the brace was measured using a six-axis force sensor, and the individual strap tensions (TT/TM/TB) were recorded using tensiometers. The prescribed overall strap tension (TO) was calculated as the average of the TT/TM/TB values. Mean distractive force ranged from $10.6 \mathrm{~N}$ to $27.3 \mathrm{~N}$, and individual strap tension ranged from $22.6 \mathrm{~N}$ to $51.2 \mathrm{~N}$. Individual strap tensions for M-T-B-M and M-B-T-M orders were $35.8 \mathrm{~N} / 38.3 \mathrm{~N} / 32.6 \mathrm{~N}(\mathrm{TO}=$ $35.5 \mathrm{~N})$ with $19.8 \mathrm{~N}$ FD and $37.0 \mathrm{~N} / 37.6 \mathrm{~N} / 32.5 \mathrm{~N}(\mathrm{TO}=35.7 \mathrm{~N})$ with $18.3 \mathrm{~N} \mathrm{FD}$, respectively, when averaged among orthotists. The measured strap tension range is supported by literature $[16,19,35]$. The same distractive force and overall strap tension was achieved by using either tightening sequence. The relationship between the magnitude of each individual strap tension (TT/TM/TB) and distractive load (FD) was determined using Bivariate Pearson Correlations. For both strapping sequences, TT was negatively correlated with FD $(\mathrm{p}<0.01)$, meaning that greater distractive force was measured when the top strap was relatively loose.

\section{Factors Influencing Discomfort}

Goonetileke et al. reported that as an applied force on the human body increased their discomfort also increased [60]. An applied force on the human body could cause discomfort, pain, or possibly injury [61]. Moreover, the load bearing capacity of a structure could be enhanced by concentrating the forces on stronger sections thus concentrating the load across stronger sections of the human body should minimize discomfort [62]. It has been found that the major cause of pressure sores is localized high pressures on the body [63]. Tsay et al. reported that shear stress is a major factor in the formation of pressure sores, stating that they originated in deep tissue where the highest shear stress was found [64]. 


\section{CHAPTER 3. STUDY ONE: DESIGN AND VALIDATION TESTING OF CONTROLLED TENSION FASTENING DEVICES}

\section{Objective}

The objective of this study was to determine the tension-displacement properties of the CTU devices for different rates of spring distraction and for different amounts of spring tension output.

The design parameters for the CTU devices were the range of strap tension output force and the amount of brace gap opening and closing (Figure 3-1). These values were estimated from data found in the literature and fitting trial studies with two local orthotists who measured the prescribed strap tension settings at the time of their patient's brace fitting visit. The force values ranged from 20 to $60 \mathrm{~N}$ and the range of gap opening was set to approximately 5 to $40 \mathrm{~mm}$ ( $1 / 4$ to $1 \frac{1}{2}$ inches). The gap range was set to about 12 $\mathrm{mm}(1 / 2 \mathrm{inch})$ in this study to simulate brace gap expansion associated during deep breathing.

\section{Materials}

Various types of equipment were used for this research. The equipment consisted of the components that made up the controlled tension units and a standard mechanical testing platform.

\section{Controlled Tension Units (CTU)}

The controlled tension unit (CTU) (Figure 3-1) was made up of a male rivet 5 and a female rivet $\mathbf{6}$ which secured the constant-force spring $\mathbf{2}$ and the frictionless bearings $\mathbf{4}$ to the case $\mathbf{1}$. An internal cable 35 was connected to the constant-force spring and when pulled rotated about the female rivet allowing the spring to extend towards the end of the case. Spring extension was accommodated by the length of the case. The tension setting of the CTU device was determined by the strength of the constant-force spring. Therefore, multiple CTU devices could be made with various tension settings which allowed for a wide range of tension selection. A lid 7 could be easily attached to the case using lid screws $\mathbf{3 3}$ resulting in a closed system. A Velcro strip $\mathbf{8}$ on the back of the case allowed for quick attachment of the straight outlet CTU 18 to the preexisting Velcro strap 15 on a standard brace $\mathbf{1 4 .}$

The overall travel of spring was set to $38 \mathrm{~mm}\left(1^{1 / 2 "}\right)$ and was limited by the length of the casing. For this prototype, the working stroke for the tension-displacement test was set to $\pm 6.3 \mathrm{~mm}(1 / 4)$. The enclosed casing for the CTU device was intended to be low profile so as to be worn comfortably under clothing and during daily activities. Three 


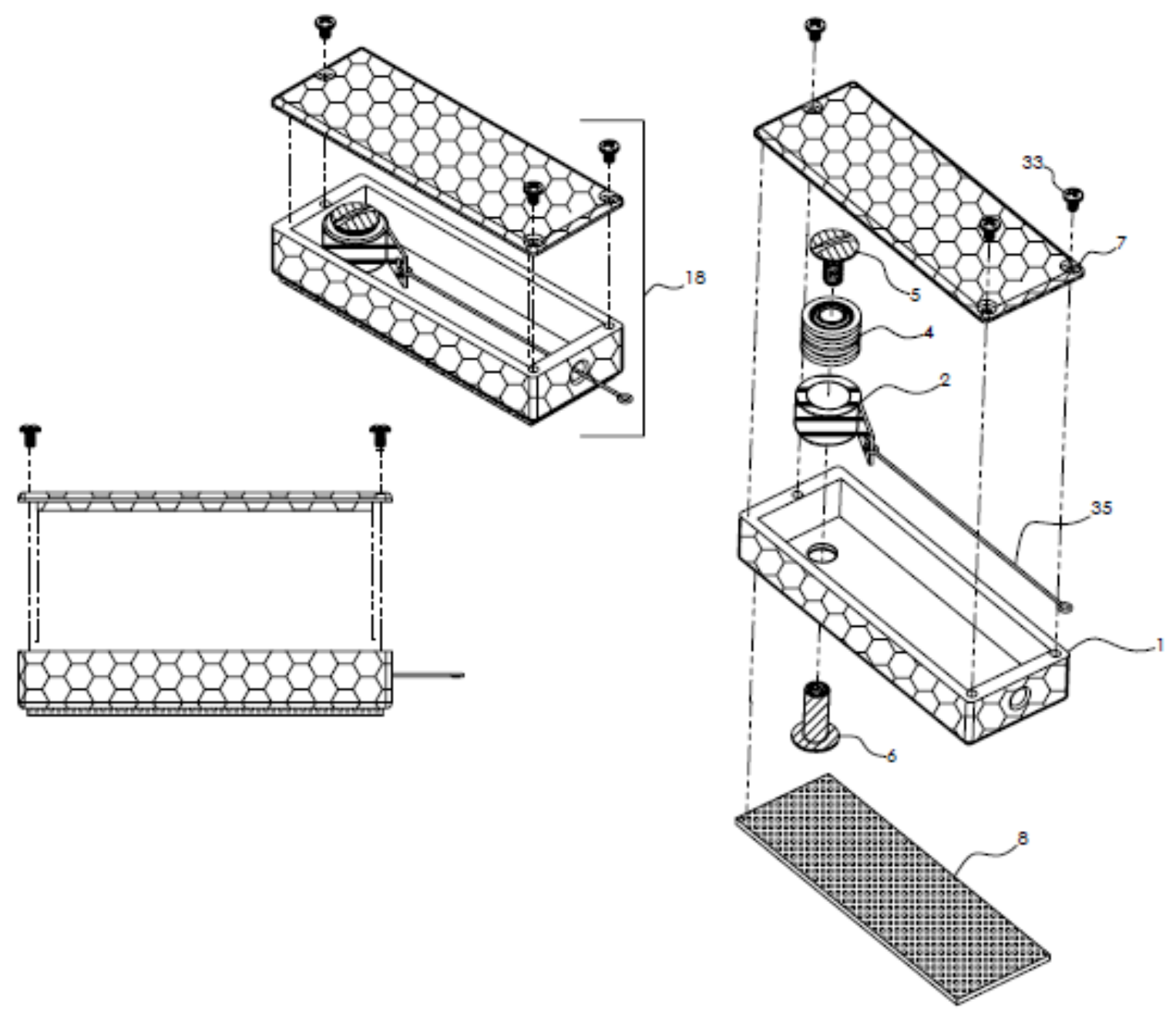

Figure 3-1. Exploded Line Drawing of a CTU Device. 
different spring capacities were selected having force outputs of $20 \mathrm{~N}, 30 \mathrm{~N}$, and $40 \mathrm{~N}$ to accommodate different strap tension settings. In the end, the CTU devices were designed to work with any type of strapping system currently used on conventional braces.

The main component of the CTU was the constant-force spring. Constant-force springs have the unique capability of applying the same force over a large range or working length to within $\pm 10 \%$ of the targeted value (referred to as the load tolerance). The tension-displacement behavior of a constant-force spring is shown in Figure 3-2. After some initial spring displacement the change in the spring's force response is small over a large amount of spring displacement. Constant-force springs have a fatigue life that ranges from 2,500 cycles to over a million cycles. The springs would need to be replaced every 1- 3 months, or at each follow-up visit. The force output of the spring is a function of the thickness, width, diameter, and material type. Most off-the-shelf constantforce springs are made of stainless steel. By laminating or stacking constant-force springs together, higher total forces can be achieved while maintaining a low profile CTU device design (Figure 3-3). When selecting a constant-force spring, additional factors that must be included in the design are the spool which must be $15-20 \%$ greater than inside diameter of spring, the spring must have $1 \frac{1}{2}$ wraps remaining on spool when fully extended, and the full rated load is achieved when deflected a length of approximately $1 \frac{1}{2}$ times spool diameter.

\section{Robotic Testing Platform}

A multi-axis programmable testing platform shown in Figure 3-4 was used that allowed the user to program the amount and rate of displacement and measure the force along the displaced axis [57]. The platform had 4 programmable axes: 2 translational and 2 rotational. The axes could be controlled under displacement, load, or combinations thereof. Position resolution was: $2 \mu \mathrm{m}$ in $\mathrm{x}, 0.31 \mu \mathrm{m}$ in $\mathrm{z}$, and $0.002^{\circ}$ about $\mathrm{y}$. There were 2 six-axis load cells attached to the upper gimbal assembly and base platform. The Upper Load Cell (ULC) had a max capacity of $800 \mathrm{~N}$ and a resolution of $0.2 \mathrm{~N}$. The Bottom Load Cell (BLC) had a max capacity of $4450 \mathrm{~N}$ and a resolution of $0.73 \mathrm{~N}$. The use of the ULC was validated and shown in Appendix (Figure A-1).

\section{Methods}

The controlled tension units were mounted in a robotic testing platform (Figure 3-5) that was programmed to displace the CTU device at a set speed and measure the force-displacement response of the device. Three different speeds or rates of spring displacement were chosen: a Fast Speed (F) with maximum speed of $18 \mathrm{~mm} / \mathrm{s}$, an Intermediate Speed (I) of $12 \mathrm{~mm} / \mathrm{s}$, and a Slow Speed (S) of about $6 \mathrm{~mm} / \mathrm{s}$. Similarly three different CTU devices were fabricated and tested having a Low Tension (L) setting of $20 \mathrm{~N}$, a Medium Tension (M) setting of $30 \mathrm{~N}$, and a High Tension (H) setting of $40 \mathrm{~N}$. Each set of CTU devices (L,M,H) was tested four times at each speed (S,I,F). The testing protocol is shown in Table 3-1. The output tension and displacement of the CTU devices 


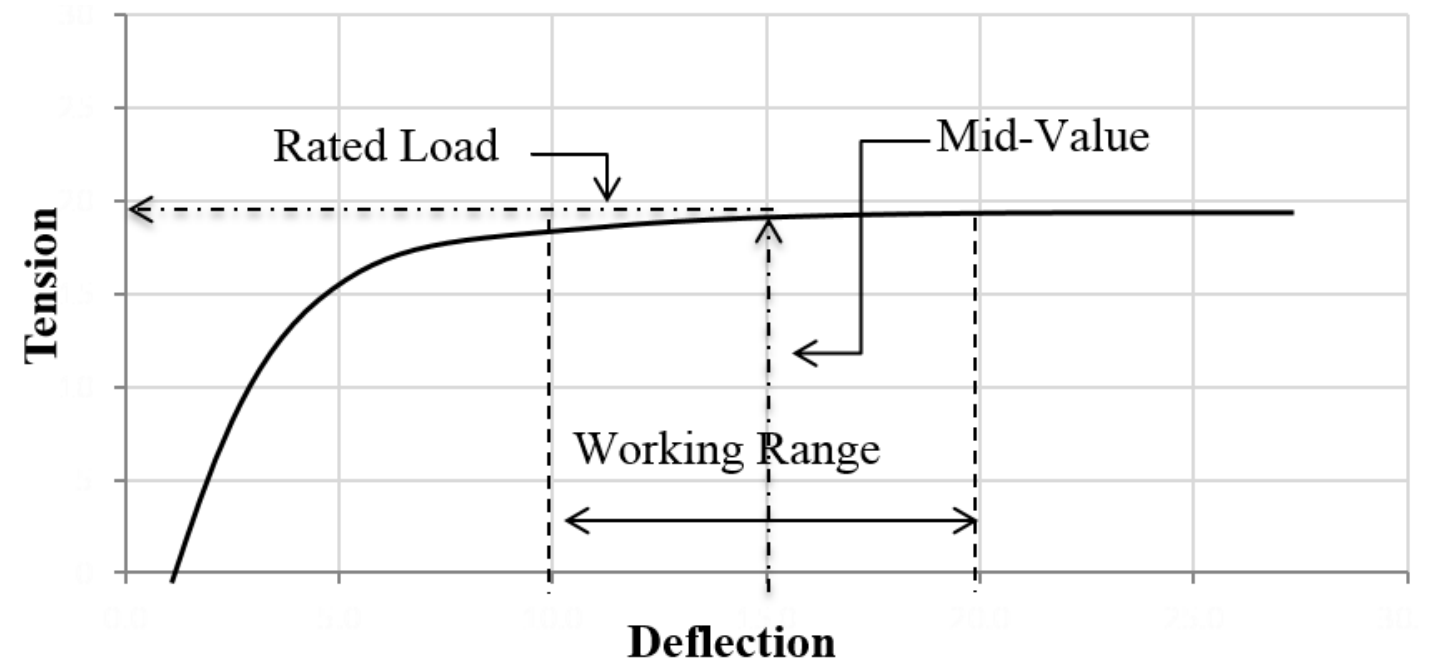

Figure 3-2. Behavior of a Constant-Force Spring.

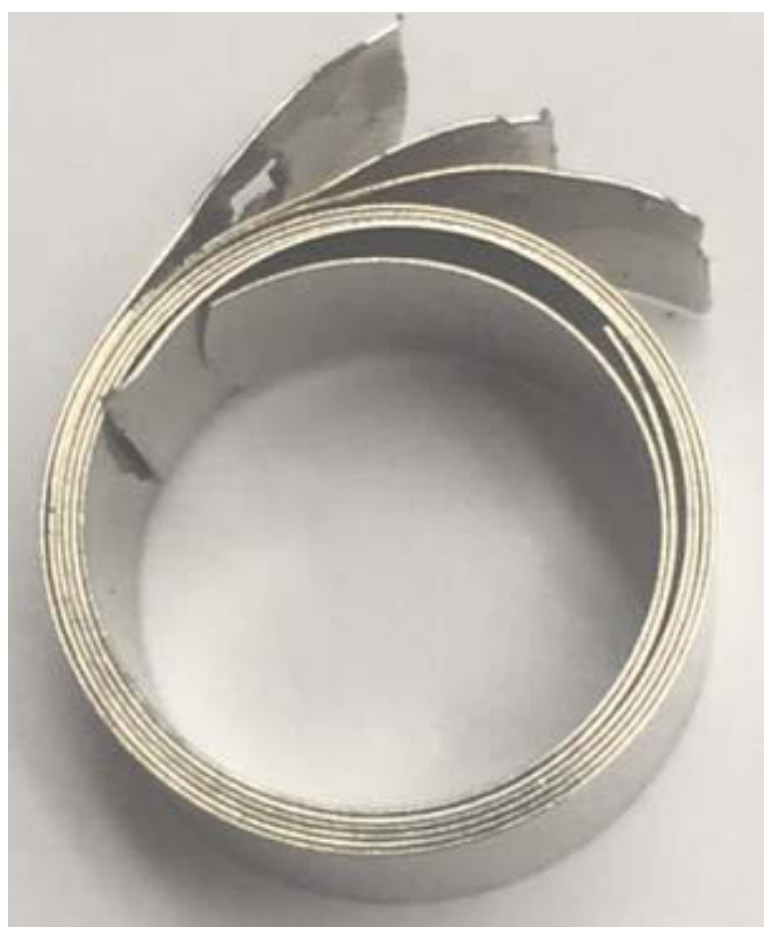

Figure 3-3. Laminating the Springs for Increased Force Output. 


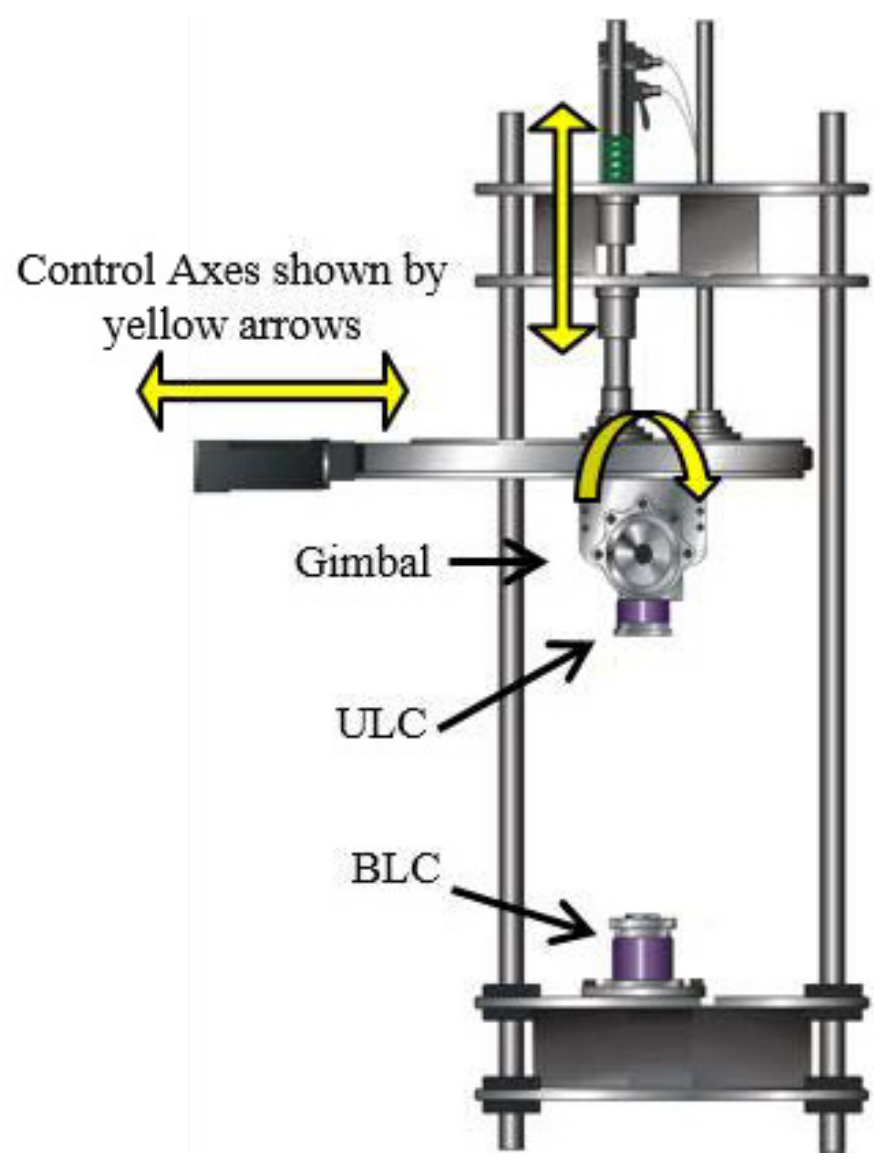

Figure 3-4. Robotic Testing Platform. 


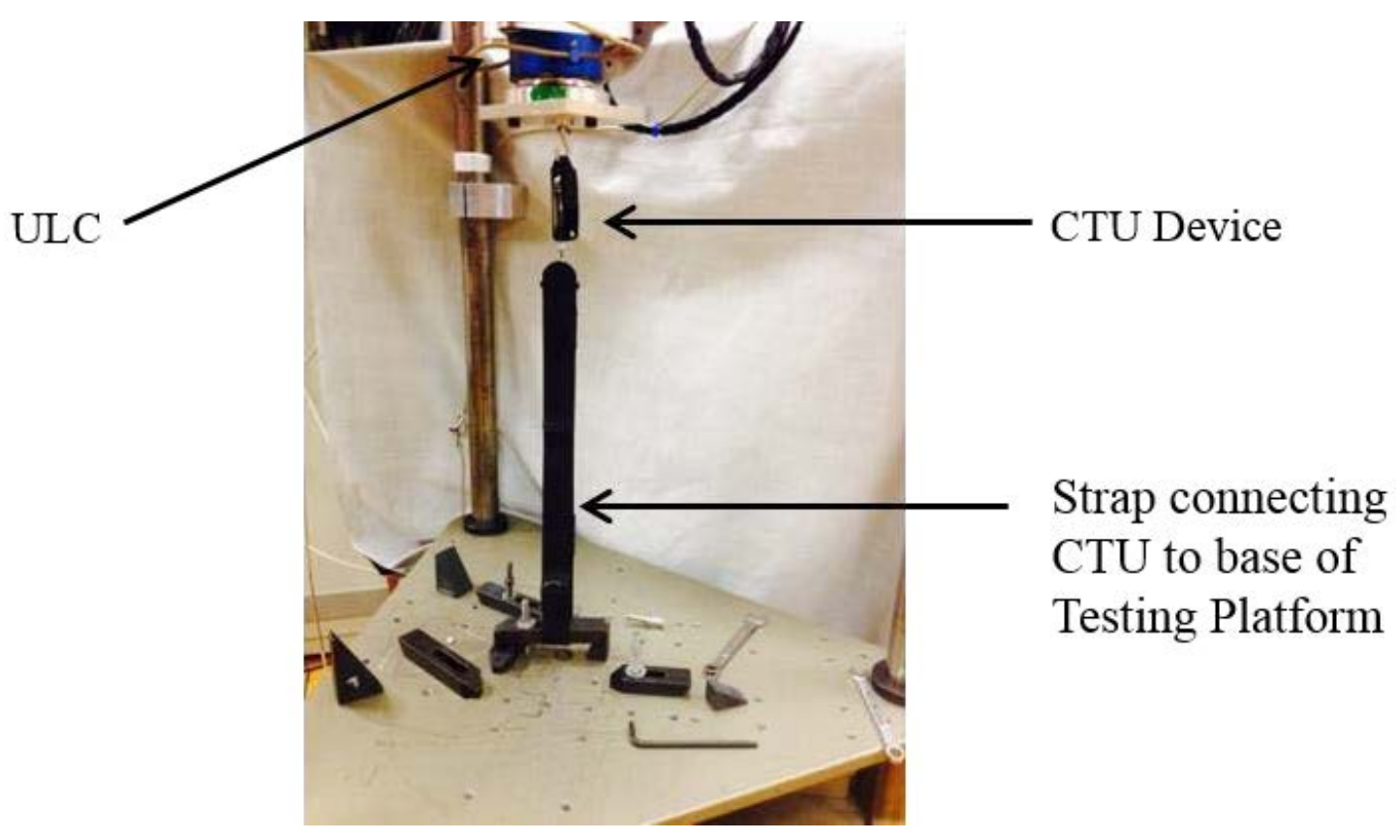

Figure 3-5. Test Set-up of a CTU on the Testing Platform.

The ULC was connected to the actuator which was programmed to move upward and extend the constant-force spring enclosed in the CTU housing.

Table 3-1. Tension Setting and Speed Combinations.

\begin{tabular}{cccc}
\hline \multirow{2}{*}{ Tension } & \multicolumn{3}{c}{ Speed } \\
\cline { 2 - 4 } & Slow (S) & Intermediate (I) & Fast (F) \\
\hline Low (L) & $\mathrm{L} / \mathrm{S}$ & $\mathrm{L} / \mathrm{I}$ & $\mathrm{L} / \mathrm{F}$ \\
Medium (M) & $\mathrm{M} / \mathrm{S}$ & $\mathrm{M} / \mathrm{I}$ & $\mathrm{M} / \mathrm{F}$ \\
High (H) & $\mathrm{H} / \mathrm{S}$ & $\mathrm{H} / \mathrm{I}$ & $\mathrm{H} / \mathrm{F}$ \\
\hline
\end{tabular}


were measured and plotted to determine the working range and load tolerance of each CTU device (Figure 3-6). The load tolerance was calculated using Equation 3-1.

$$
\text { Load Tolerance }=\left(\frac{1}{2}\right)\left(\frac{\Delta}{\text { Rated Load }}\right) \times 100 \% \quad \text { (Eq. 3-1) }
$$

\section{Results}

The tension-displacement responses of the three different CTU devices are shown in Figures 3-7 through 3-9 for the three different rates of displacement. Four trials were run at each speed and averaged. The corresponding mean values of the rated load and load tolerances are listed in Table 3-2. The targeted rated loads of $20 \mathrm{~N}, 30 \mathrm{~N}$, and $40 \mathrm{~N}$ were achieved and the load tolerances were all within the spring manufacturer's specification of $\pm 10 \%$.

\section{Conclusion}

The feasibility of designing CTU devices with load settings of $20 \mathrm{~N}, 30 \mathrm{~N}$, and $40 \mathrm{~N}$ was successful. The devices applied a relatively constant tension over a working range of $12.7 \mathrm{~mm}$ and maintained a load tolerance within $\pm 10 \%$. The force output response and load tolerances were independent of the rate of spring displacement. The next step of this research was to compare the structural stiffness properties of a standard brace with conventional Velcro straps versus CTU devices as the fastening system. 


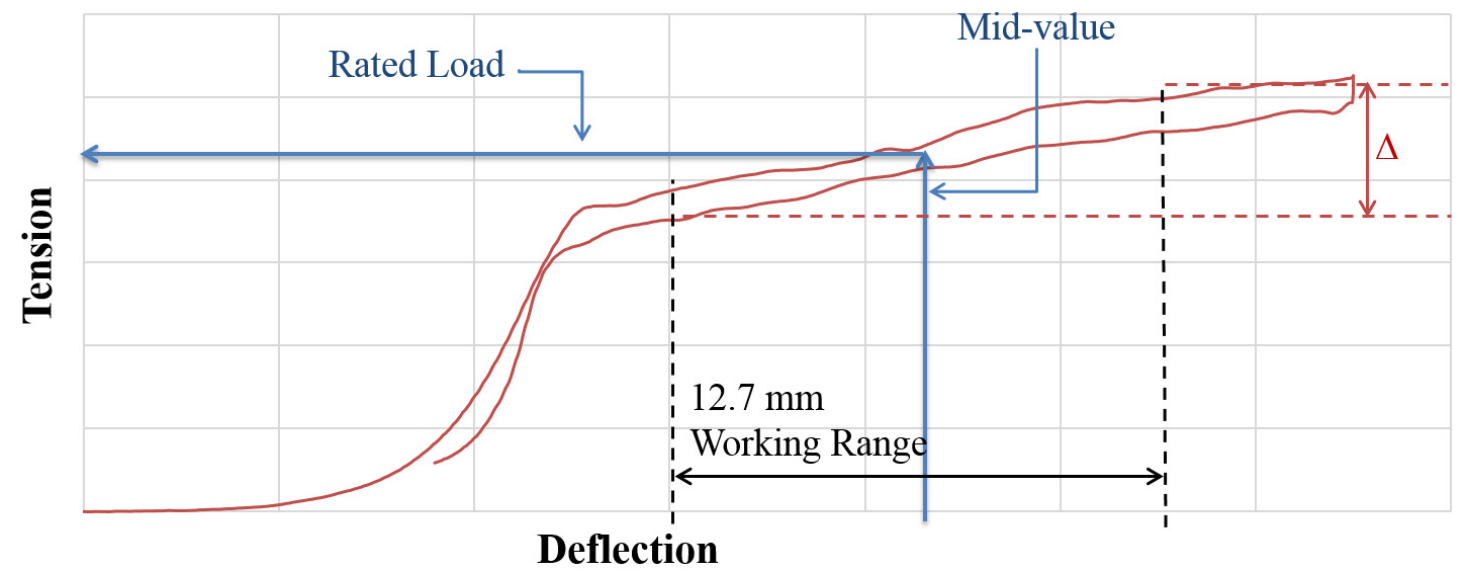

Figure 3-6. Tension-Displacement Relationship of a CTU Device.

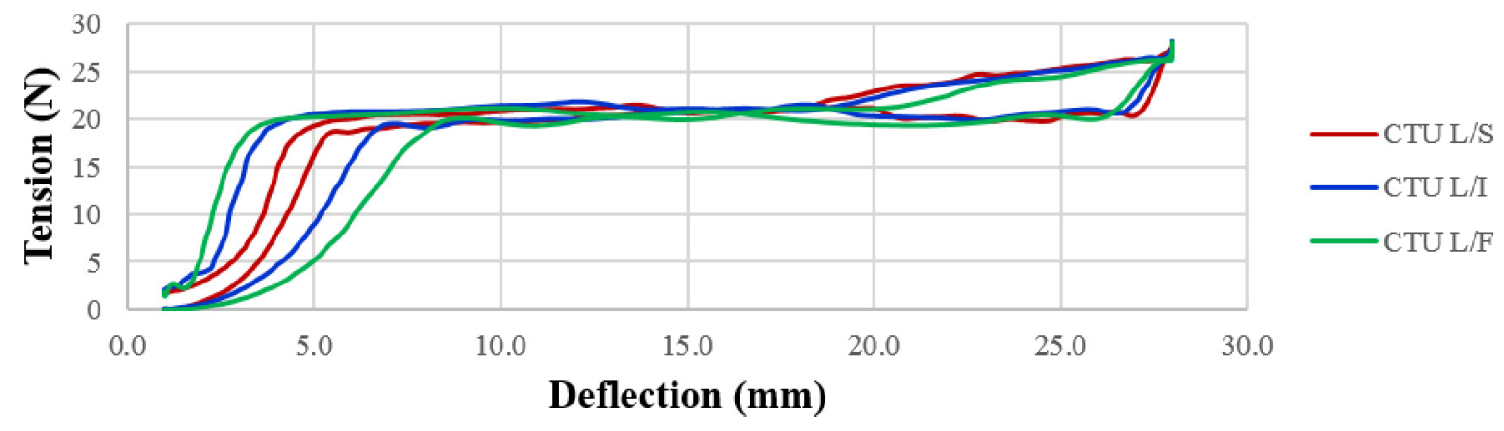

Figure 3-7. Low Tension at Varying Speeds.

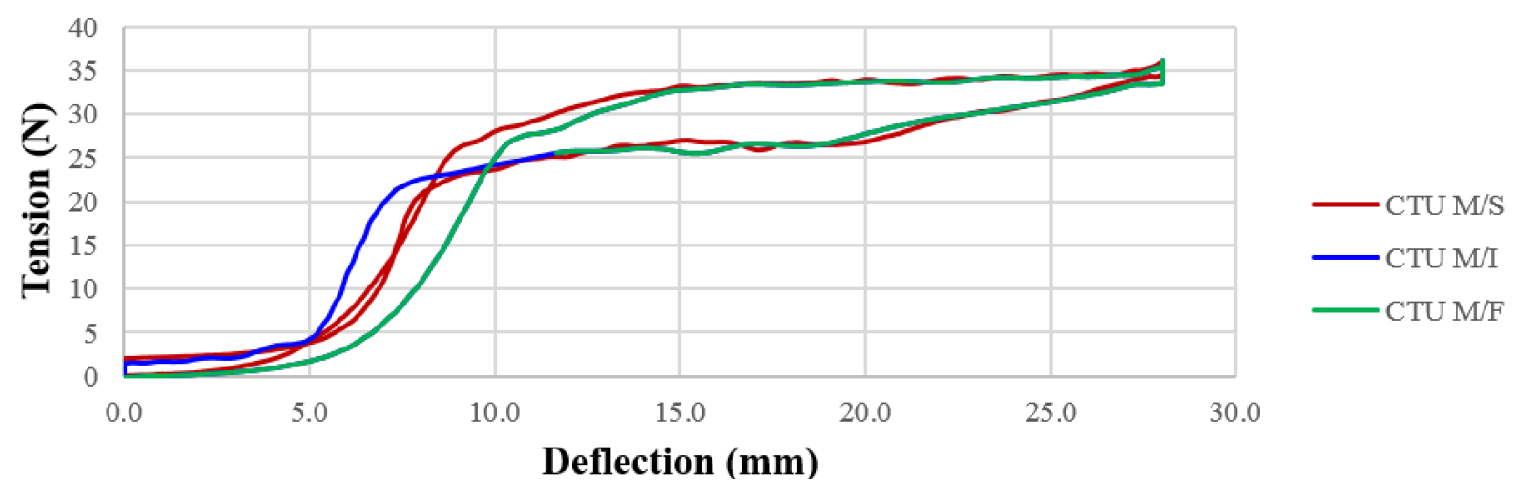

Figure 3-8. Medium Tension at Varying Speeds. 


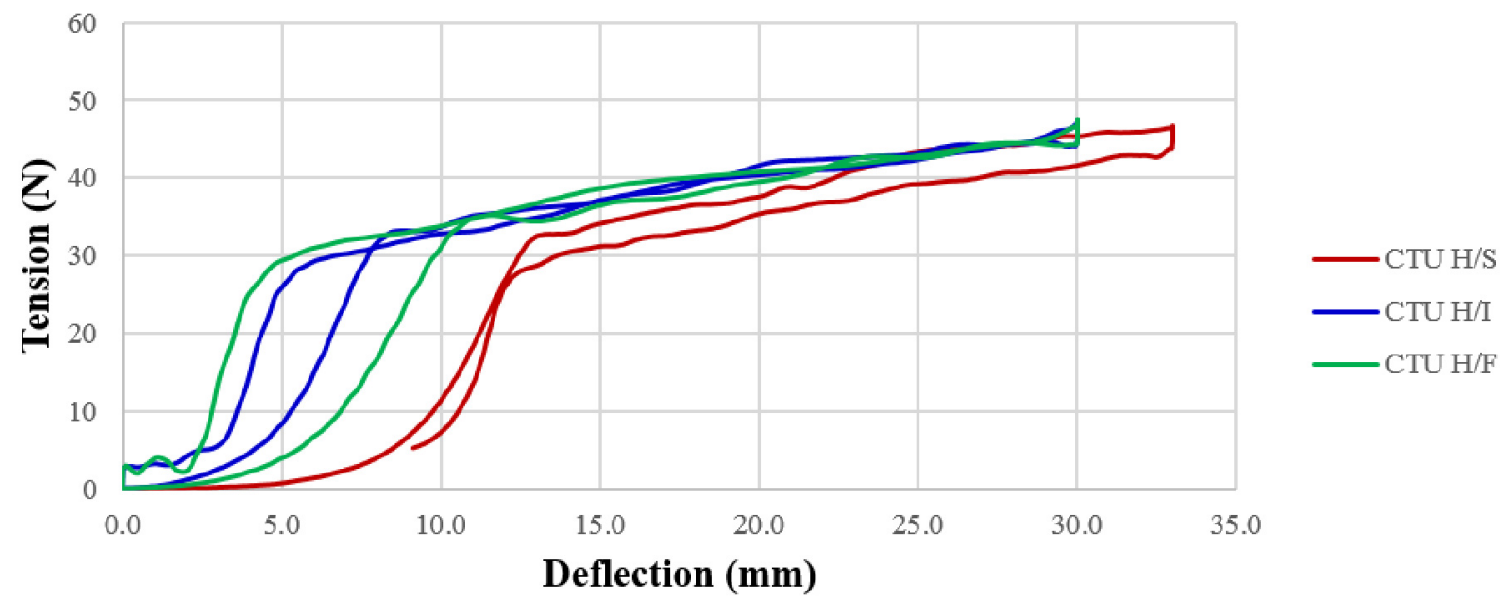

Figure 3-9. High Tension at Varying Speeds.

Table 3-2. $\quad$ Rated Load of CTU.

\begin{tabular}{clll}
\hline $\begin{array}{c}\text { Working } \\
\text { Range } \\
\text { Tension }\end{array}$ & \multicolumn{1}{c}{ Slow } & \multicolumn{2}{c}{ Speed } \\
\cline { 2 - 4 } Low & Rated Load $=20.9 \mathrm{~N}$ & Rated Load $=20.9 \mathrm{~N}$ & \multicolumn{1}{c}{ Fast } \\
& Load Tolerance $= \pm 7 \%$ & Load Tolerance $= \pm 6 \%$ & Load Tolerance $= \pm 5 \%$ \\
& & & \\
\multirow{2}{*}{ Medium } & Rated Load $=30.7 \mathrm{~N}$ & Rated Load $=30.7 \mathrm{~N}$ & Rated Load $=31.1 \mathrm{~N}$ \\
& Load Tolerance $= \pm 8 \%$ & Load Tolerance $= \pm 9 \%$ & Load Tolerance $= \pm 7 \%$ \\
\multirow{2}{*}{ High } & Rated Load $=40 \mathrm{~N}$ & Rated Load $=41.3 \mathrm{~N}$ & Rated Load $=41.3 \mathrm{~N}$ \\
& Load Tolerance $= \pm 8 \%$ & Load Tolerance $= \pm 6 \%$ & Load Tolerance $= \pm 6 \%$ \\
\hline
\end{tabular}




\section{CHAPTER 4. STUDY TWO: COMPARATIVE LABORATORY TESTING OF TRADITIONAL VELCRO STRAPS VERSUS VELCRO STRAPS WITH CTU DEVICES}

\section{Objective}

There were two objectives for this study. The first objective was to validate that the CTU force output was constant over a finite amount of brace gap opening and closing (as it relates to the brace gap separation). The second study objective was to determine the corrective force capacity and structural stiffness properties of a standard 3-strap brace using either Velcro straps or CTU devices as the fastening system.

\section{Materials}

\section{Controlled Tension Units}

See the description in Chapter 3.

\section{Standard (Velcro Strap) Brace}

A one piece rigid plastic Boston Brace fabricated by an orthotist that uses Velcro straps to engage brace to the wearer's torso (Figure 4-1).

\section{Standard (CTU) Brace}

In Figure 4-2, a Velcro strip 8 on the back of the CTU 18 allowed for quick attachment to the Velcro strap 15 on a standard brace 14. A chafe 17 connected the preexisting chafe and loop $\mathbf{1 6}$ on the brace to the cable 35 by chafe connectors $\mathbf{1 9}$. When attached to a brace, the CTU allowed the brace to open or close a set distance while applying a constant tension. The various brace gap distances could be accommodated by translating the unit along the length of the strap to its optimal placement. 


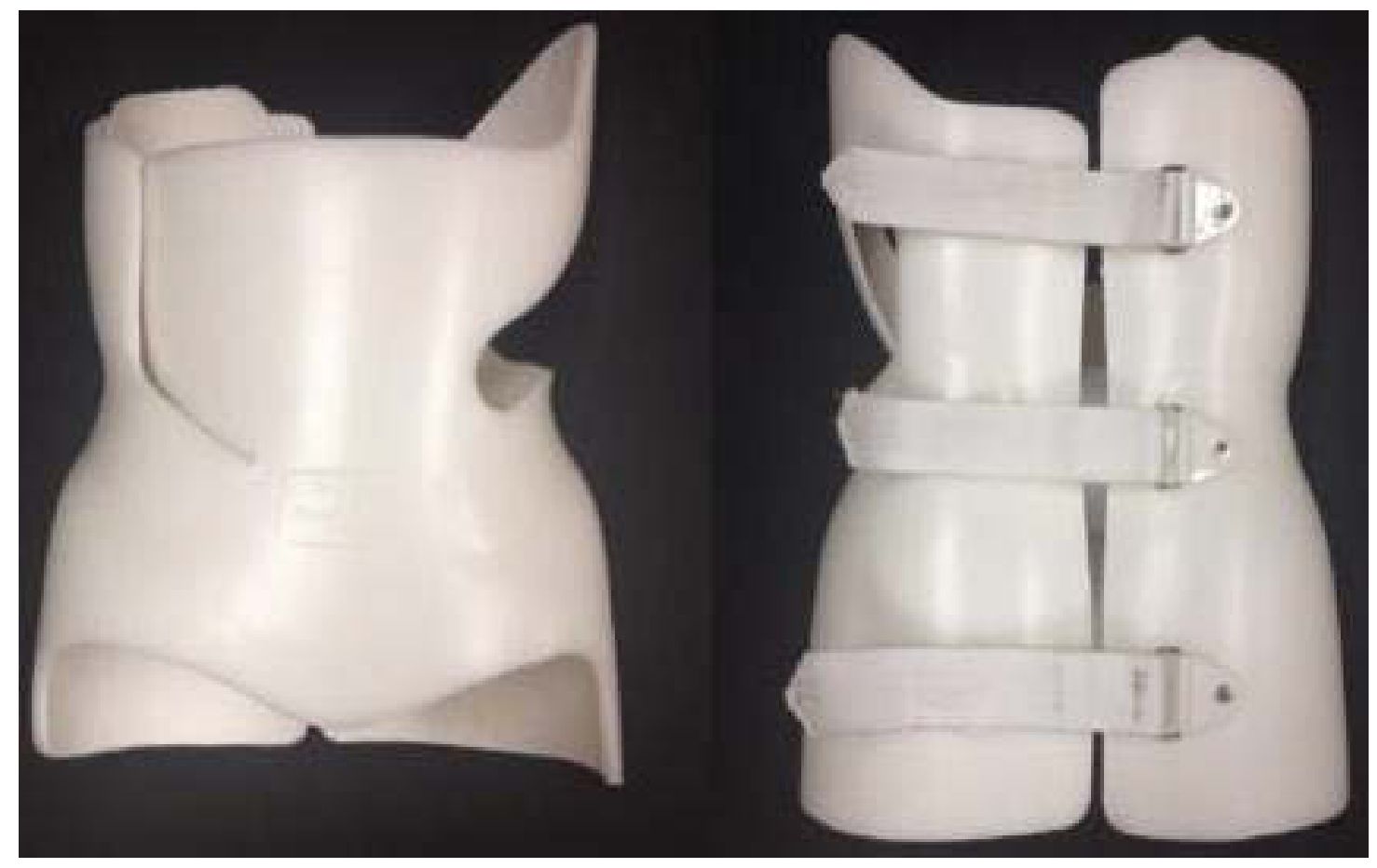

Figure 4-1. In This Study, the Boston Brace Was Called the Standard (Velcro Strap) Brace. 


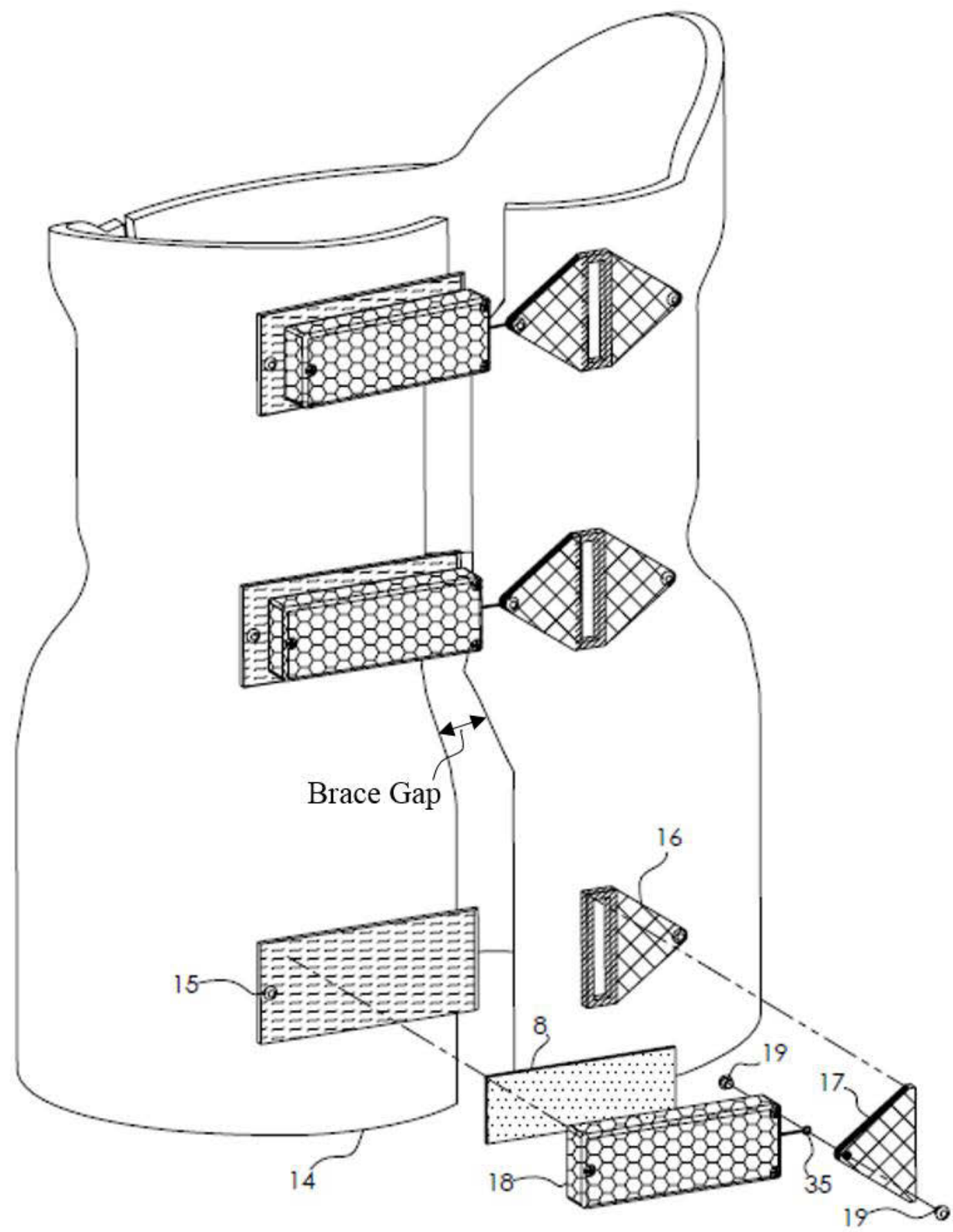

Figure 4-2. Standard (CTU) Brace.

A Velcro strip 8 on the back of the CTU 18 allowed for quick attachment to the Velcro strap 15 on a standard brace $\mathbf{1 4}$. A chafe 17 connected the preexisting chafe and loop 16 on the brace to the cable 35 by chafe connectors 19 . 


\section{Robotic Testing Platform}

See description in Chapter 3.

\section{Scoliosis Analog Model (SAM)}

The scoliosis Analog Model (SAM) (Figure 4-3) is a linkage-based mechanical analog model of a scoliotic spine. When combined with the robotic testing assembly, programmed actuator movement displaced the SAM linkage system which changed the degree of curvature (or Cobb angle) of the spinal deformity. A load cell placed between the upper actuator and SAM measured the amount of corrective spinal force applied by the brace. See detailed description in Background.

\section{Lab Tensiometers}

A set of commercial tensiometers (Berkley, USA, Max Capacity: 222N, Resolution: $\pm 0.1 \mathrm{~N}$ ) (Figure 4-4) were fixed to the brace to allow for measurement of the Velcro strap tension. The tensiometers were controlled and monitored using a custom LabVIEW program that allowed for continuous recording of strap tension.

\section{Methods}

Three brace configurations were tested: Native Standard Brace, Standard (CTU) Brace, and Standard (Velcro Strap) Brace. A low tension CTU $(\approx 20 \mathrm{~N})$ was used for all tests and the actuator was programmed to move $10 \mathrm{~mm}$ at the intermediate speed of approximately $12 \mathrm{~mm} / \mathrm{s}$. It was noted that the CTU did not exceed the working range due to this movement. Throughout the movement, the reaction forces in the craniocaudal axis were continuously recorded by the ULC and the strap tension in the mediolateral axis were continuously recorded by the lab tensiometers. Also, the digital readouts on the tensiometers were recorded initially, at maximum displacement, and when reset to original position. This test was repeated 3 times and the data were averaged.

\section{Native Standard Brace Test}

It was theorized that the inherent structural properties of the brace would act like a conventional spring. Unlike constant-force springs, the force response of conventional springs changes as the spring displacement changes. Since the inherent stiffness behavior of the native brace is part of the stiffness response of any brace with a fastening device connected, the contribution of the fastening devices (i.e., Velcro straps, CTU devices) will be equal to the Stiffness of Native Brace plus Fastening Devices minus the Stiffness of Native Brace alone. Thus, a native standard brace (i.e., Boston Brace) was tested three times using the same distance actuator parameters as those described above (Figure 4-5). 


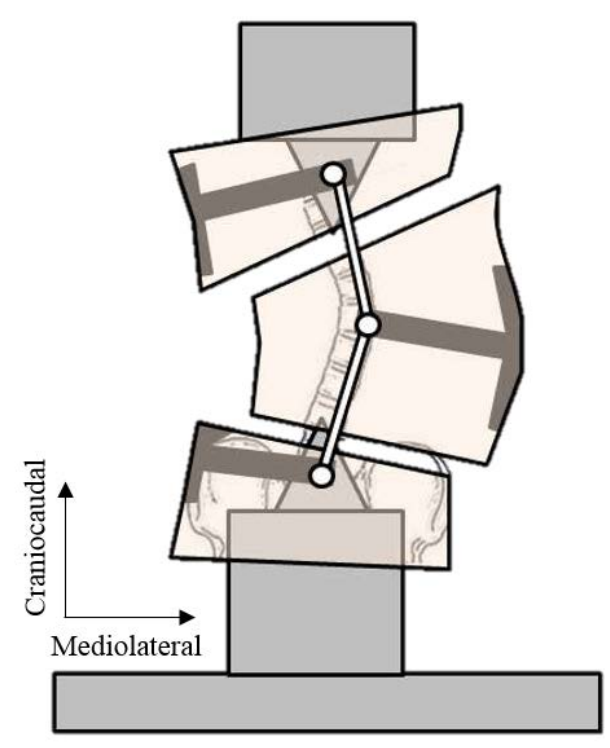

(a)

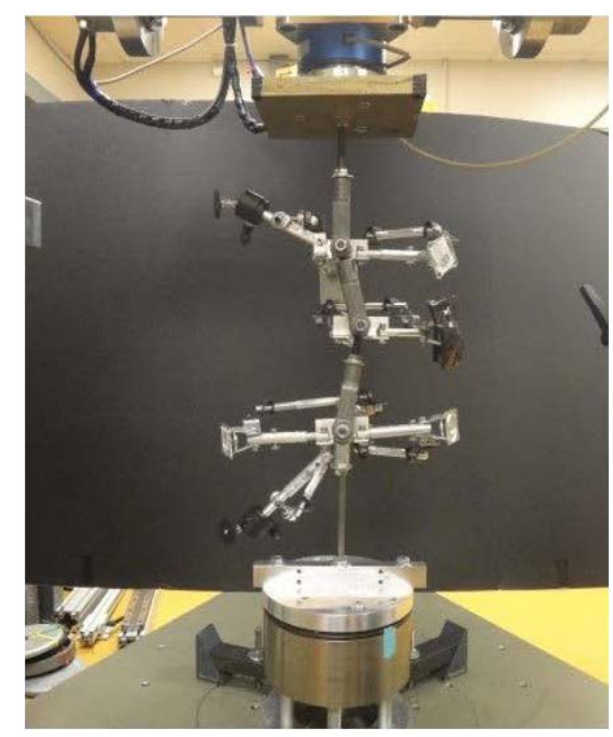

(c)

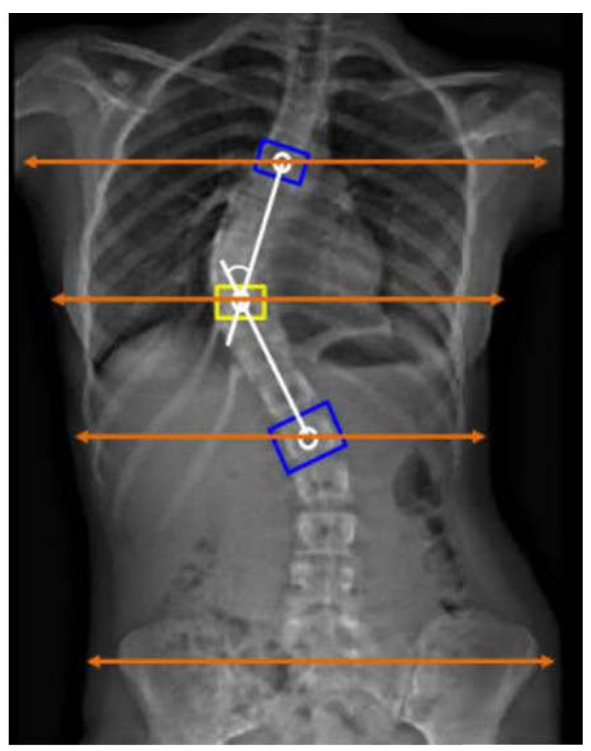

(b)

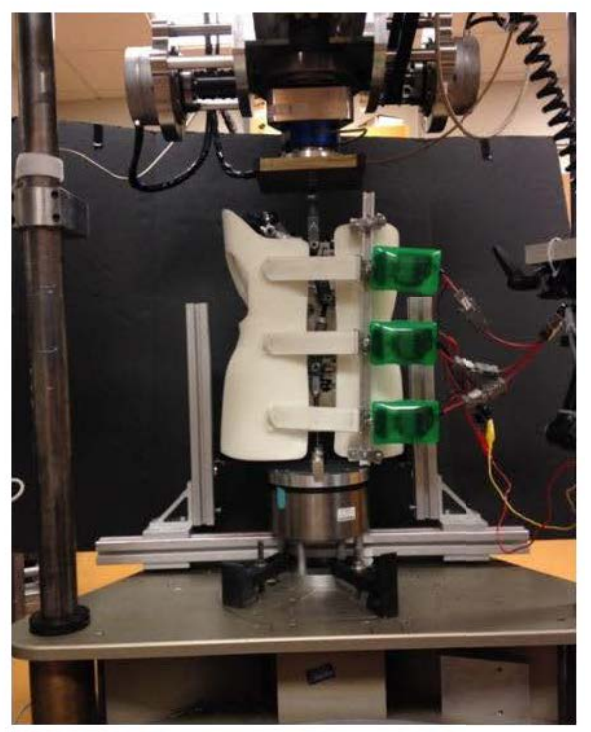

(d)

Figure 4-3. SAM Customization and Testing Setup.

A) SAM Concept, B) X-Ray Measures, C) SAM Assembly, D) SAM and Brace. Source: Modified with permission. Chung CL. Scoliosis Analog Model for the Evaluation of Bracing Technology [Master's]. (2015). Orthopaedic Surgery and Biomedical Engineering, The University of Tennessee Health Science Center, 54-59. [65] 


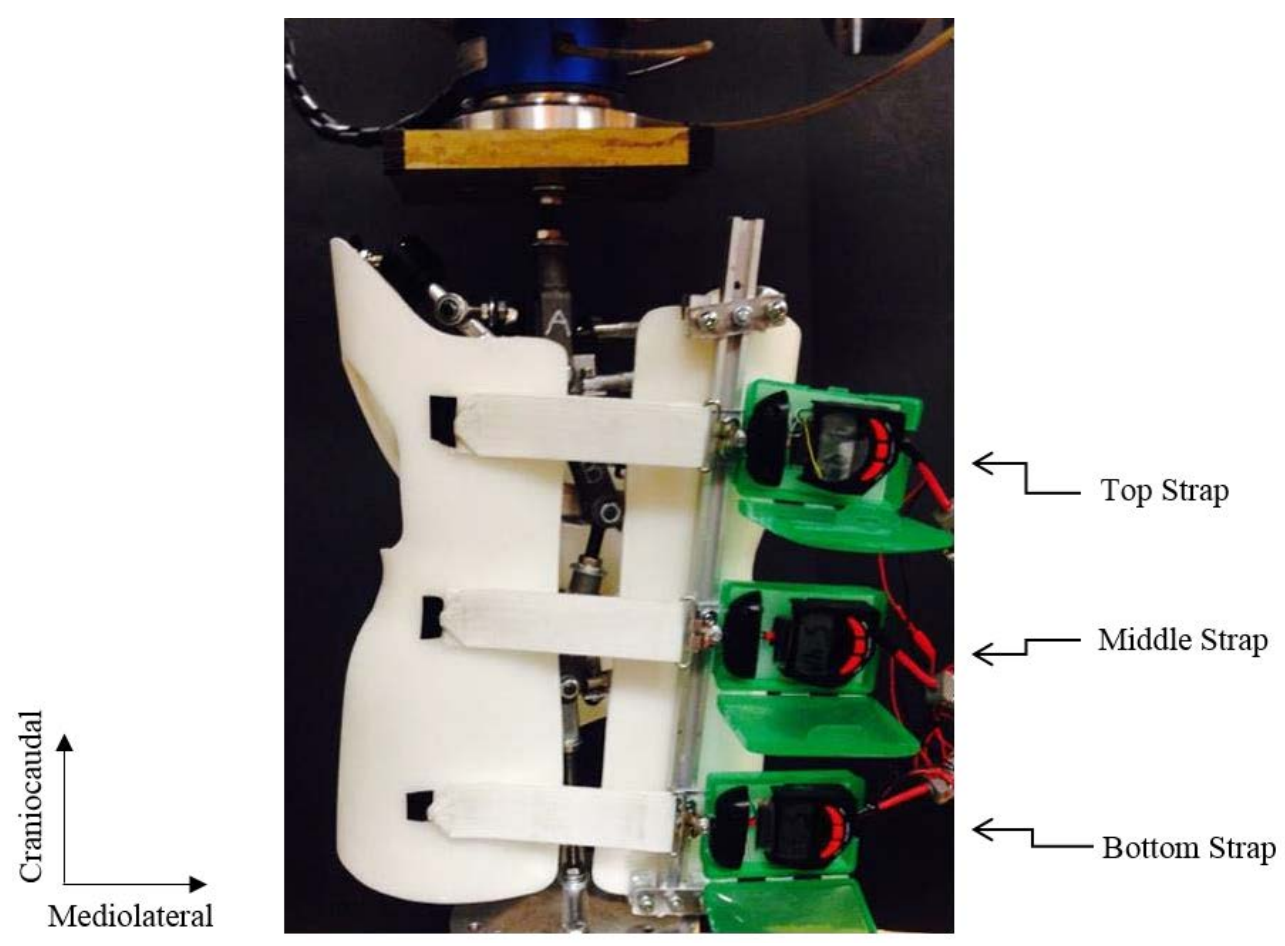

Figure 4-4. Lab Tensiometers.

The tensiometers were attached to a bracket that was rigidly mounted to the brace.

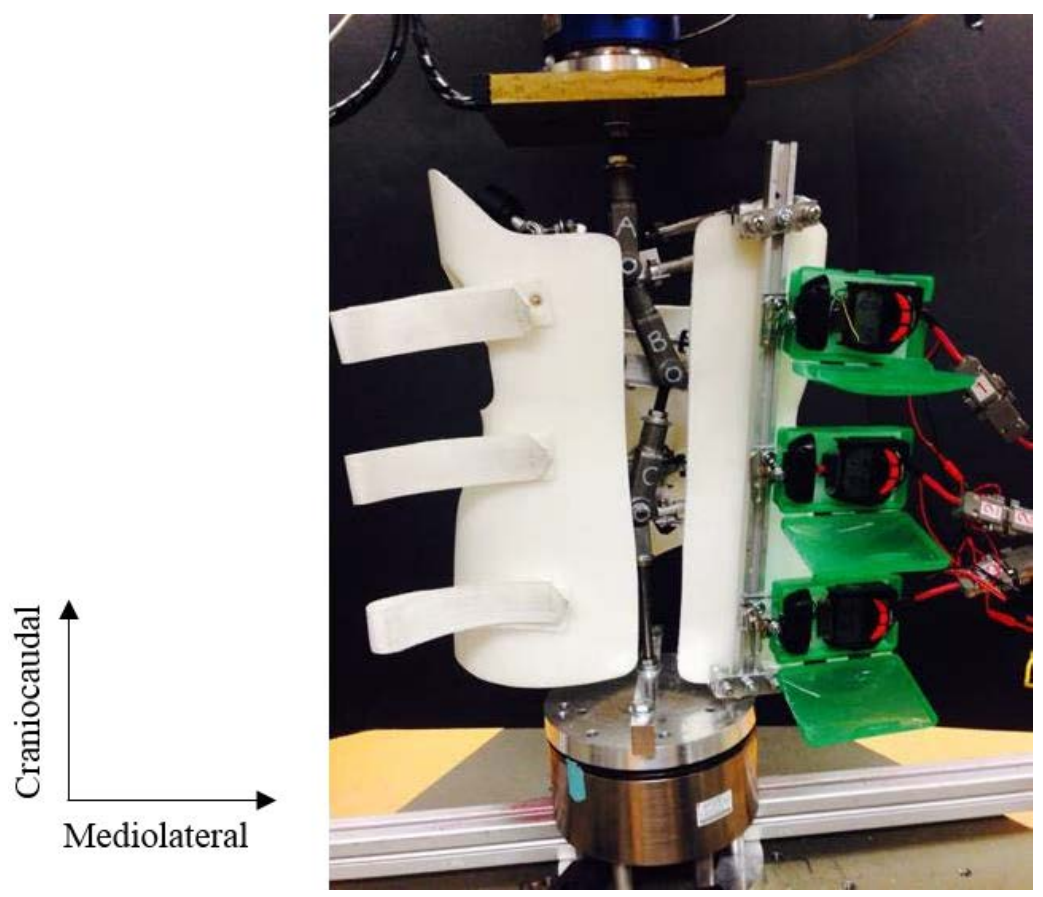

Figure 4-5. Native Standard Brace Test. 


\section{Standard (CTU) Brace Test}

In this set up the conventional Velcro straps were replaced by the CTU devices. The CTU housing was wrapped in Velcro and easily connected to the preexisting Velcro straps. When attached to the brace, the CTU devices allowed the brace to open and close a set distance while applying a constant tension across the brace gap. Various brace gaps could be accommodated. The CTU translated along the length of the strap. To set the tension on the CTU spring, the cable was pulled out of the housing and attached to a chafe on the other side of the brace gap. Figure 4-6 shows a Standard (CTU) Brace prototype using Velcro and chafes to connect the CTU to the brace. The Standard (CTU) Brace was tested three times using the same distance actuator parameters as those described above.

\section{Standard (Velcro Strap) Brace Test}

For this brace configuration, the CTU devices were removed and the conventional Velcro straps were reconnected (Figure 4-7). The actuator and ULC were set to the same starting position as seen in the Standard (CTU) Brace Test and displaced downwards the same distance. Using the lab tensiometers, the initial strap tension was tightened to approximately the same amount as seen in the Standard (CTU) Brace Test. As in the previous tests, throughout the movement, the reaction forces in the craniocaudal axis were continuously recorded by the ULC and the strap tension in the mediolateral axis were continuously recorded by the lab tensiometers. Also, the digital readouts on the tensiometers were recorded initially, at maximum displacement, and when reset to original position. This test was repeated 3 times and the data were averaged in the same way previously described. The inherent native brace structural properties were then subtracted from these results prior to being compared with the Standard (CTU) Brace properties.

\section{Results}

A summary of the tensiometers values at the beginning, end, and reset positions is provided in Tables 4-1 and 4-2 for the two fastening brace conditions, along with the maximum brace gap values. The CTU maintained initial tension while Velcro lost tension after the movement.

The force-displacement (structural stiffness) properties of the two "fastened" bracing configurations are shown in Figures 4-8 and 4-9. The overall force-displacement response (shown in blue) included the contribution of the native brace. The actual properties of each brace fastening configuration are shown by the red line where the native brace contribution was subtracted from the overall response.

The mean tension responses of the tensiometers over the entire range of displacement is shown in Figures 4-10 and 4-11 for the two different fastening systems. The CTU devices provided a greater range of brace gap displacement compared to the 


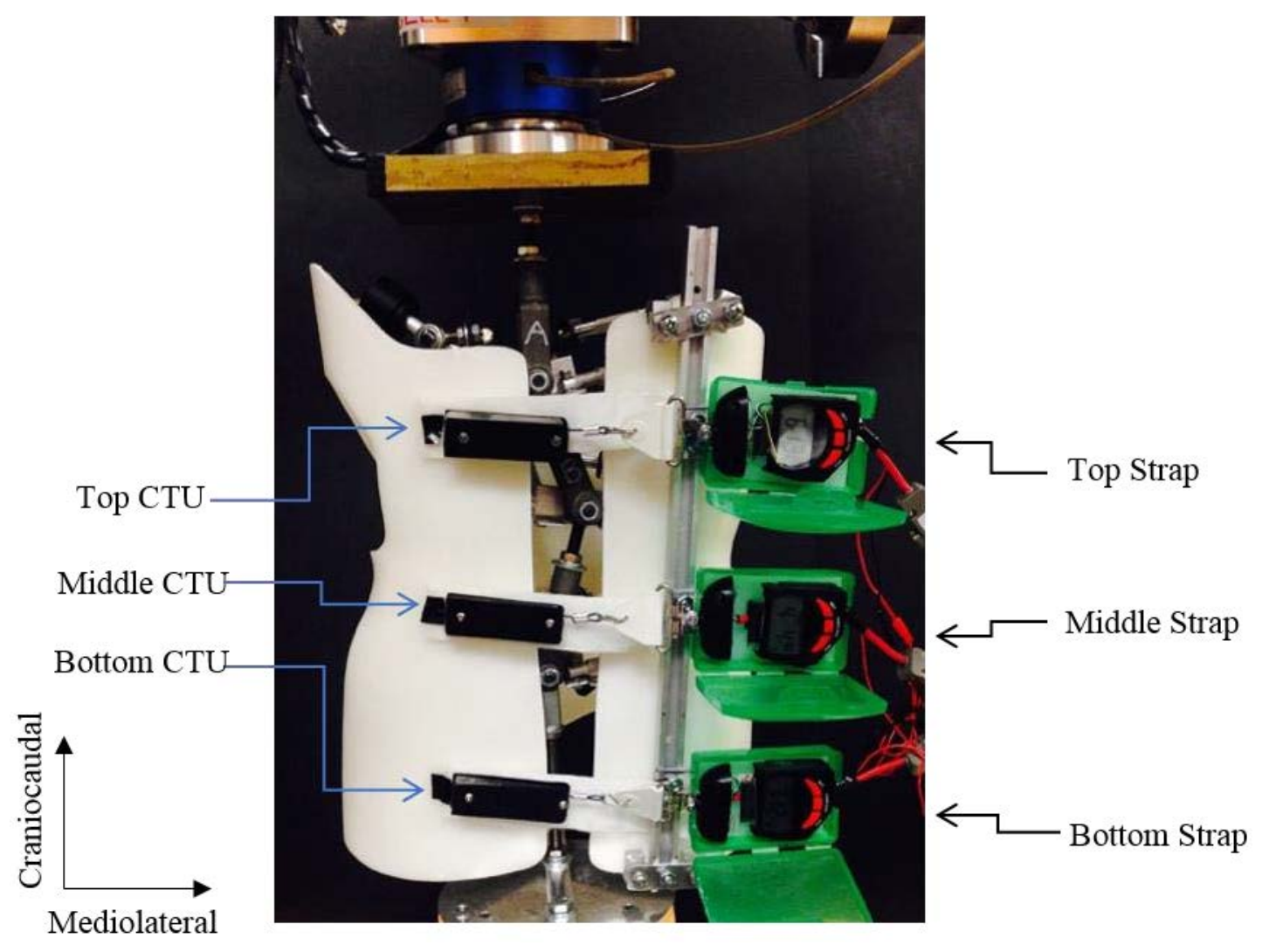

Figure 4-6. Standard (CTU) Brace Test. 


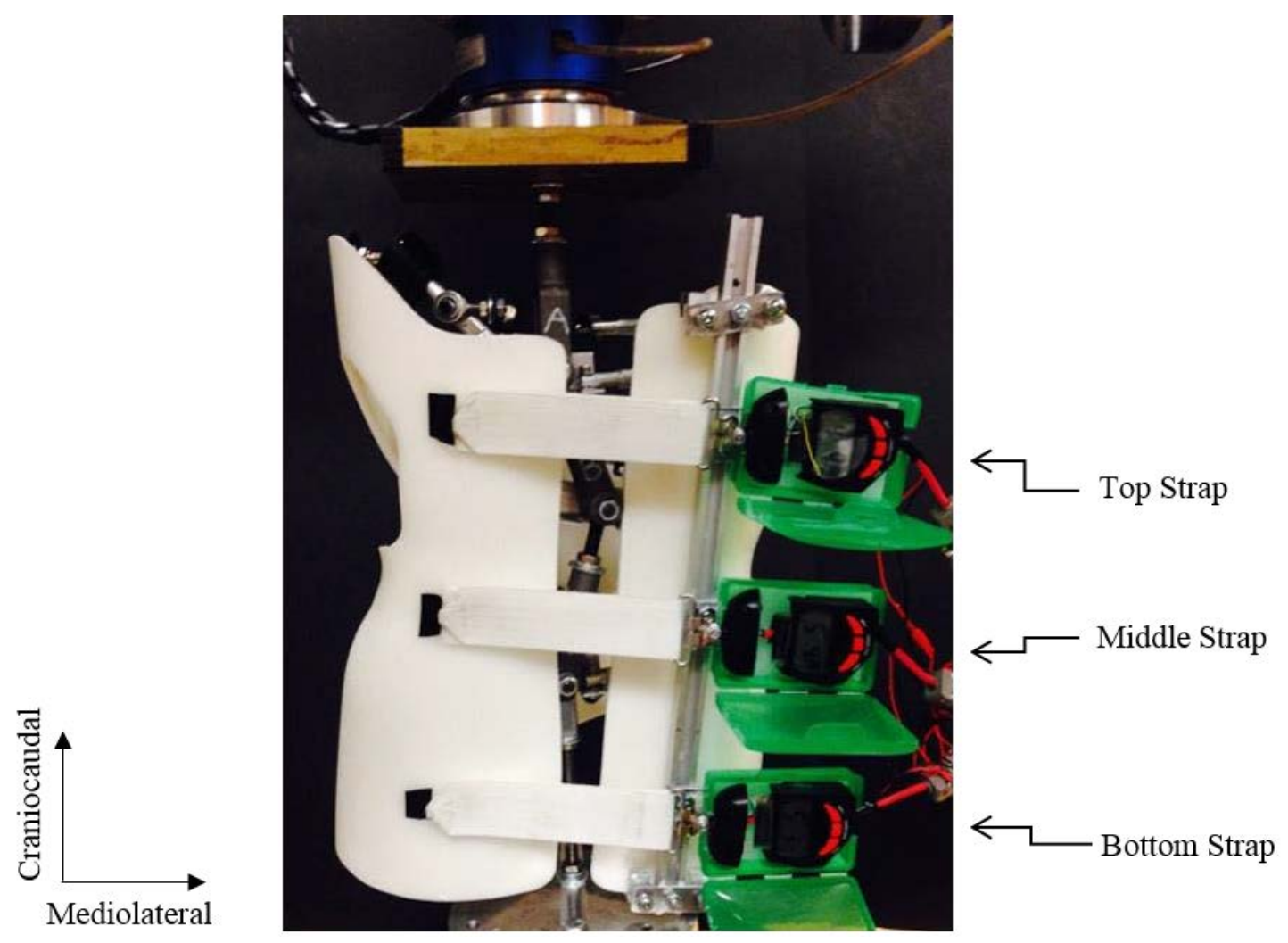

Figure 4-7. Standard (Velcro Strap) Brace Test. 
Table 4-1. Standard (CTU) Brace: Mean Tensiometer Readout Values.

\begin{tabular}{cccc}
\hline Measure & Top Strap & Middle Strap & Bottom Strap \\
\hline Initial Tension (N) & 19.6 & 21.8 & 19.6 \\
$\begin{array}{c}\text { Final Tension at Max } \\
\text { Displacement (N) }\end{array}$ & 22.7 & 25.3 & 21.3 \\
Tension after Reset (N) & 19.1 & 21.8 & 19.1 \\
Displacement (mm) & 15.0 & 6.8 & 1.0 \\
\hline
\end{tabular}

Table 4-2. Standard (Velcro Strap) Brace: Mean Tensiometer Readout Values for Displacement in All Straps $<1 \mathrm{~mm}$.

\begin{tabular}{cccc}
\hline Measure & Top Strap & Middle Strap & Bottom Strap \\
\hline Initial Tension (N) & 26.2 & 28.0 & 24.5 \\
$\begin{array}{c}\text { Final Tension at Max } \\
\text { Displacement (N) }\end{array}$ & 107.2 & 47.6 & 26.7 \\
Tension after Reset (N) & 18.2 & 25.8 & 23.1 \\
\hline
\end{tabular}




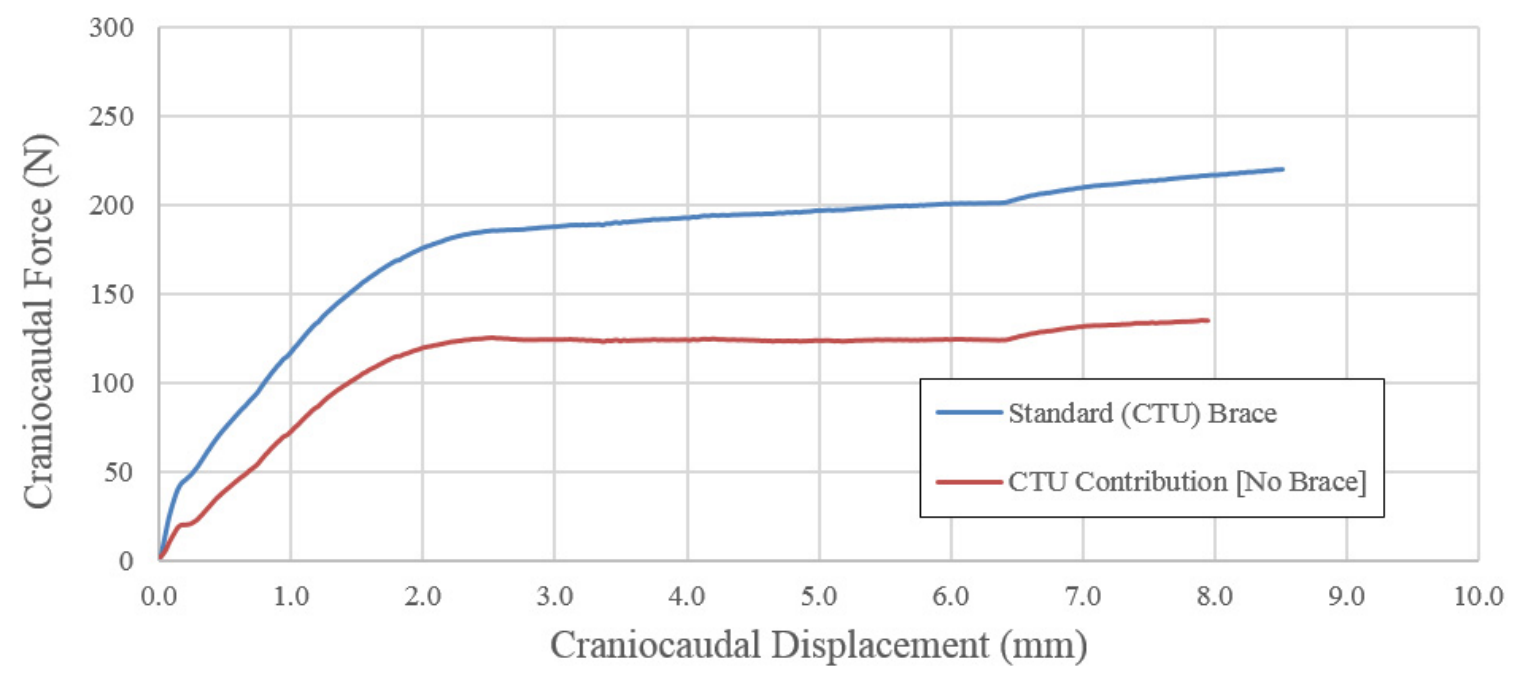

Figure 4-8. Force-Displacement Response along the Craniocaudal Axis of the Standard (CTU) Brace.

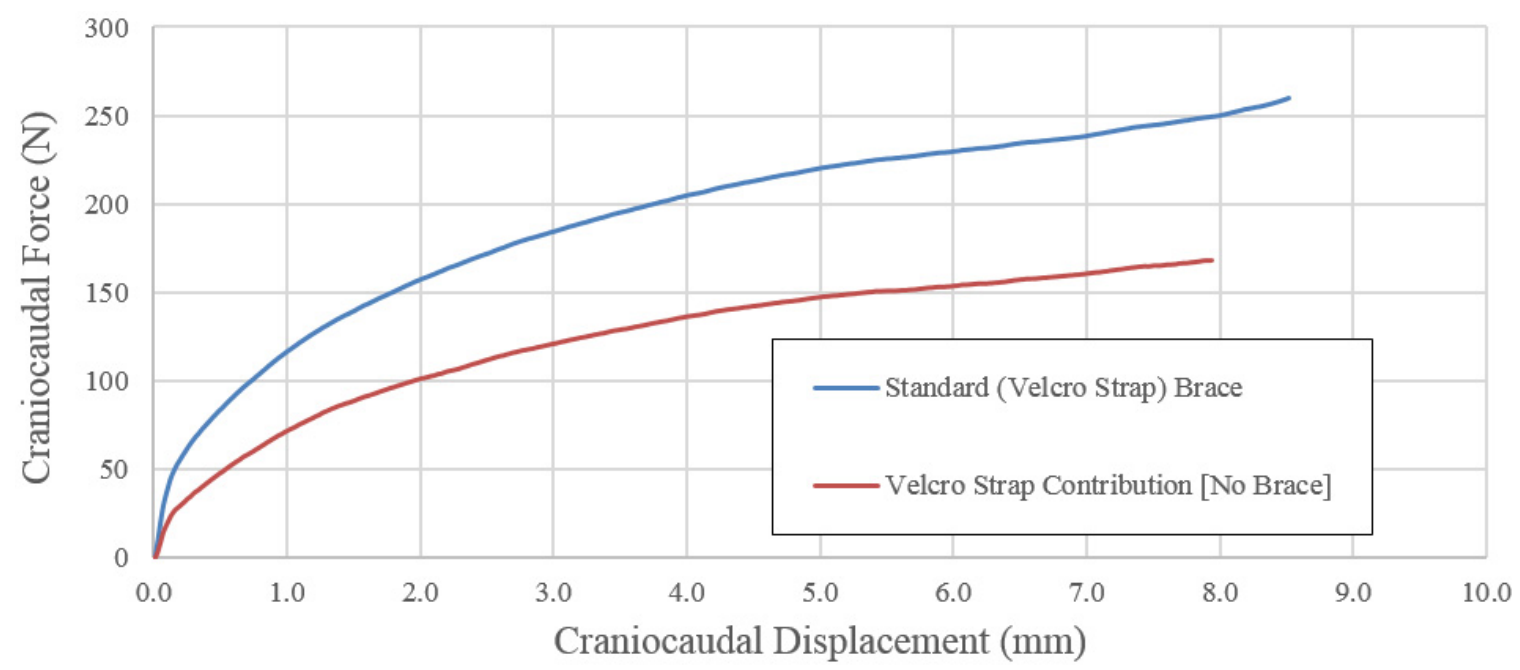

Figure 4-9. Force-Displacement Response along the Craniocaudal Axis of the Standard (Velcro Strap) Brace.

Blue line: Axial Load due to Brace plus Tensioning Device. Red line: Axial Load due to Tensioning Device Alone. 


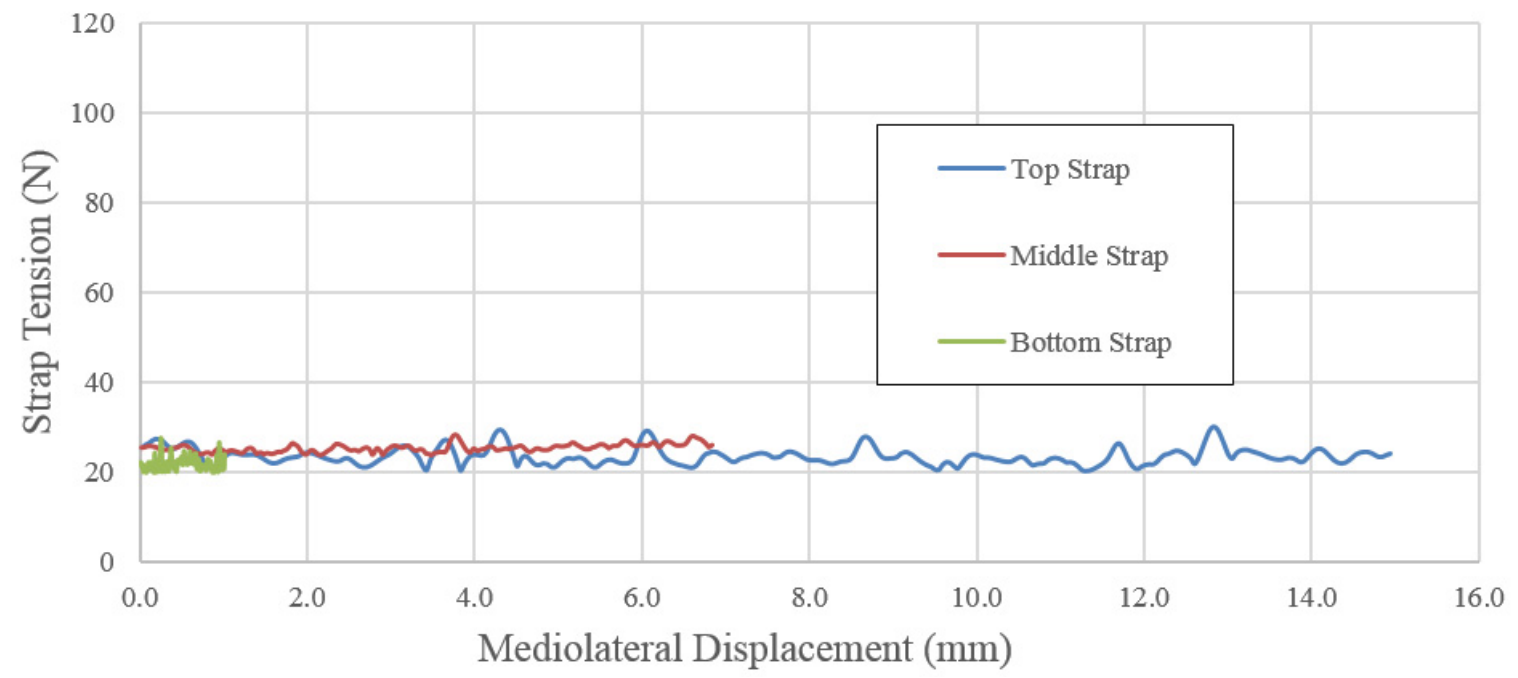

Figure 4-10. Mean CTU Tension Throughout Mediolateral Displacement.

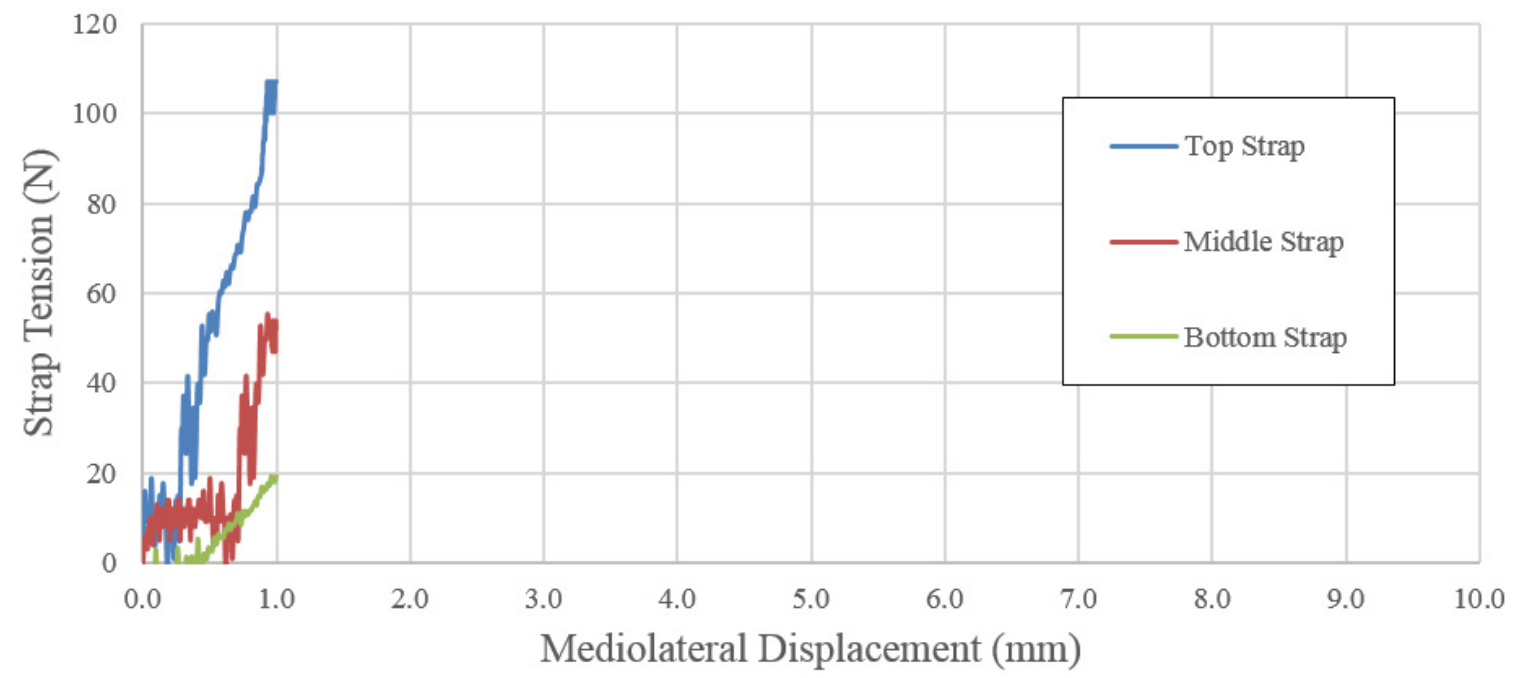

Figure 4-11. Mean Velcro Strap Tension Throughout Mediolateral Displacement. 
Velcro straps. Minimal displacement occurred with the Velcro Strap configuration as shown in Figure 4-11.

The maximal tensiometer readings occurred at the end of travel as shown in Figures 4-12 and 4-13. For the CTU devices, the strap tension was constant over the range of displacement and remained close to the tension value of the CTU device (approximately 20N). However the tensiometer readings were significantly greater with the Velcro straps being greatest at the top strap and lowest at the bottom (Figure 4-13).

\section{Discussion}

During the Standard (CTU) Brace Test, more brace gap opening and CTU displacement occurred at the top strap and was least at the bottom strap. This difference may have occurred as more expansion is needed at the top of the brace for breathing, bending, twisting, which occurs mostly in the upper trunk. Although many different movements can occur during various daily living activities, these tests were limited to simulation of one type of movement over a limited number of cycles.

\section{Conclusion}

The load-displacement behavior of the Standard (CTU) Brace (after subtraction of the native brace), was constant throughout movement. This finding supports the design rationale that the CTU devices can be used to develop a more flexible dynamic brace that allows for directional movement without compromising the corrective force capacity of the brace. That is, the strap tension setting will remain present independent of the brace gap allowing for opportunities of deep breathing, increased range of movement, and/or improved brace force correction. Moreover, the stiffness properties of the conventional Standard (Velcro Strap) Brace (after subtraction of the Native Standard Brace) were not constant.

Lastly the tensiometer values for Standard (CTU) Brace were the same at the end of the movement as well as when the brace was reset to the original position. However, the tensiometers values for the Standard (Velcro Strap) Brace configuration increased significantly with minimal gap opening and returned to the original lower setting when the brace reset to the original position. 


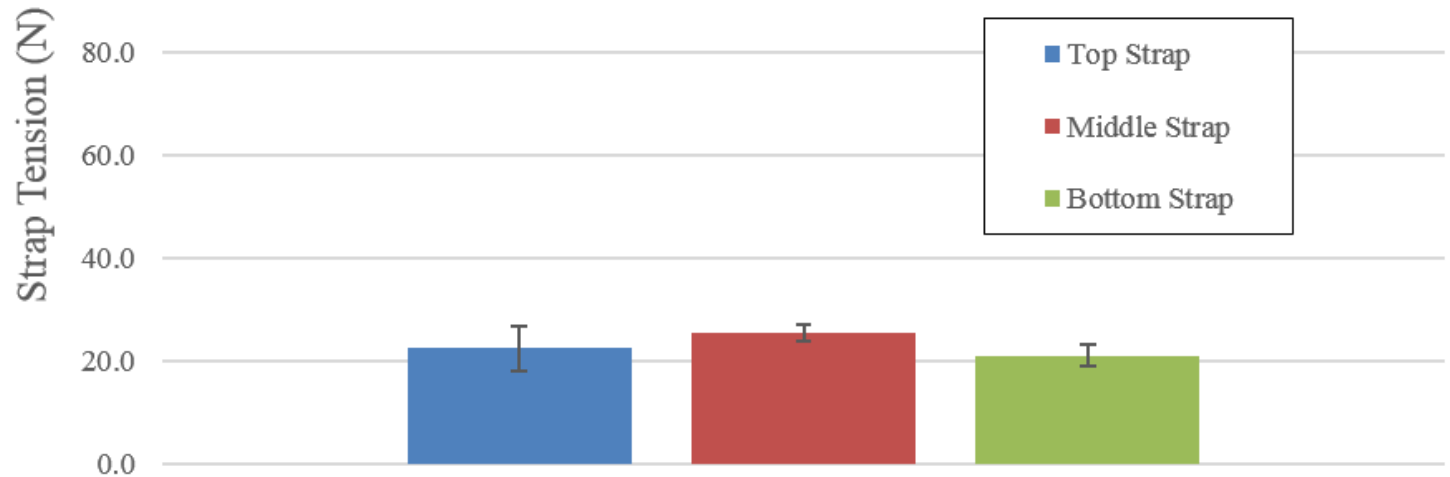

Final Tension

Figure 4-12. Mean Tensiometer Readouts at End Limit of Travel for CTU Devices, $\mathbf{N}=3$.

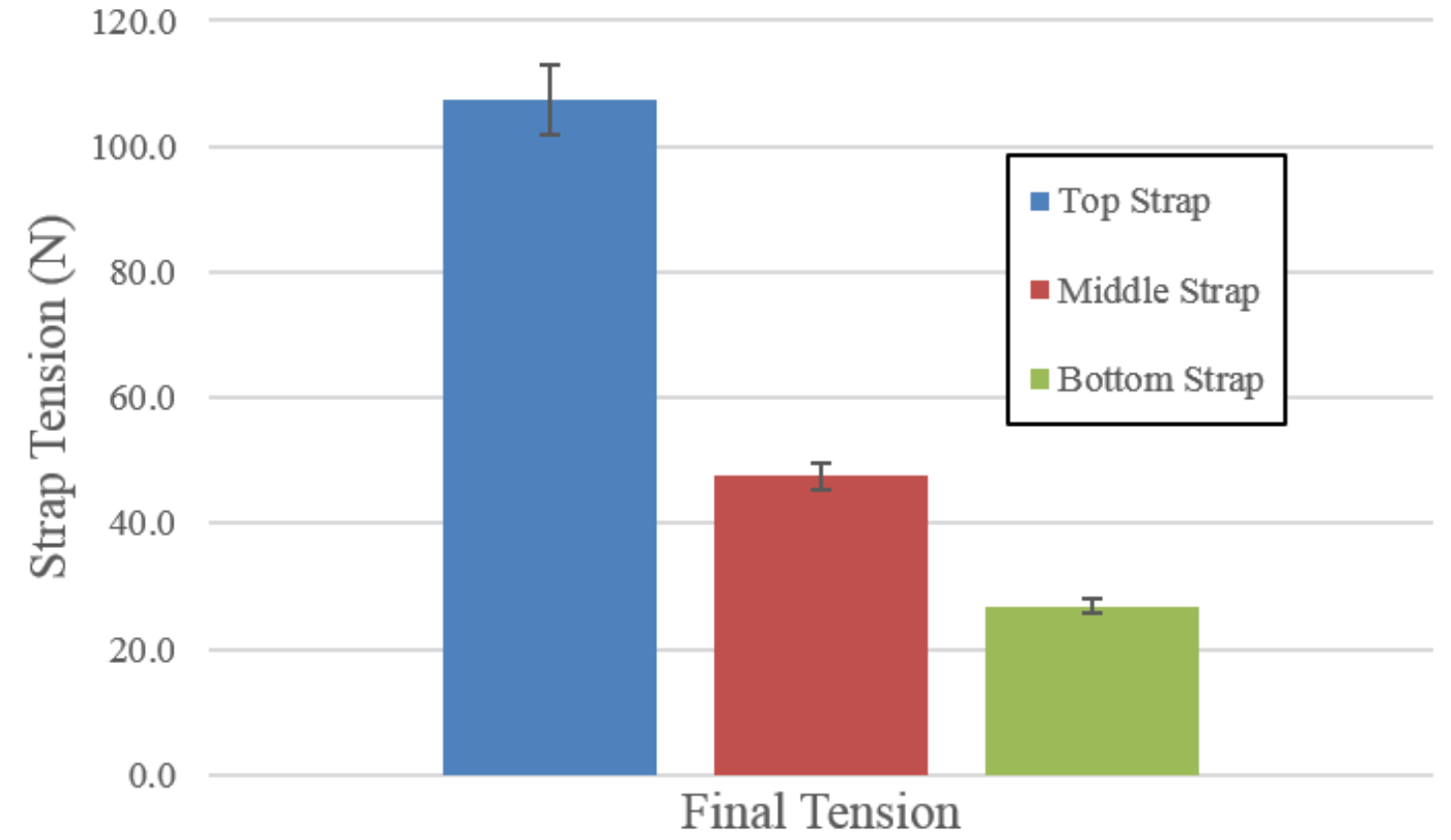

Figure 4-13. Mean Tensiometer Readouts at End Limit of Travel for Velcro Straps, $\mathbf{N}=3$. 


\section{CHAPTER 5. STUDY THREE: COMPARATIVE CLINICAL TESTING OF TRADITIONAL VELCRO STRAPS VERSUS VELCRO STRAPS WITH CTU DEVICES}

\section{Objective}

The objective of this study was to determine if CTU fastening device reduced discomfort while maintaining a constant strap tension. Several hypotheses were made: the CTU devices would maintain strap tension while the Velcro would not, the CTU devices would allow for greater brace flexibility, the CTU devices would decrease discomfort, and the CTU devices could increase strap tensions without influencing discomfort.

\section{Materials}

\section{Internal Review Board 16-04475-XP}

This study was approved by the internal review board at UTHSC.

\section{Standard (Velcro Strap) Brace}

See the description in Chapter 4.

\section{Standard (CTU) Brace}

See the description in Chapter 4.

\section{Portable Tensiometers}

Digital, portable tensiometers (Figure 5-1) had a modified housing that allowed for a simple and quick attachment to the existing hardware on a brace. The maximum capacity was $489 \mathrm{~N}$ and the resolution was $\pm 0.09 \mathrm{~N}$. The attachment caused no damage to the brace and was not permanent. This system allowed for the tension to be analyzed for a conventional Velcro strap. 


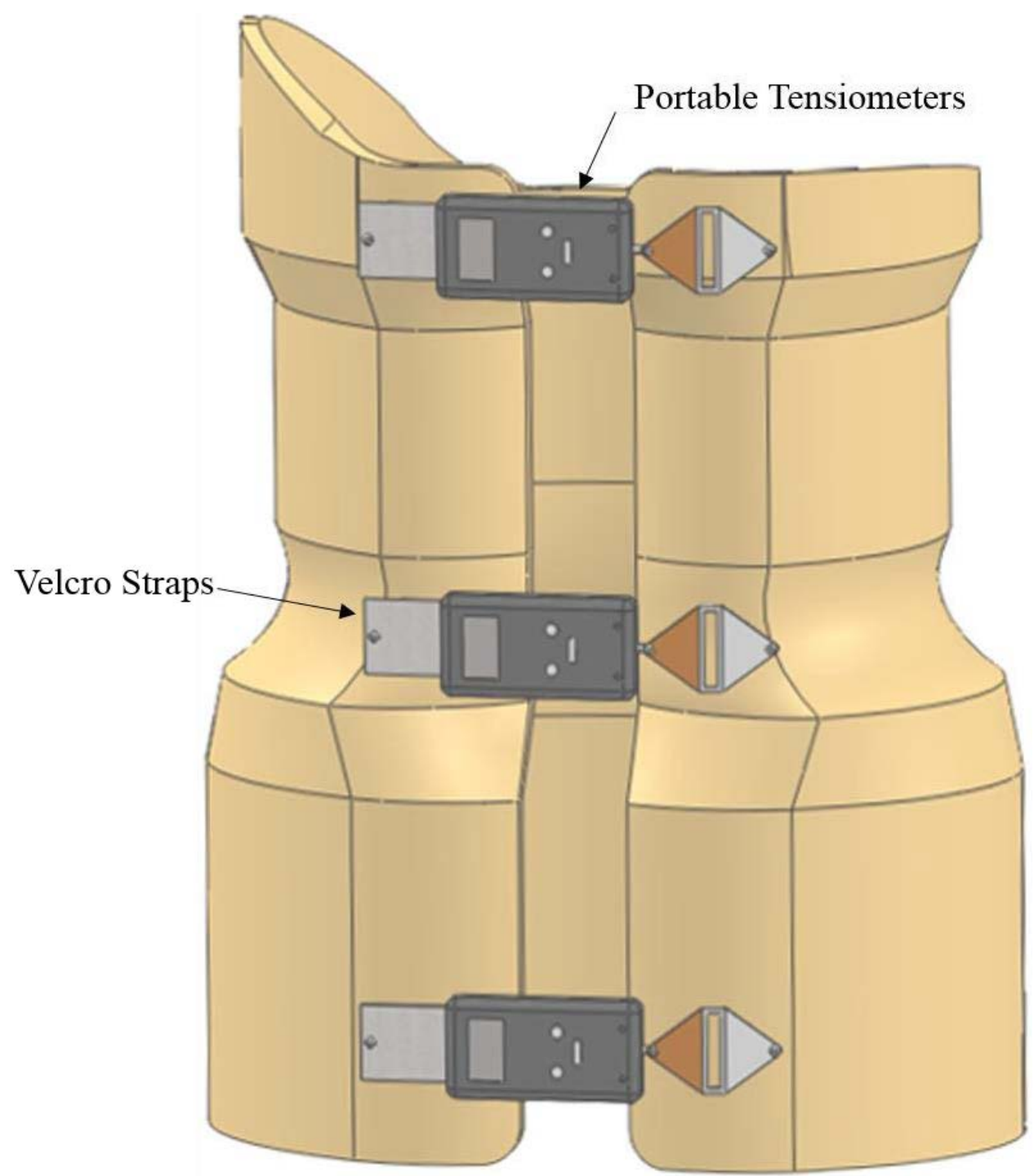

Figure 5-1. Portable Tensiometers on a Brace. 


\section{Wong-Baker FACES ${ }^{\mathrm{TM}}$ Pain Rating Scale}

This scale was used to aid the patient in describing discomfort (Figure 5-2).

\section{Goniometer}

This tool was used to measure the amount of forward bend.

\section{Fold-up Bed}

A portable bed was brought into the clinic to simulate sleeping conditions.

\section{Methods}

\section{Standard (Velcro Strap) Brace Test}

The Standard (Velcro Strap) Brace was outfitted with portable tensiometers and the straps were tightened to the prescribed tension while the patient was in the standing position. The tension values displayed by the portable tensiometers were recorded. The patient then performed the following activities: (1) Stand Initial, (2) Maximum Inspiration, (3) Concave Side Lying, (4) Convex Side Lying, (5) Forward Bend, and (6) Stand Final (Figures 5-3 and 5-4)

The strap tension, gap distance (Figure 5-5), and discomfort were evaluated for each activity. Strap tension was measured using the portable tensiometers, gap distance was measured using calipers, and the discomfort was evaluated using the Wong-Baker FACES ${ }^{\mathrm{TM}}$ Pain Rating Scale. The amount of forward bend was measured using a goniometer.

\section{Standard (CTU) Brace Test}

The conventional straps were then replaced with CTU devices. Each CTU device was selected to match the prescribed tension previously recorded in the initial standing position set by the orthotist. It may have been that the top, middle, and bottom CTU device each had a different tension setting. The gap distance and discomfort were recorded for each activity as well as amount of forward bend. 

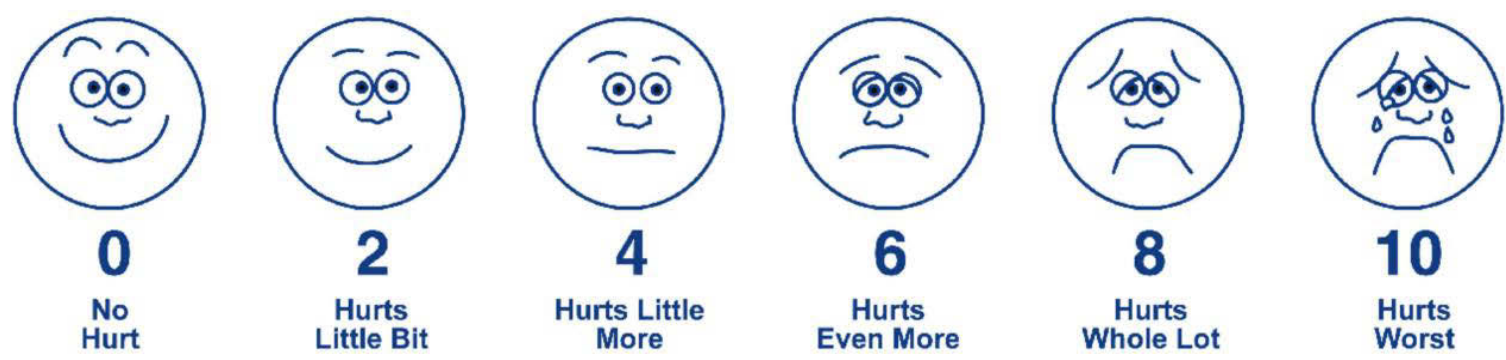

Figure 5-2. Wong-Baker FACES ${ }^{\mathrm{TM}}$ Pain Rating Scale.

Source: Reprinted with permission. WongBakerFACES Foundation (2016).

WongBakerFACES ${ }^{\circledR}$ Pain Rating Scale. Retrieved with permission from http://www.WongBakerFACES.org.

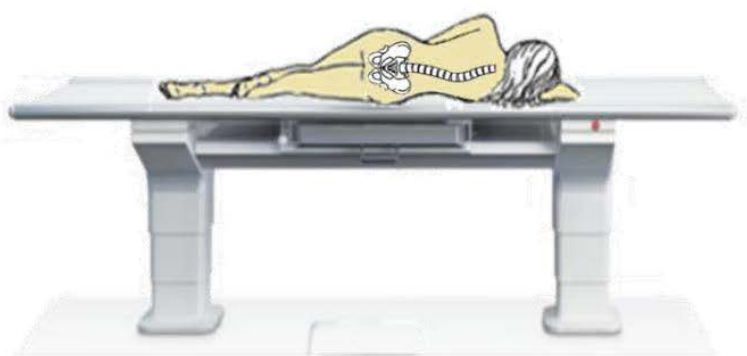

Concave

Side Lying

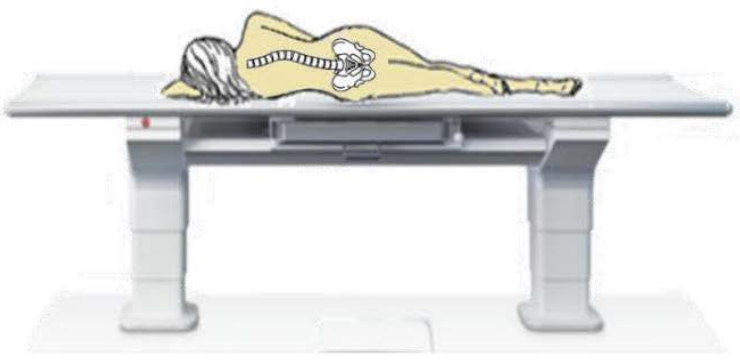

Convex

Side Lying

Figure 5-3. Concave and Convex Side Lying.

Depending on the orientation of the curve in the coronal plane, the apex would either be between the body weight and the bed or above it. It was theorized that this abnormality would influence the results. Orientation of the curve was determined by an orthopedic surgeon using radiographs. 


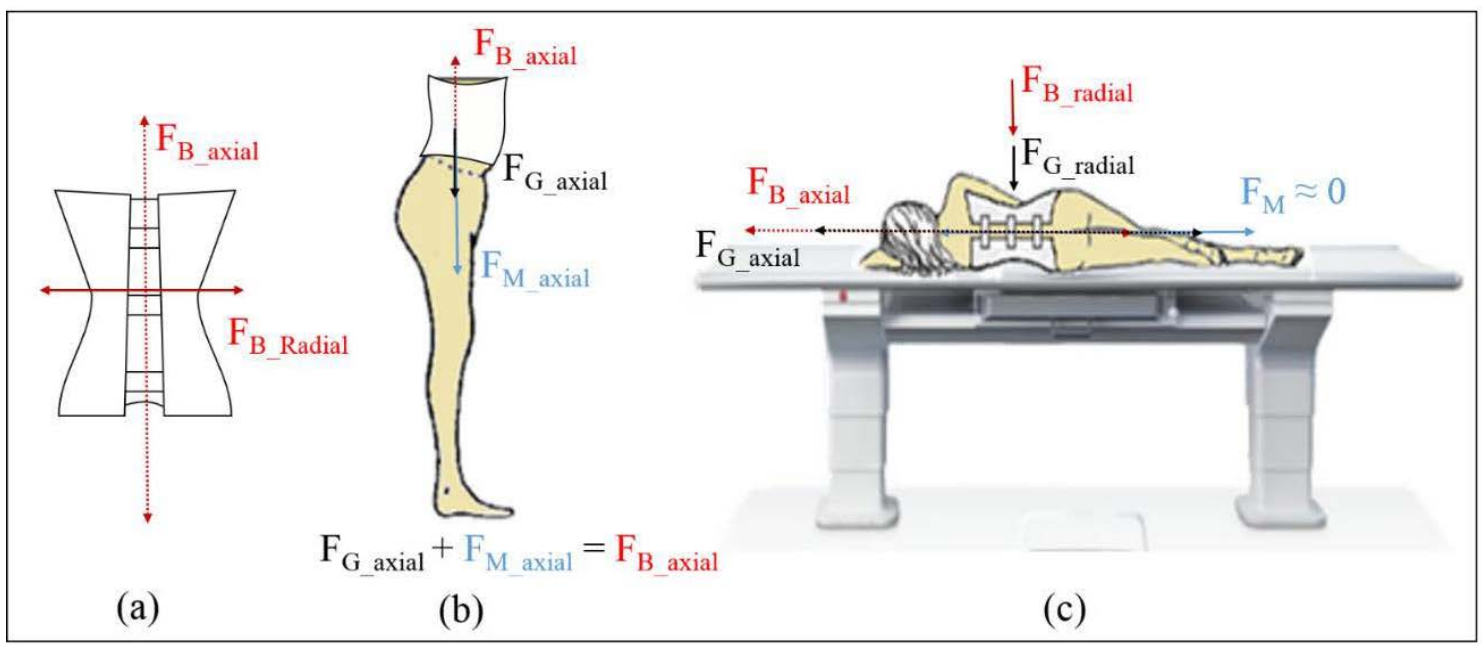

Figure 5-4. Body Mechanics During Bracing While Standing Versus Side Lying. (a) Coordinate directions on a brace. (b) Mechanics during upright stance. (c) Mechanics during side lying. The scoliosis brace applies a multi-directional force to the spine that has components which align along the axial direction or long axis of the brace $\left(\mathrm{F}_{\mathrm{B} \_ \text {axial }}\right)$ as well as in the radial direction of the brace $\left(\mathrm{F}_{\mathrm{B}_{-} \text {radial }}\right)$ (see $(\mathrm{a})$ ). During upright stance, the gravitational force of the upper torso weight $\left(\mathrm{F}_{\mathrm{G} \_ \text {axial }}\right)$ aligns with the axial direction of the brace and spinal muscles ( $\left.\mathrm{F}_{\mathrm{M} \_ \text {axial }}\right)$ are recruited to maintain postural control [44] that also align with the axial direction of the brace (See (b)). However, when lying down the gravitational force of the upper torso weight aligns with the radial direction $\left(\mathrm{F}_{\mathrm{G}_{-} \text {radial }}\right)$ and muscle forces are minimal $\left(\mathrm{F}_{\mathrm{M}}=0\right)$ and are no longer present to act against the brace (See (c)). The directional force components of the brace do not change. 


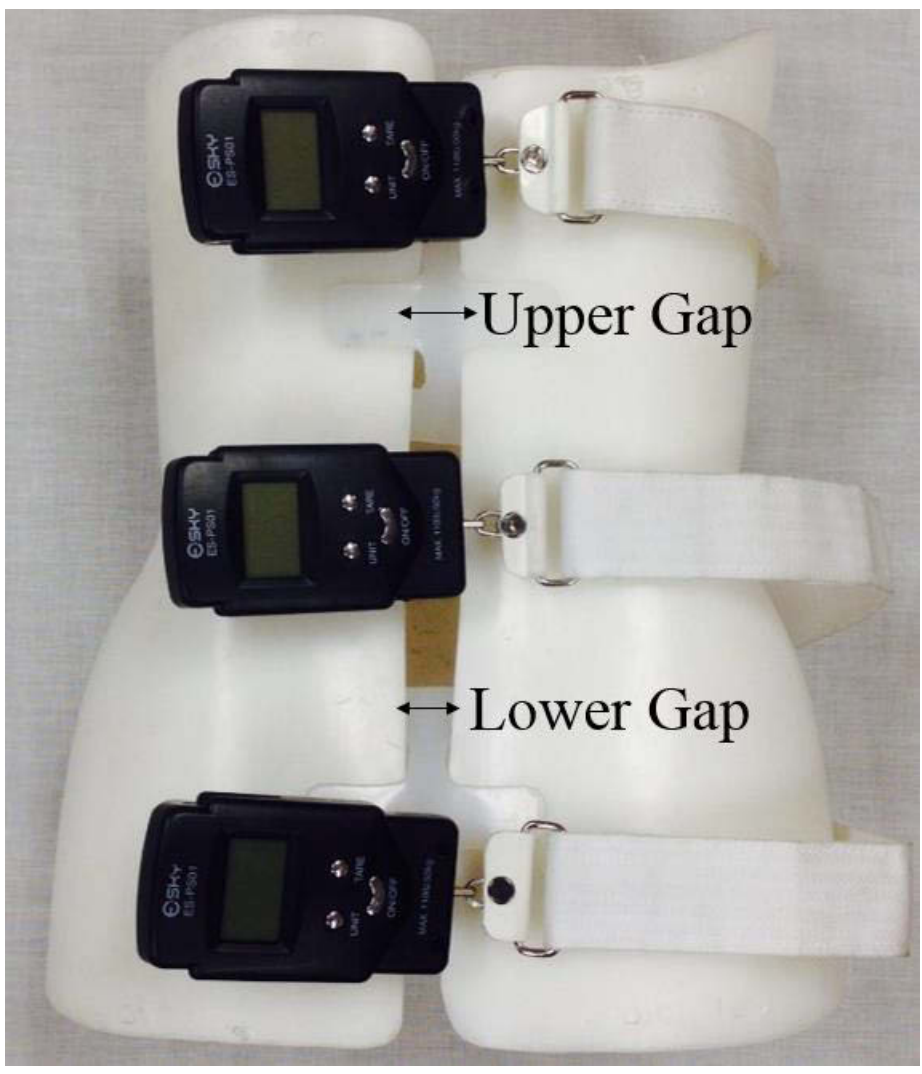

Figure 5-5. Strap Tension and Gap Distance Measurement. 


\section{CTU Increase Test}

At initial standing, the tension in each CTU was incrementally increased until the patient experienced a greater level of discomfort than when the Velcro straps were fastened to the prescribed tension. The goal was to achieve the highest tension possible without exceeding the discomfort level set with the Velcro straps. A paired t-test was used to analyze the data from the 8 subjects and to ensure normality a power analysis was performed for a power $\geq 0.8$.

\section{Results}

\section{Strap Tension}

Velcro straps showed a significant loss of tension ( $p \leq 0.05$, power $\geq 0.8$ ) afterwards while the CTU tension was maintained (Table 5-1 and Figure 5-6). During inspiration, top $(p \leq 0.05$, power $\geq 0.8)$ and middle $(p \leq 0.05)$ Velcro strap tension was significantly higher than CTU tension (Table 5-2 and Figure 5-7). Concave and Convex side lying saw significant loss of Velcro strap tension ( $\mathrm{p} \leq 0.05$, power $\geq 0.8)$ whereas the CTU maintained tension in both side lying positions. During forward bending, the tensions were significantly higher than the CTU for the top $(\mathrm{p} \leq 0.05)$ and middle $(\mathrm{p} \leq 0.05$, power $\geq 0.8$ ) Velcro straps, whereas the bottom Velcro tension was significantly lower than the CTU $(\mathrm{p} \leq 0.05$, power $\geq 0.8)$.

\section{Gap Distance}

During inspiration, the CTU allowed the upper gap to expand significantly $(\mathrm{p} \leq 0.05)$ further than the Velcro straps, but more subjects are needed for significance with a power $\geq 0.8$ (Table 5-3 and Figure 5-8). In convex side lying, CTU decreased the upper gap distance significantly but more subjects are needed for significance with a power $\geq 0.8$. More subjects are needed for the other side lying measures as well. During forward bending, the CTU showed a trend for allowing the upper gap to expand further. In stand final, CTU decreased the lower gap distance significantly with a power $\geq 0.8$. More subjects are needed to show significance for the upper gap as well.

\section{Discomfort}

The CTU devices significantly improved discomfort for forward bending $(\mathrm{p} \leq 0.05)$ (Table 5-4 and Figure 5-9). The CTU devices showed a trend for improving discomfort in inspiration $(\mathrm{p}=0.24)$, concave and convex side lying, and stand final. 
Table 5-1. Velcro Tension Loss at Top, Middle, and Bottom Levels.

\begin{tabular}{ccc}
\hline Location/Fastener & Initial Tension & Final Tension \\
\hline Top Velcro (N) & 26 & 17 \\
Top CTU (N) & 27 & 27 \\
Middle Velcro (N) & 18 & 13 \\
Middle CTU (N) & 19 & 19 \\
Bottom Velcro (N) & 32 & 17 \\
Bottom CTU (N) & 33 & 33 \\
\hline
\end{tabular}

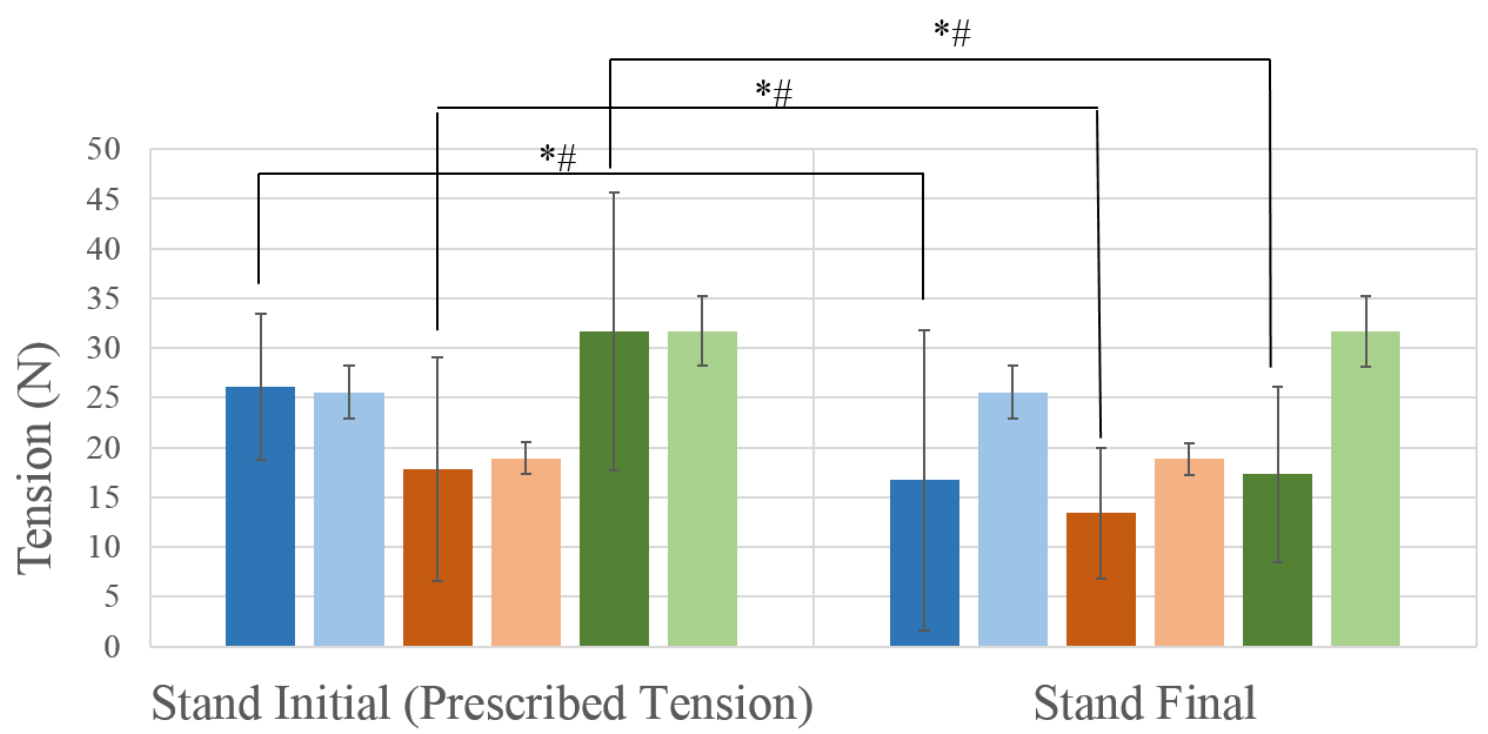

$\square$ Top Velcro $\square$ Top CTU $\square$ Middle Velcro $\square$ Middle CTU $\square$ Bottom Velcro $\square$ Bottom CTU

Figure 5-6. Velcro Tension Loss at Top, Middle, and Bottom Levels.

$*$ if Velcro initial value is significantly different $(\mathrm{p} \leq 0.05)$ from final value at that level. \# if Power $\geq 0.8$. 
Table 5-2. Velcro Versus CTU Mean Tension at Top, Middle, and Bottom Levels.

\begin{tabular}{ccccc}
\hline Location/Fastener & Inspiration & $\begin{array}{c}\text { Concave } \\
\text { Side Lying }\end{array}$ & $\begin{array}{c}\text { Convex } \\
\text { Side Lying }\end{array}$ & $\begin{array}{c}\text { Forward } \\
\text { Bend }\end{array}$ \\
\hline Top Velcro (N) & 55 & 16 & 13 & 39 \\
Top CTU (N) & 27 & 27 & 27 & 27 \\
Middle Velcro (N) & 24 & 5 & 5 & 37 \\
Middle CTU (N) & 19 & 19 & 19 & 19 \\
Bottom Velcro (N) & 32 & 5 & 3 & 19 \\
Bottom CTU (N) & 33 & 33 & 33 & 33 \\
\hline
\end{tabular}

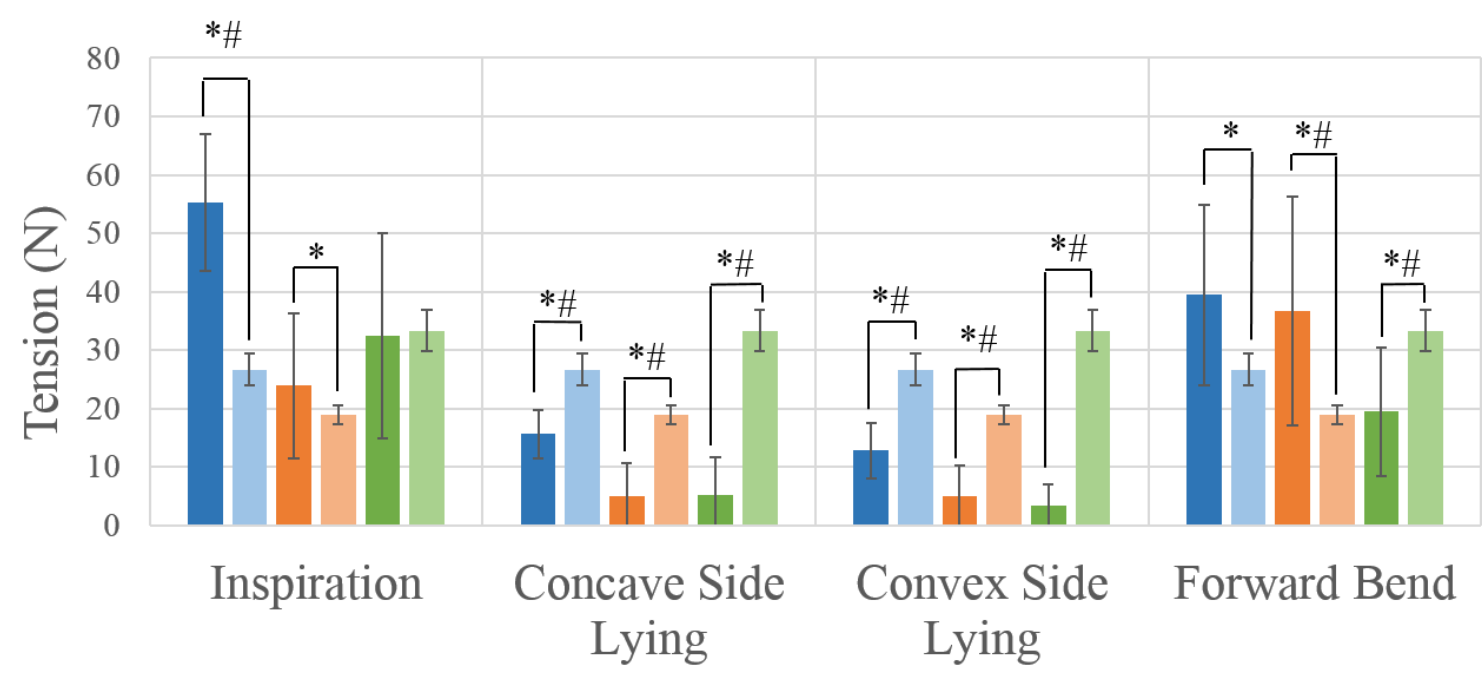

$\square$ Top Velcro $\square$ Top CTU $\square$ Middle Velcro $\square$ Middle CTU $\square$ Bottom Velcro $\square$ Bottom CTU

Figure 5-7. Velcro Versus CTU Mean Tension at Top, Middle, and Bottom Levels.

* if Velcro value is significantly different $(\mathrm{p} \leq 0.05)$ from CTU value at that level. \# if Power $\geq 0.8$. $\mathrm{N}$ denotes the total number of subjects needed to obtain significance with a power $\geq 0.8$. $\mathrm{P}$ is the current $\mathrm{p}$-value with 8 subjects. 
Table 5-3. Velcro Versus CTU Mean Upper and Lower Gap Distance Change Relative to Stand Initial.

\begin{tabular}{cccccc}
\hline Location/Fastener & Inspiration & $\begin{array}{c}\text { Concave } \\
\text { Side } \\
\text { Lying }\end{array}$ & $\begin{array}{c}\text { Convex } \\
\text { Side } \\
\text { Lying }\end{array}$ & $\begin{array}{c}\text { Forward } \\
\text { Bend }\end{array}$ & $\begin{array}{c}\text { Stand } \\
\text { Final }\end{array}$ \\
\hline $\begin{array}{c}\text { Upper Gap Velcro } \\
(\mathbf{m m})\end{array}$ & 1.4 & -1.2 & -1.9 & 4.0 & 1.4 \\
$\begin{array}{c}\text { Upper Gap CTU } \\
\quad(\mathbf{m m})\end{array}$ & 4.0 & -3.6 & -4.1 & 5.0 & -0.6 \\
$\begin{array}{c}\text { Lower Gap Velcro } \\
\quad(\mathbf{m m})\end{array}$ & 0.3 & -6.1 & -5.3 & 1.2 & -0.1 \\
$\begin{array}{c}\text { Lower Gap CTU } \\
(\mathbf{m m})\end{array}$ & 1.3 & -7.8 & -7.5 & -2.6 & -2.8 \\
\hline
\end{tabular}

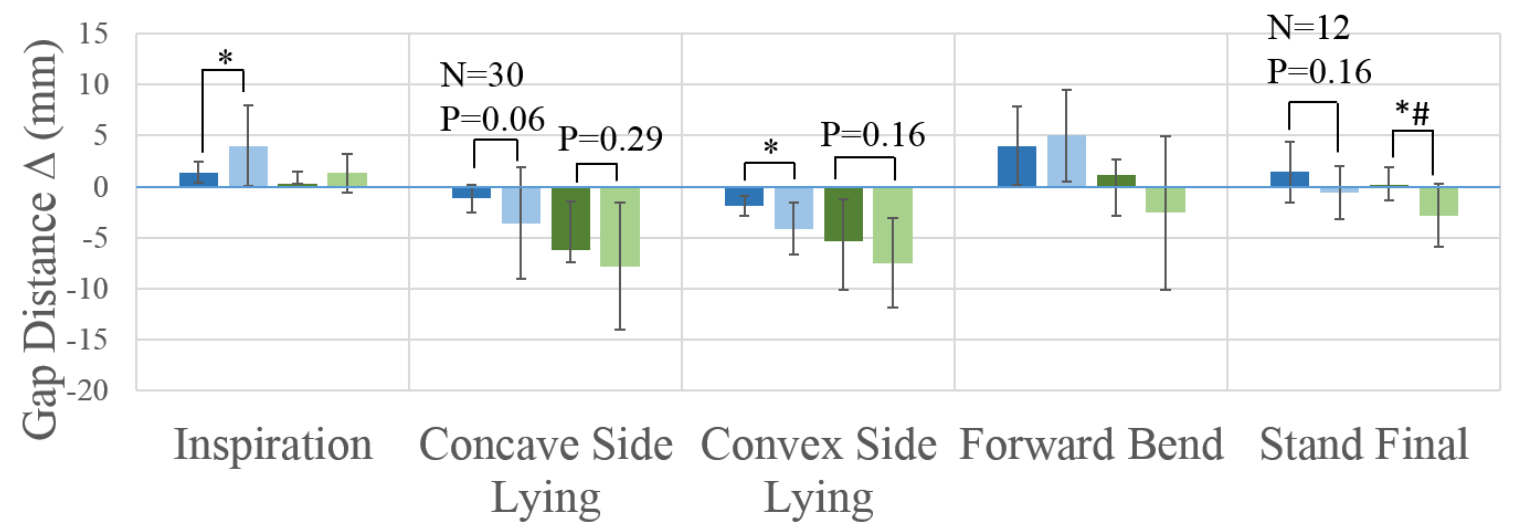

- Upper Velcro $\backsim$ Upper CTU $\backsim$ Lower Velcro $\square$ Lower CTU

Figure 5-8. Velcro Versus CTU Mean Upper and Lower Gap Distance Change Relative to Stand Initial.

* if Significantly different $(\mathrm{p} \leq 0.05)$. \# if Power $\geq 0.8$. $\mathrm{N}$ denotes the total number of subjects needed to obtain significance with a power $\geq 0.8$. $\mathrm{P}$ is the current $\mathrm{p}$-value with 8 subjects. 
Table 5-4. Velcro Versus CTU Mean Discomfort.

\begin{tabular}{ccccccc}
\hline Fastener & $\begin{array}{c}\text { Stand } \\
\text { Initial }\end{array}$ & Inspiration & $\begin{array}{c}\text { Concave } \\
\text { Side } \\
\text { Lying }\end{array}$ & $\begin{array}{c}\text { Convex } \\
\text { Side } \\
\text { Lying }\end{array}$ & $\begin{array}{c}\text { Forward } \\
\text { Bend }\end{array}$ & $\begin{array}{c}\text { Stand } \\
\text { Final }\end{array}$ \\
\hline $\begin{array}{c}\text { Velcro } \\
\text { Discomfort }\end{array}$ & 2 & 2 & 2 & 1 & 3 & 1 \\
$\begin{array}{c}\text { CTU } \\
\text { Discomfort }\end{array}$ & 1 & 1 & 1 & 1 & 1 & 1 \\
\hline
\end{tabular}

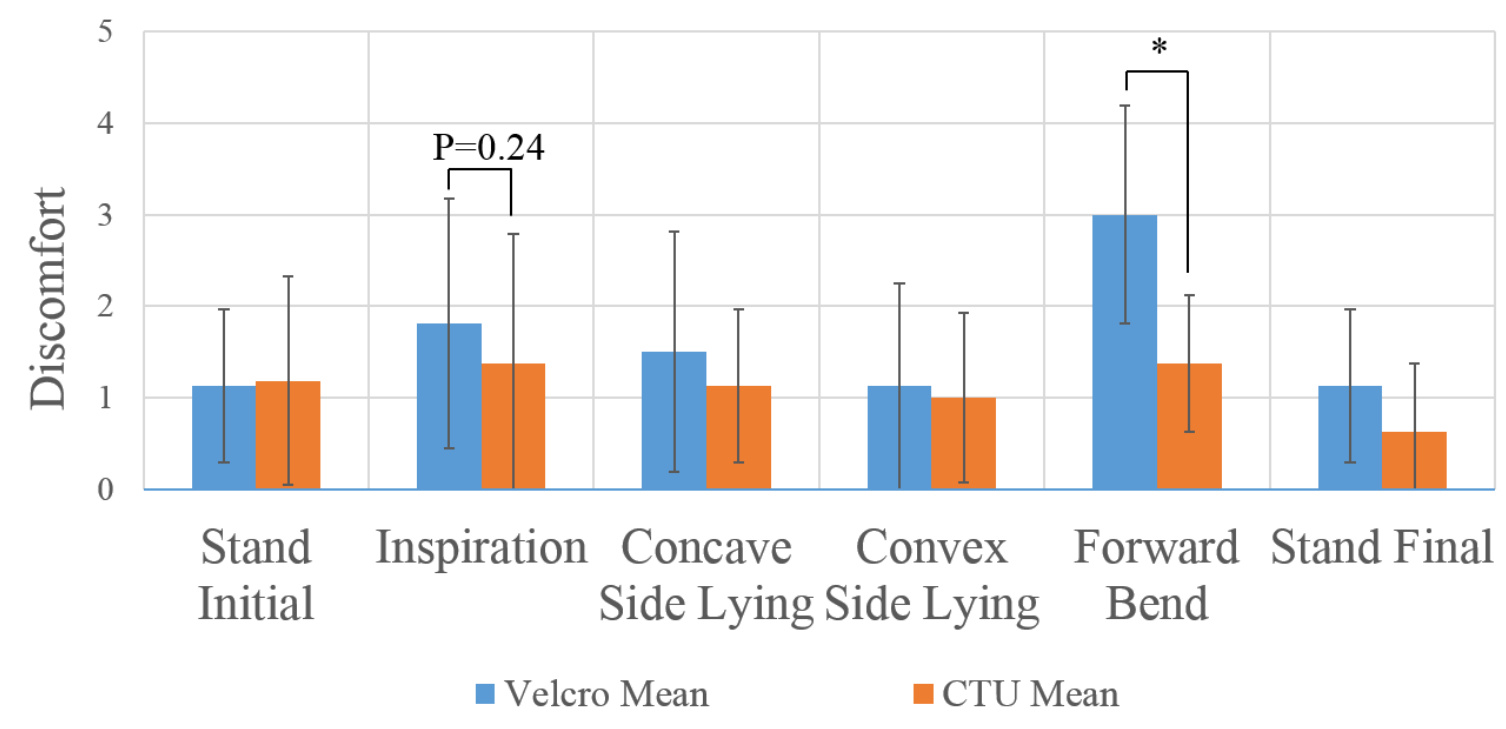

Figure 5-9. Velcro Versus CTU Mean Discomfort.

* if Significantly different $(\mathrm{p} \leq 0.05)$. \# if Power $\geq 0.8$. $\mathrm{N}$ denotes the total number of subjects needed to obtain significance with a power $\geq 0.8$. $\mathrm{P}$ is the current $\mathrm{p}$-value with 8 subjects. 


\section{CTU Increase Test}

The CTU devices allowed for significantly greater strap tensions for the top $(p \leq 0.05)$, middle ( $\mathrm{p} \leq 0.05$, power $\geq 0.8)$, and bottom $(\mathrm{p} \leq 0.05)$ straps. The CTU devices allowed for significantly shorter gap distances $(\mathrm{p} \leq 0.05$, power $\geq 0.8)$ without increasing discomfort (Table 5-5, Figures 5-10 and 5-11).

\section{Discussion}

\section{Strap Tension}

Strap tension is referring to the amount of force each Velcro strap or CTU was applying across the gap on the back of the brace.

Stand Initial/Final. Velcro straps showed a significant loss of tension $(\mathrm{p} \leq 0.05$, power $\geq 0.8$ ) afterwards while the CTU tension was maintained. The Academy of Orthotists and Prosthetists as well as many authors conclude that a loss of strap tension directly results in a loss of in-brace curve correction, consequently leading to decreased brace efficacy $[18,19,39,43]$.

Inspiration. During inspiration, top $(\mathrm{p} \leq 0.05$, power $\geq 0.8)$ and middle $(\mathrm{p} \leq 0.05)$ Velcro strap tension was significantly higher than CTU tension. This increase is likely a factor in strap tension loss. It also suggests that more effort is required during deep breathing. Studies have reported an increase in strap tension during inspiration $[19,35,38,39]$. Others have concluded that increase restriction to chest expansion impedes pulmonary function $[34,41]$.

Side Lying. Concave and Convex side lying saw significant loss of Velcro strap tension ( $\mathrm{p} \leq 0.05$, power $\geq 0.8$ ) whereas the CTU devices maintained tension in both side lying positions, similar to reported findings $[38,39,40,43]$. This finding shows that Velcro strap tension is not maintained during sleep whereas it is maintain using CTU devices. Aubin et al. concluded that a loss of strap tension during nighttime wear may have important consequences concerning brace efficacy [19]. Katz et al. reported that patients who wore their brace during the day were more strongly associated with successful outcomes than those who wore it at night [42]. It is possible that this outcome is due to a loss of strap tension when lying down. Also, no significant difference was found in the discomfort for concave or convex side lying, in other words maintaining strap tension did not change the discomfort. 
Table 5-5. CTU Increase Test Mean Values.

\begin{tabular}{ccc}
\hline Measure & Prescribed Velcro & CTU Increase Test \\
\hline Discomfort & 1 & 1 \\
Top Strap (N) & 27 & 36 \\
Middle Strap (N) & 19 & 34 \\
Bottom Strap (N) & 33 & 44 \\
Upper Gap (mm) & 64 & 49 \\
Lower Gap (mm) & 61 & 48 \\
\hline
\end{tabular}

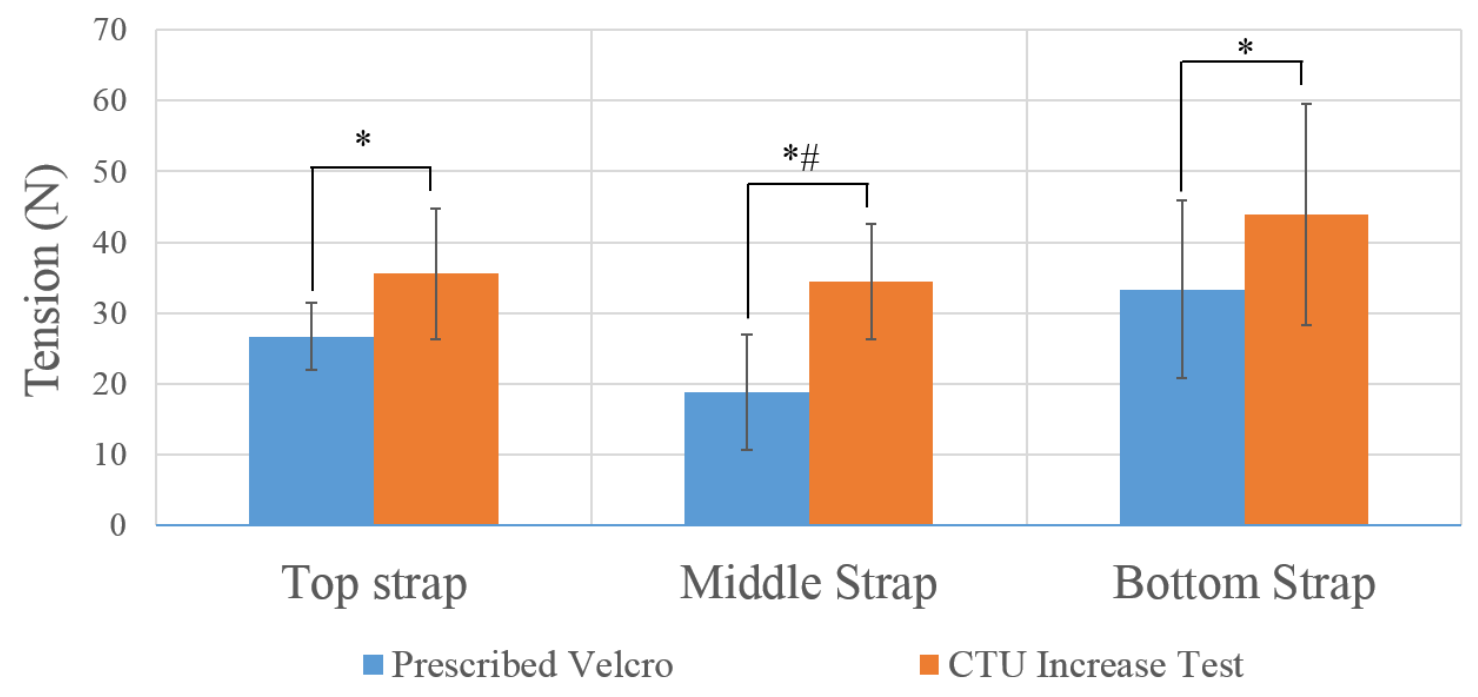

Figure 5-10. CTU Increase Test Mean Strap Tension with 8 Subjects.

* if Significantly different $(\mathrm{p} \leq 0.05)$. \# if Power $\geq 0.8$. 


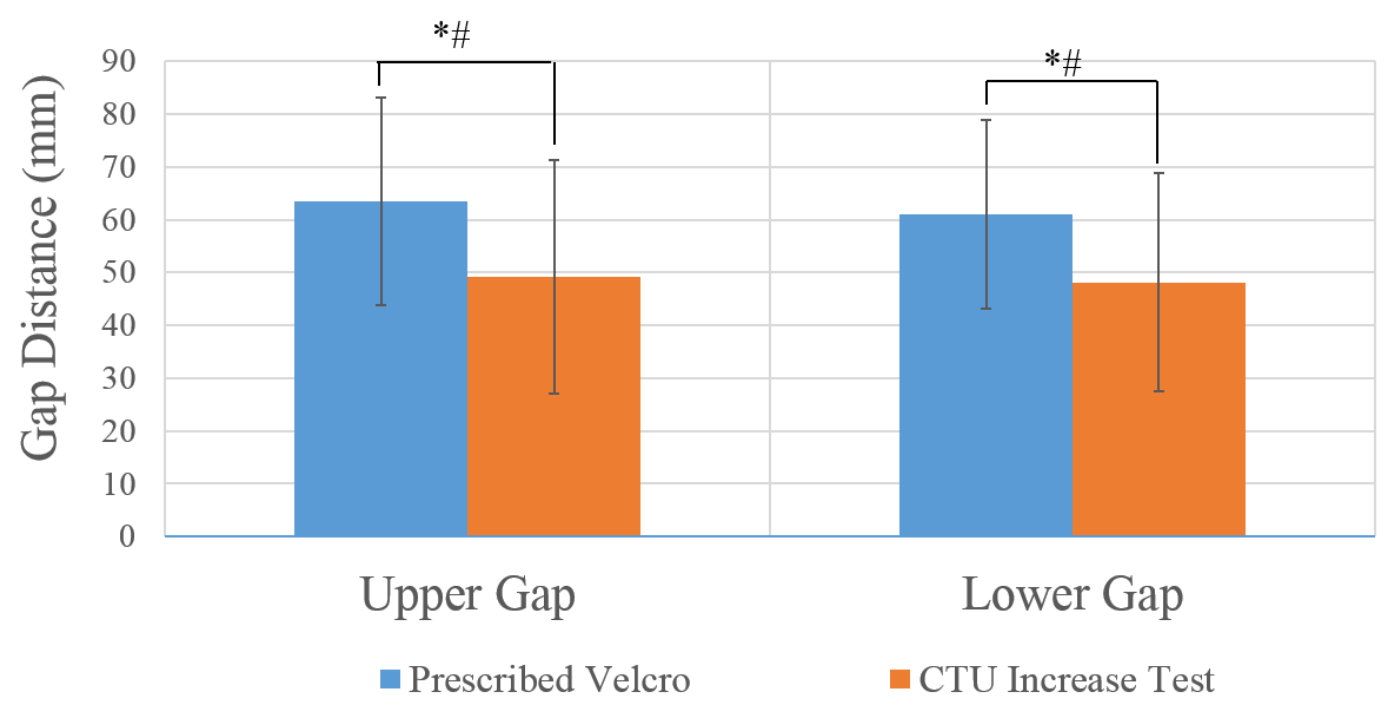

Figure 5-11. CTU Increase Test Mean Gap Distance with 8 Subjects.

$*$ if Significantly different $(\mathrm{p} \leq 0.05)$. \# if Power $\geq 0.8$. 
Forward Bend. During forward bending, the tensions were significantly higher than the CTU for the top $(p \leq 0.05)$ and middle ( $\mathrm{p} \leq 0.05$, power $\geq 0.8)$ Velcro straps. MacThiong et al. concluded that high strap tensions correlated with greater discomfort [34].

Limitations. Any small amount of body fluctuation, breathing for example, altered the Velcro tension readout. The values were accurate to about $\pm 2 \mathrm{~N}$. However, the statistics were recalculated using the maximum error values and significance was unaffected for all activities. Also, the portable tensiometers were not connected to the CTU during the test. Thus it was assumed that the working range of the CTU was not exceeded. If the CTU was overextended, then the tension would have been higher than the recorded values. If the CTU was not extended at all, then no tension would have been present. This issue is easily resolved by creating CTU devices with a greater working range.

\section{Gap Distance}

Gap distance is referring to either the absolute length of the gap on the back of the brace, or the change in the length of the gap. The change in gap distance is often referred to as relative gap distance.

Stand Initial. For this measure, statistical analysis was performed on absolute gap distances as well as relative gap distance. No significant differences were found in the upper or lower gap distance between Velcro strap and CTU configurations for either absolute or relative values. This outcome shows that at similar tensions, the brace rested at close to the same place on the body, theoretically achieving similar curve correction.

Inspiration. During inspiration, the CTU allowed the upper gap to expand significantly $(p \leq 0.05)$ further than the Velcro straps, but more subjects are needed for significance with a power $\geq 0.8$. Authors have concluded that increasing brace flexibility enhances comfort and improves patient compliance [27,32].

Side Lying. In convex side lying, CTU decreased the upper gap distance significantly but more subjects are needed for significance with a power $\geq 0.8$. More subjects are needed for the other side lying measures as well. Studies show greater curve correction and trunk muscle relaxation when lying down [27,39,44], which could contribute to gap closure. It was noted during the test that side lying naturally decreased the brace gap distance regardless of strap tension. In many cases, the amount of natural gap decrease exceeded the working range of the $\mathrm{CTU}$, thus rendering it irrelevant. However, this problem could be easily solved by repositioning the CTU so that it is engaged or creating a CTU with a longer working range. 
Forward Bend. During forward bend relative values, the CTU showed a trend for allowing the upper gap to expand further. This difference shows that the CTU provided greater flexibility and comfort during forward bending, which could lead to more hours of brace wear [27,32].

Stand Final. In stand final relative values, the CTU devices decreased the lower gap distance significantly with a power $\geq 0.8$. An estimated four more subjects are needed to show significance for the upper gap with a power $\geq 0.8$. This decrease shows that even though the CTU devices allowed for the brace to expand during certain movements, it was able to pull the brace back to the proper position when the patient relaxed. Therefore, the CTU increased flexibility without compromising corrective capacity of the brace.

\section{Discomfort}

The CTU devices significantly improved discomfort for forward bending $(\mathrm{p} \leq 0.05)$. The CTU devices showed a trend for improving discomfort in inspiration $(\mathrm{p}=0.24)$, concave and convex side lying, and stand final. It has been reported that discomfort often leads to poor patient compliance to the prescribed duration of brace wear $[13,28]$. Moreover, several authors have concluded that poor patient compliance decreases treatment efficacy $[2,13,17,42]$. Therefore, decreasing discomfort increases treatment efficacy.

During activity, the patients may have consciously or subconsciously prevented themselves from experiencing pain or great discomfort. Kennedy et al. found that braces cause increased upper ribcage movement and decreased lower ribcage movement [41].

\section{Range of Motion}

The patients were not able to perform this motion consistently thus the data were inconclusive.

\section{CTU Increase Test}

The CTU devices allowed for significantly greater strap tensions for the top $(\mathrm{p} \leq 0.05)$, middle $(\mathrm{p} \leq 0.05$, power $\geq 0.8)$, and bottom $(\mathrm{p} \leq 0.05)$ straps. The CTU devices allowed for significantly shorter gap distances $(p \leq 0.05$, power $\geq 0.8)$ without increasing discomfort. Several authors agree that increasing strap tension improves in-brace correction, which enhances treatment efficacy [28,34,35,36,37]. On the flip-side, increasing strap tension also increases discomfort [34,40]. By using CTU devices, strap tension could increase while maintaining discomfort, then treatment efficacy of scoliosis bracing would be enhanced. 


\section{Conclusion}

The CTU devices improved bracing in scoliosis by maintaining strap tension, improving brace flexibility, decreasing discomfort at similar tensions, or achieving higher tensions without increasing discomfort. CTU tension can also be selected and consistently replicated outside of the clinic. These improvements should enhance the treatment efficacy leading to fewer surgeries and enhanced quality of life. 


\section{CHAPTER 6. FUTURE WORK}

For the Standard (CTU) Brace, more samples are needed for the trends to become significant. There is also a need to compare radiographs of the Standard (Velcro Strap) Brace and the Standard (CTU) Brace to confirm that similar in-brace correction is achieved. It would also be beneficial to create CTU with larger working ranges. It is hypothesized that strategic cut-outs can be made on a brace to enhance directional flexibility and decrease discomfort. If this hypothesis is true then higher corrective forces

may be applied by combining the modified brace with CTU and/or Velcro straps, then the brace effectiveness can increase even further without increasing discomfort. Radiographs in this modified brace are also necessary. For comfortable brace wear over a prolonged period of time, the CTU will have to be lower profile. One way this design can be accomplished is by implementing cavities in the brace shell for the CTU device to fit into. 


\section{LIST OF REFERENCES}

1. De Graaff, V., Fox, K. M., \& Van De, S. I. K. M. (1995). Concepts of human

anatomy \& physiology (No. QP 36. V36 1995).

2. Maruyama, T., Grivas, T. B., \& Kaspiris, A. (2011). Effectiveness and outcomes of brace treatment: a systematic review. Physiotherapy theory and practice, 27(1), 2642.

3. Altaf, F., Gibson, A., Dannawi, Z., \& Noordeen, H. (2013). Adolescent idiopathic scoliosis. Bmj, 346, f2508.

4. Scoliosis Research Society. (n.d.). Retrieved July 26, 2016, from http://www.srs.org/

5. National Scoliosis Foundation. (n.d.). Retrieved July 26, 2016, from http://www.scoliosis.org/

6. Greiner, K. A. (2002). Adolescent idiopathic scoliosis: radiologic decisionmaking. American family physician, 65(9), 1817-1822.

7. Deschênes, S., Charron, G., Beaudoin, G., Labelle, H., Dubois, J., Miron, M. C., \& Parent, S. (2010). Diagnostic imaging of spinal deformities: reducing patients radiation dose with a new slot-scanning X-ray imager. Spine, 35(9), 989-994.

8. Illés, T., Tunyogi-Csapó, M., \& Somoskeöy, S. (2011). Breakthrough in threedimensional scoliosis diagnosis: significance of horizontal plane view and vertebra vectors. European Spine Journal, 20(1), 135-143.

9. Risser, J. C. (2010). The classic: the iliac apophysis: an invaluable sign in the management of scoliosis. Clinical Orthopaedics and Related Research ${ }^{\circledR}, 468(3), 646-$ 653.

10. Wong, H. K., \& Tan, K. J. (2010). The natural history of adolescent idiopathic scoliosis. Indian journal of orthopaedics, 44(1), 9.

11. Lamarre, M. E., Parent, S., Labelle, H., Aubin, C. E., Joncas, J., Cabral, A., \& Petit, Y. (2009). Assessment of spinal flexibility in adolescent idiopathic scoliosis: suspension versus side-bending radiography. Spine, 34(6), 591-597.

12. Kuroki, H., Inomata, N., Hamanaka, H., Chosa, E., \& Tajima, N. (2012). Significance of hanging total spine x-ray to estimate the indicative correction angle by brace wearing in idiopathic scoliosis patients. Scoliosis, 7(1), 1. 
13. Weinstein, S. L., Dolan, L. A., Wright, J. G., \& Dobbs, M. B. (2013). Effects of bracing in adolescents with idiopathic scoliosis. New England Journal of Medicine, 369(16), 1512-1521.

14. Lenke, L. G., Betz, R. R., Harms, J., Bridwell, K. H., Clements, D. H., Lowe, T. G., \& Blanke, K. (2001). Adolescent idiopathic scoliosis. The Journal of Bone \& Joint Surgery, 83(8), 1169-1181.

15. Rinsky, L. A., \& Gamble, J. G. (1988). Adolescent idiopathic scoliosis. Western Journal of Medicine, 148(2), 182.

16. Mac-Thiong, J. M., Petit, Y., Aubin, C. É., Delorme, S., Dansereau, J., \& Labelle, H. (2004). Biomechanical evaluation of the Boston brace system for the treatment of adolescent idiopathic scoliosis: relationship between strap tension and brace interface forces. Spine, 29(1), 26-32.

17. Yrjönen, T., Ylikoski, M., Schlenzka, D., \& Poussa, M. (2007). Results of brace treatment of adolescent idiopathic scoliosis in boys compared with girls: a retrospective study of 102 patients treated with the Boston brace.European Spine Journal, 16(3), 393-397.

18. Online Learning Center. (n.d.). Retrieved May 24, 2016, from http://www.oandp.org/olc/lessons/html/200407-20/

19. Aubin, C. É., Labelle, H., Ruszkowski, A., Petit, Y., Gignac, D., Joncas, J., \& Dansereau, J. (1999). Variability of strap tension in brace treatment for adolescent idiopathic scoliosis. Spine, 24(4), 349-354.

20. Lipton, G. E., \& Bowen, J. R. (2013). The Wilmington brace in the treatment of adolescent idiopathic scoliosis. Scoliosis Research Society, Publishers. Updated.

21. Emans, J. (2003). The Bracing Manual, The Boston Brace. Scoliosis Research Society (www. srs. org).

22. Bernardini, F., \& Rushmeier, H. (2002, June). The 3D model acquisition pipeline. In Computer graphics forum (Vol. 21, No. 2, pp. 149-172). Blackwell Publishers Ltd.

23. Global CAD/CAM solution for CPO. (n.d.). Retrieved July 26, 2016, from http://rodin4d.com/en

24. Boivie, K., Dolinšek, S., \& Homar, D. (2011). Hybrid Manufacturing: Integration of Additive Technologies for Competitive Production of Complex Tools and Products. In Proceedings of the International Research/Expert Conference:" Trends in the Development of Machinery and Associated Technology” TMT. 
25. Wong, M. S., Cheng, J. C. Y., Wong, M. W., \& So, S. F. (2005). A work study of the CAD/CAM method and conventional manual method in the fabrication of spinal orthoses for patients with adolescent idiopathic scoliosis. Prosthetics and orthotics international, 29(1), 93-104.

26. Summit, S., \& Trauner, K. B. (2013). U.S. Patent No. 8,613,716. Washington, DC: U.S. Patent and Trademark Office.

27. Wong, M. S., Cheng, J. C., Lam, T. P., Ng, B. K., Sin, S. W., Lee-Shum, S. L., ... \& Tam, S. Y. (2008). The effect of rigid versus flexible spinal orthosis on the clinical efficacy and acceptance of the patients with adolescent idiopathic scoliosis. Spine, 33(12), 1360-1365.

28. Nicholson, G. P., Ferguson-Pell, M. W., Smith, K., Edgar, M., \& Morley, T. (2003). The objective measurement of spinal orthosis use for the treatment of adolescent idiopathic scoliosis. Spine, 28(19), 2243-2250.

29. Miller, J. J. (1996). U.S. Patent No. 5,503,621. Washington, DC: U.S. Patent and Trademark Office.

30. Simanovsky, N. (2010). U.S. Patent No. 7,766,850. Washington, DC: U.S. Patent and Trademark Office.

31. Ogilvie, J. W. (2011). U.S. Patent No. 7,967,767. Washington, DC: U.S. Patent and Trademark Office.

32. Veldhuizen, A. G., Cheung, J., Bulthuis, G. J., \& Nijenbanning, G. (2002). A new orthotic device in the non-operative treatment of idiopathic scoliosis.Medical engineering \& physics, 24(3), 209-218.

33. Zeh, A., Planert, M., Klima, S., Hein, W., \& Wohlrab, D. (2008). The flexible TriacBrace for conservative treatment of idiopathic scoliosis. An alternative treatment option. Acta Orthop Belg, 74(4), 512-521.

34. Mac-Thiong, J. M., Petit, Y., Aubin, C. É., Delorme, S., Dansereau, J., \& Labelle, H. (2004). Biomechanical evaluation of the Boston brace system for the treatment of adolescent idiopathic scoliosis: relationship between strap tension and brace interface forces. Spine, 29(1), 26-32.

35. Wong, M. S., Mak, A. F. T., Luk, K. D. K., Evans, J. H., \& Brown, B. (2000). Effectiveness and biomechanics of spinal orthoses in the treatment of adolescent idiopathic scoliosis (AIS). Prosthetics and orthotics international,24(2), 148-162.

36. Noonan, K. J., Weinstein, S. L., Jacobson, W. C., \& Dolan, L. A. (1996). Use of the Milwaukee brace for progressive idiopathic scoliosis. J Bone Joint Surg Am, 78(4), 557-67. 
37. Jiang, H., Raso, V., Hill, D., Durdle, N., \& Moreau, M. (1992). Interface pressures in the Boston brace treatment for scoliosis. A preliminary study. InInternational symposium on (pp. 395-399).

38. Pham, V. M., Houilliez, A., Schill, A., Carpentier, A., Herbaux, B., \& Thevenon, A. (2008). Study of the pressures applied by a Chêneau brace for correction of adolescent idiopathic scoliosis. Prosthetics and orthotics international, 32(3), 345 355.

39. Loukos, I., Zachariou, C., Nicolopoulos, C., Korres, D., \& Efstathopoulos, N. (2011). Analysis of the corrective forces exerted by a dynamic derotation brace (DDB). Prosthetics and orthotics international, 35(4), 365-372.

40. Wong, M. S., \& Evans, J. H. (1998). Biomechanical evaluation of the Milwaukee brace. Prosthetics and orthotics international, 22(1), 54-67.

41. Kennedy, J. D., Robertson, C. F., Hudson, I., \& Phelan, P. D. (1989). Effect of bracing on respiratory mechanics in mild idiopathic scoliosis. Thorax,44(7), 548-553.

42. Katz, D. E., Herring, J. A., Browne, R. H., Kelly, D. M., \& Birch, J. G. (2010). Brace wear control of curve progression in adolescent idiopathic scoliosis. The Journal of Bone \& Joint Surgery, 92(6), 1343-1352.

43. Lou, E., Hill, D., Hedden, D., Mahood, J., Moreau, M., \& Raso, J. (2011). An objective measurement of brace usage for the treatment of adolescent idiopathic scoliosis. Medical engineering \& physics, 33(3), 290-294.

44. YOKOYAMA, S. (1985). Evaluation of resting and working postures from the viewpoint of local muscle energy metabolic rate. The Annals of physiological anthropology, 4(4), 309-314.

45. Desbiens-Blais, F., Clin, J., Parent, S., Labelle, H., \& Aubin, C. E. (2012). New brace design combining $\mathrm{CAD} / \mathrm{CAM}$ and biomechanical simulation for the treatment of adolescent idiopathic scoliosis. Clinical biomechanics, 27(10), 999-1005.

46. Nie, W. Z., Ye, M., Liu, Z. D., \& Wang, C. T. (2009). The patient-specific brace design and biomechanical analysis of adolescent idiopathic scoliosis. Journal of biomechanical engineering, 131(4), 041007.

47. Chung CL, Kelly DM, Steele JR, \& DiAngelo DJ. (2015). Scoliosis Analog Model for the Evaluation of Bracing Technology. JPO Journal of Prosthetics and Orthotics. Under Review.

48. Illés, T., \& Somoskeöy, S. (2013). Comparison of scoliosis measurements based on three-dimensional vertebra vectors and conventional two-dimensional measurements: 
advantages in evaluation of prognosis and surgical results. European spine journal, 22(6), 1255-1263.

49. Chung CL, \& DiAngelo DJ. (2015). Scoliosis Analog Model for the Evaluation of Bracing Technology. Journal of Mississippi Academy of Sciences: 31 st SBEC Digest of Paper, 60(S1), 187-192.

50. DiAngelo DJ, \& Chung CL. (2015). Scoliosis Analog Model for the Evaluation of Bracing Technology. Podium. Biomedical Engineering Society Meeting, Tampa, FL.

51. Chung CL, Kelly DM, Steele JR, \& DiAngelo DJ. (2016). Effects of Strap Options on Scoliosis Bracing Mechanics. Poster. 32nd Southern Biomedical Engineering Conference (SBEC), Shreveport, LA.

52. Chung CL, Kelly DM, Steele JR, \& DiAngelo DJ. (2015). Scoliosis Analog Model for the Evaluation of Bracing Technology. Poster. Life Science Tennessee Conference, Nashville, TN.

53. Chung CL, Kelly DM, Steele JR, \& DiAngelo DJ. (2016). A Mechanical Analog Model of Adolescent Idiopathic Scoliosis. Poster. Le Bonheur Pediatric Research Day, Le Bonheur Children's Hospital, Memphis, TN.

54. Chung CL, Kelly DM, Steele JR, \& DiAngelo DJ. (2016). Effects of Strap Options on Scoliosis Bracing Mechanics. Poster. Le Bonheur Pediatric Research Day, Le Bonheur Children's Hospital, Memphis, TN.

55. Chung CL, Kelly DM, Steele JR, Tate TS, Bateman CK, \& DiAngelo DJ. Effects of Strap Tension on Brace Corrective Forces. Poster. Le Bonheur Pediatric Research Day, Le Bonheur Children's Hospital, Memphis, TN.

56. Chung CL. Scoliosis Analog Model for the Evaluation of Bracing Technology [Master's]. (2015). Orthopaedic Surgery and Biomedical Engineering, The University of Tennessee Health Science Center.

57. Kelly, B. P., \& DiAngelo, D. J. (2013). A multiaxis programmable robot for the study of multibody spine biomechanics using a real-time trajectory path modification force and displacement control strategy. Journal of Medical Devices, 7(3), 034502.

58. Lebel, D. E., Al-Aubaidi, Z., Shin, E. J., Howard, A., \& Zeller, R. (2013). Three dimensional analysis of brace biomechanical efficacy for patients with AIS. European Spine Journal, 22(11), 2445-2448.

59. van den Hout, J. A. A. M., Van Rhijn, L., Van den Munckhof, R., \& Van Ooy, A. (2002). Interface corrective force measurements in Boston brace treatment. European Spine Journal, 11(4), 332-335. 
60. Goonetilleke, R. S., \& Eng, T. J. (1994, October). Contact area effects on discomfort. In Proceedings of the Human Factors and Ergonomics Society Annual Meeting (Vol. 38, No. 10, pp. 688-690). SAGE Publications.

61. Goonetilleke, R. S. (1998). Designing to minimize discomfort. In Ergonomics in Design.

62. Floyd, W. F., \& Roberts, D. F. (1958). ANATOMICAL AND PHYSIOLOGICAL PRINCIPLES IN CHAIR AND TABLE DESIGN*. Ergonomics, 2(1), 1-16.

63. Dinsdale, S. M. (1974). Decubitus ulcers: role of pressure and friction in causation. Archives of physical medicine and rehabilitation, 55(4), 147-152.

64. Tsay, D. F. (1991). Pressure distribution in tissue. Prevention of Pressure Sores. Philadelphia: Adam Hilger, 19-34.

65. Carter, HV . Anatomy of the Spine. Public domain, via Wikimedia Commons, from https://en.wikipedia.org/wiki/Vertebral_column.

66. WongBakerFACES Foundation (2016). WongBakerFACES® Pain Rating Scale. Retrieved with permission from http://www.WongBakerFACES.org. 


\section{APPENDIX. ROBOTIC TESTING PLATFORM LOAD CELL VALIDATION}

\section{Introduction}

When determining the absolute value of the weight of an object, it is common practice to use a load cell with an appropriate load range. For example, it is advantageous to measure the weight of a $100 \mathrm{~N}$ object using a load cell with a range of $\pm 200 \mathrm{~N}$. During the robotic testing in chapters 3 and 4 , an $800 \mathrm{~N}$ load cell was used to evaluate much lower forces. However, if the goal is to determine the relative fluctuation of a force, meaning the amount of applied force is fluctuating due to an external factor such as friction, then it may not be necessary to use a load cell with the appropriate range. For example, a load cell with an $800 \mathrm{~N}$ and a resolution of $0.2 \mathrm{~N}$ range may be capable of accurately determining the relative fluctuation of a $20 \mathrm{~N}$ force. Therefore, since the primary goal of chapters 3 and 4 was to compare the force increase and decrease on the upper load cell due to different strapping configurations, it is theorized that the $800 \mathrm{~N}$ load cell was suffcient.

\section{Purpose}

To evaluate the use of a load cell with an $800 \mathrm{~N}$ range for determining relative fluctuations of forces as low as $20 \mathrm{~N}$.

\section{Materials}

The robotic testing platform uses a JR3-100M40A3 Load Cell (Standard range: $\pm 800 \mathrm{~N}$; Resolution $\pm 0.2 \mathrm{~N})$. Cable: A standard steel cable. Weight: A small metal block.

\section{Methods}

An experiment was performed in order to validate the use of the load cell used in chapters 3 and 4 . In this experiment, an object with a weight of approximately $20 \mathrm{~N}$ was attached to the upper load cell of the robotic testing platform and secured so that it hung freely. After a steady state was reached, the upper load cell displaced vertically upwards $25 \mathrm{~mm}$, stopped, then displaced downwards $25 \mathrm{~mm}$ to the original starting position while continuously recording the forces at a sampling rate of $100 \mathrm{~Hz}$. The displacement speed was approximately $12 \mathrm{~mm} / \mathrm{s}$. Though it was a multi-axis load cell, only the forces along the Z-axis were of interest. The magnitude of the weight, the amount of displacement, the speed of displacement, and the sampling rate were similar to those used in the aforementioned tests.

The three runs were averaged. The maximum error was calculated by determining the difference between the highest and lowest values. The maximum percent error was calculated by dividing the max error by the average value and multiplying by 100 . 


\section{Results}

The average Z-Force was $21.6 \mathrm{~N}$ with a max error of $0.6 \mathrm{~N}$. This results in a percent error of about 2.8\%. As seen in Figure A-1, the maximum error in this system is less than $5 \%$ when using a $21.6 \mathrm{~N}$ weight.

\section{Conclusion}

The maximum error in this system was less than $5 \%$ when using a $21.6 \mathrm{~N}$ weight. Therefore, this load cell can be used to accurately determine the relative fluctuation of a $20 \mathrm{~N}$ force.

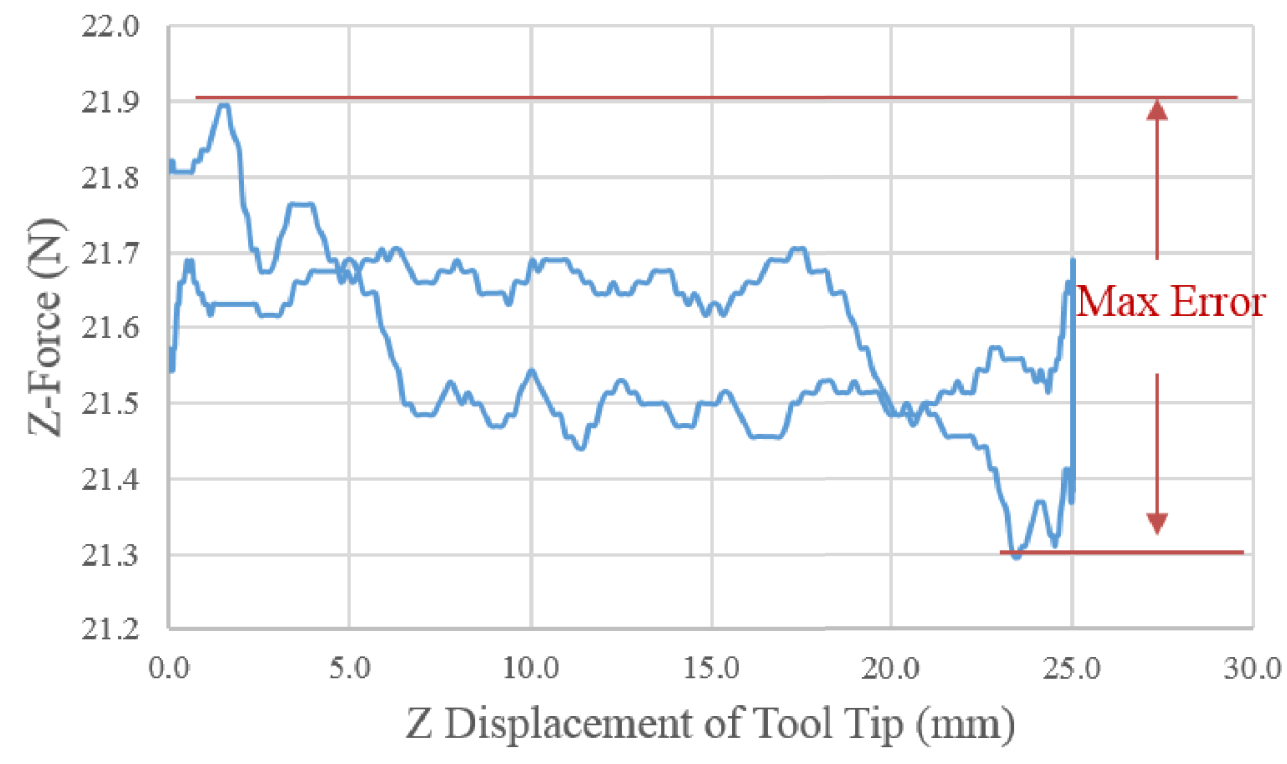

Figure A-1. Displacement Versus Force Plot Showing Max Load Cell Error. 


\section{VITA}

Cody Keith Bateman was born in Memphis, Tennessee in 1992. He grew up in Memphis where he graduated from Arlington High School in 2010. He attended the University of Memphis and graduated with a Bachelor of Science in Mechanical Engineering in Spring 2014. During his undergraduate career he was a member of the Helen Hardin Honors Program all four years, served as Vice President of Pi Tau Sigma for 2 years, participated in the Industrial Assessment Center Program for two years receiving IAC certification, and studied abroad in Ulm, Germany. He then matriculated into the Joint Graduate Program in Biomedical Engineering and Imaging at the University of Tennessee Health Science Center and University of Memphis in Fall 2014. Under the guidance of Dr. Denis J DiAngelo, he focused his research efforts on understanding and improving scoliosis bracing technology. Cody expects to receive his Master of Science degree in May 2017. 